\title{
Invasive Haemophilus influenzae Infections after 3 Decades of Hib Protein Conjugate Vaccine Use
}

\author{
DM. P. E. Slack, a A. W. Cripps, ${ }^{a, b}$ K. Grimwood, ${ }^{a, b, c, d}$ G. A. Mackenzie, ${ }^{e, f, g}$ M. Ulanova ${ }^{h}$ \\ aSchool of Medicine and Dentistry, Griffith University, Gold Coast Campus, Southport, Queensland, Australia \\ bMenzies Health Institute Queensland, Griffith University, Gold Coast Campus, Southport, Queensland, Australia \\ cDepartment of Infectious Diseases, Gold Coast Health, Southport, Queensland, Australia \\ dDepartment of Paediatrics, Gold Coast Health, Southport, Queensland, Australia \\ eLondon School of Hygiene and Tropical Medicine, London, United Kingdom \\ 'Medical Research Council Unit, The Gambia at LSHTM, Fajara, The Gambia \\ 9Murdoch Children's Research Institute, Parkville, Victoria, Australia \\ nMedical Sciences Division, Northern Ontario School of Medicine, Lakehead University, Thunder Bay, Ontario, Canada
}

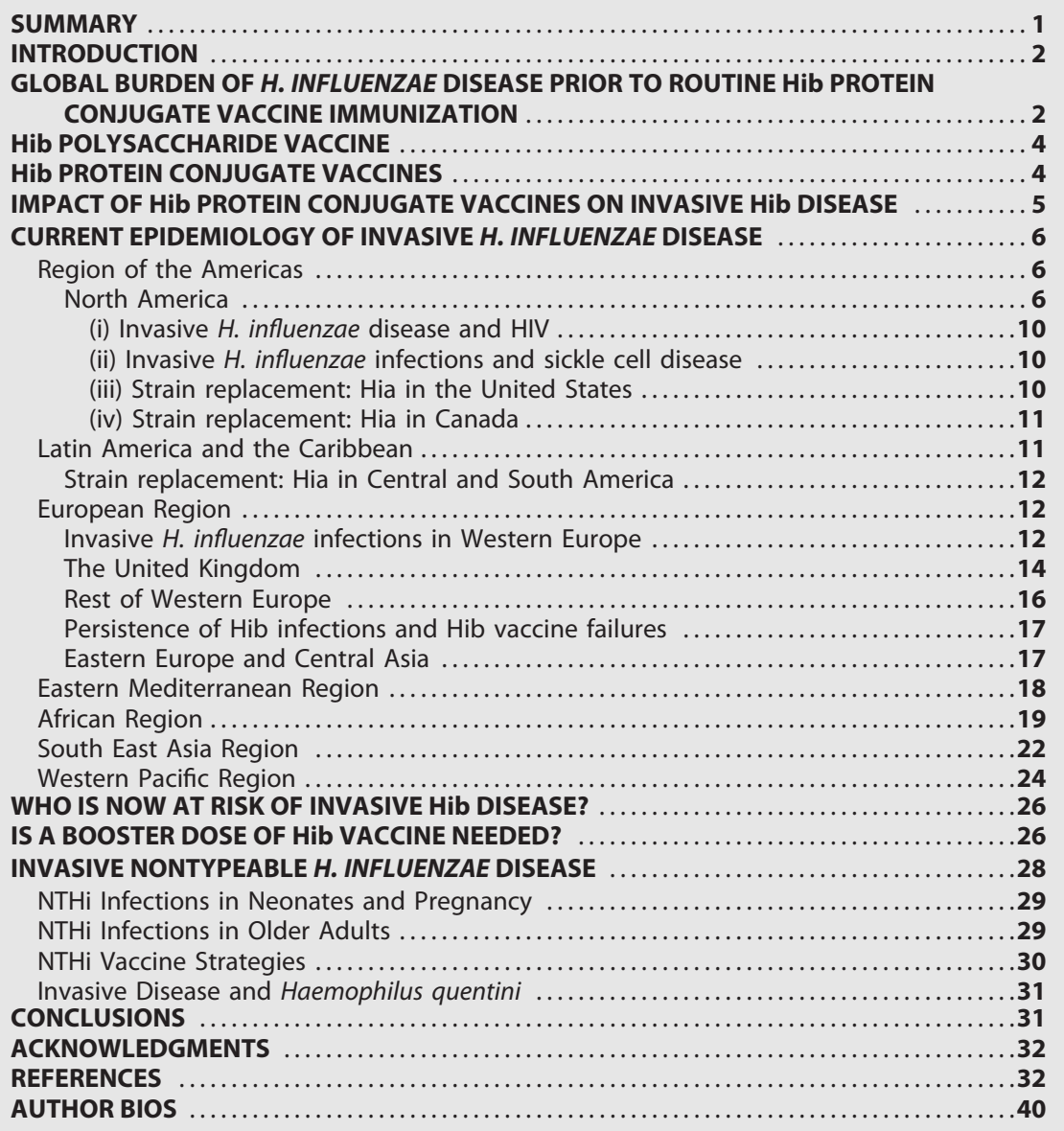

SUMMARY Haemophilus influenzae serotype b (Hib) was previously the most common cause of bacterial meningitis and an important etiologic agent of pneumonia in children aged $<5$ years. Its major virulence factor is the polyribosyl ribitol phosphate (PRP) polysaccharide capsule. In the 1980s, PRP-protein conjugate Hib vaccines were developed and are now included in almost all national immunization programs, achieving a sustained 2 \section{4}

Citation Slack MPE, Cripps AW, Grimwood K, Mackenzie GA, Ulanova M. 2021. Invasive Haemophilus influenzae infections after 3 decades of Hib protein conjugate vaccine use. Clin Microbiol Rev 34:e00028-21. https://doi .org/10.1128/CMR.00028-21.

Copyright $\odot 2021$ American Society for Microbiology. All Rights Reserved.

Address correspondence to M. P. E. Slack m.slack@griffith.edu.au.

Published 2 June 2021 
decline in invasive Hib infections. However, invasive Hib disease has not yet been eliminated in countries with low vaccine coverage, and sporadic outbreaks of Hib infection still occur occasionally in countries with high vaccine coverage. Over the past 2 decades, other capsulated serotypes have been recognized increasingly as causing invasive infections. $H$. influenzae serotype a (Hia) is now a major cause of invasive infection in Indigenous communities of North America, prompting a possible requirement for an Hia conjugate vaccine. $H$. influenzae serotypes $e$ and $f$ are now more common than serotype $b$ in Europe. Significant year-to-year increases in nontypeable $H$. influenzae invasive infections have occurred in many regions of the world. Invasive $H$. influenzae infections are now seen predominantly in patients at the extremes of life and those with underlying comorbidities. This review provides a comprehensive and critical overview of the current global epidemiology of invasive $H$. influenzae infections in different geographic regions of the world. It discusses those now at risk of invasive Hib disease, describes the emergence of other severe invasive $H$. influenzae infections, and emphasizes the importance of long-term, comprehensive, clinical and microbiologic surveillance to monitor a vaccine's impact.

KEYWORDS Haemophilus influenzae, Hib, conjugate vaccine, immunization, epidemiology, nontypeable $H$. influenzae

\section{INTRODUCTION}

1 aemophilus influenzae is a fastidious Gram-negative coccobacillus, requiring two accessory growth factors, $X$ factor (hemin) and V factor (NAD). $H$. influenzae is restricted to humans, colonizing the nasopharynx and to a lesser extent the conjunctivae and genital tract (1). It is differentiated into six capsular types (a to f) according to its capsular polysaccharide structure. Other strains do not have a capsule and are classified as nonencapsulated or nontypeable $H$. influenzae (NTHi). The most virulent serotype is $H$. influenzae type b (Hib), and its capsule, composed of polyribosyl ribitol phosphate (PRP), is the predominant virulence determinant. Studies on unvaccinated individuals in Finland found that serum anti-PRP immunoglobulin G (IgG) antibody concentrations of $\geq 0.15 \mu \mathrm{g} / \mathrm{ml}$ correlated with a lower incidence of Hib meningitis $(2,3)$. Additional studies determined that serum anti-PRP IgG antibody levels of $\geq 0.15 \mu \mathrm{g} / \mathrm{ml}$ provide shortterm protection against invasive Hib disease, but long-term protection requires concentrations of $\geq 1.0 \mu \mathrm{g} / \mathrm{ml}$ (4). It is now 30 years since Hib protein conjugate vaccines were first licensed, and since then, Hib immunization has been incorporated into almost all national immunization programs (NIPs) globally. Wherever Hib protein conjugate vaccines have been introduced and high coverage has been achieved, there has been a profound and sustained decline in the incidence of invasive Hib disease (5-11). This review starts by examining the impact of Hib protein conjugate vaccines during these 3 decades and the consequent changes in the worldwide epidemiology and disease burden of $\mathrm{Hib}$ and other invasive $H$. influenzae infections. The emergence of NTHi and other $H$. influenzae non-b serotypes as important invasive pathogens is emphasized. The increased incidences of NTHi invasive infections in vulnerable patient populations where infection is associated with high rates of morbidity and mortality and of $H$. influenzae type a (Hia) as a major cause of invasive disease in Indigenous groups in North America are highlighted. Finally, we conclude that the changing epidemiology of invasive $H$. influenzae infection emphasizes the importance of continuing surveillance and the possible need for developing new vaccines to control these emerging non-b infections.

\section{GLOBAL BURDEN OF H. INFLUENZAE DISEASE PRIOR TO ROUTINE HIb PROTEIN CONJUGATE VACCINE IMMUNIZATION}

Before the introduction of routine immunization with Hib protein conjugate vaccines, Hib was the most important cause of bacterial meningitis in young children (12, 13). It was also a major cause of pneumonia globally, resulting each year in a conservative estimate of 1.76 million episodes of severe pneumonia in children aged $<5$ years and $80 \%$ of all invasive Hib infections in this age group (5). 
More than $90 \%$ of cases of invasive Hib infection were in children aged $<5$ years, and $60 \%$ of cases of Hib meningitis were in infants $<12$ months of age (14). These proportions varied across the world, with approximately 50\%, 40\%, and 55\% of Hib meningitis cases in the World Health Organization (WHO) American, European, and Western Pacific Regions occurring in < 12-month-old infants, respectively (15). In high-mortality regions, including Africa and Asia, the proportion of Hib meningitis in < 12-month-old infants was approximately $80 \%$ (15). Prior to the introduction of Hib infections protein conjugate vaccines in the United Kingdom, most cases of invasive $\mathrm{H}$. influenzae were due to Hib and affected young children, with only about $10 \%$ of all invasive Hib infections occurring in adults (16). Similarly, in Finland, 9.5\% of invasive Hib infections and 3\% of Hib meningitis cases were in individuals aged $\geq 10$ years (17). In contrast, while only approximately $10 \%$ of invasive $H$. influenzae cases in the United Kingdom were from NTHi, twothirds of these infections involved adults, especially those $\geq 65$ years of age (16).

Prior to the introduction of routine Hib vaccination, the incidence of Hib meningitis in children aged 0 to 4 years in the United States was 54/100,000 per year (range, 19 to $69 / 100,000)(5,18)$. However, much higher rates of Hib meningitis in this age group of 150 to $450 / 100,000$ per year were reported in Indigenous populations residing in Alaska (19), Northern Canada (20), and Central and Northern Australia (5, 21). Hib meningitis had a mean case fatality ratio (CFR) of 14\%, ranging from approximate values of $5 \%$ in Europe to $28 \%$ in Africa (15). The second highest CFR was in South East Asia (17\%), followed by the Eastern Mediterranean Region (12\%), the Region of the Americas (11\%), and the Western Pacific Region (6\%) (15).

In a meta-analysis of the outcomes of bacterial meningitis in high-income countries (22), long-term sequelae following Hib meningitis were observed in $26 \%$ of survivors, manifesting as sensorineural hearing loss (10\%), spasticity (5\%), intellectual impairment (6\%), and epilepsy (6\%). Additionally, survivors might develop functionally important behavioral disorders, neuropsychologic impairment, or auditory dysfunction adversely affecting academic performance $(5,23)$. In contrast, long-term sequelae following Hib meningitis were seen in 38\% of survivors in The Gambia (24). Twenty-nine percent of Navajo Indian children suffered long-term sequelae (25), notably intellectual impairment (24\%), severe hearing loss (5\%), spasticity (7\%), and seizures (12\%). Among Alaska Native infants, $29 \%$ suffered motor deficits and 7\% developed hydrocephalus (26). Age is also an important factor in determining outcome of meningitis (27), and the higher rates of adverse sequelae in Indigenous children and in Africa may have resulted from a higher proportion of cases occurring in infants $<12$ months of age in these communities. Additional potential factors contributing to adverse outcomes might also include poor access to medical care, delayed diagnosis and treatment, and in African children comorbidities such as malaria, malnutrition, and human immunodeficiency virus (HIV) infection.

Hib vaccine probe studies used data from randomized controlled trials (RCTs) to estimate the underlying burden of disease from Hib pneumonia by measuring the difference in incidence of pneumonia between vaccinated and unvaccinated children. These vaccine probe studies were conducted in The Gambia (28), Lombok in Indonesia (29), and Santiago in Chile (30). They suggested that Hib was an important cause of bacteremic and nonbacteremic pneumonia in young children (Fig. 1) in low- and middle-income countries (LMICs) and likely the most common presentation of Hib disease globally. Subsequent analyses provided an estimated annual global incidence of Hib pneumonia in unvaccinated children of 1,304/100,000 children aged $<5$ years (31). Other studies in children from Papua New Guinea and Indigenous children in the Northern Territory of Australia estimated the incidence of Hib pneumonia to be 2,860/ 100,000 and $225 / 100,000$ children $<5$ years of age, respectively $(32,33)$.

Unvaccinated HIV-infected children are at particularly high risk of invasive Hib disease in comparison to unvaccinated children from the same region but who are HIV negative (relative risk, 5.9; 95\% confidence interval [Cl], 2.7 to 12.6 ) and where pneumonia was also a more common presentation than meningitis $(34,35)$. In a pneumococcal vaccine trial in South Africa, bacteremic Hib pneumonia was the most common 


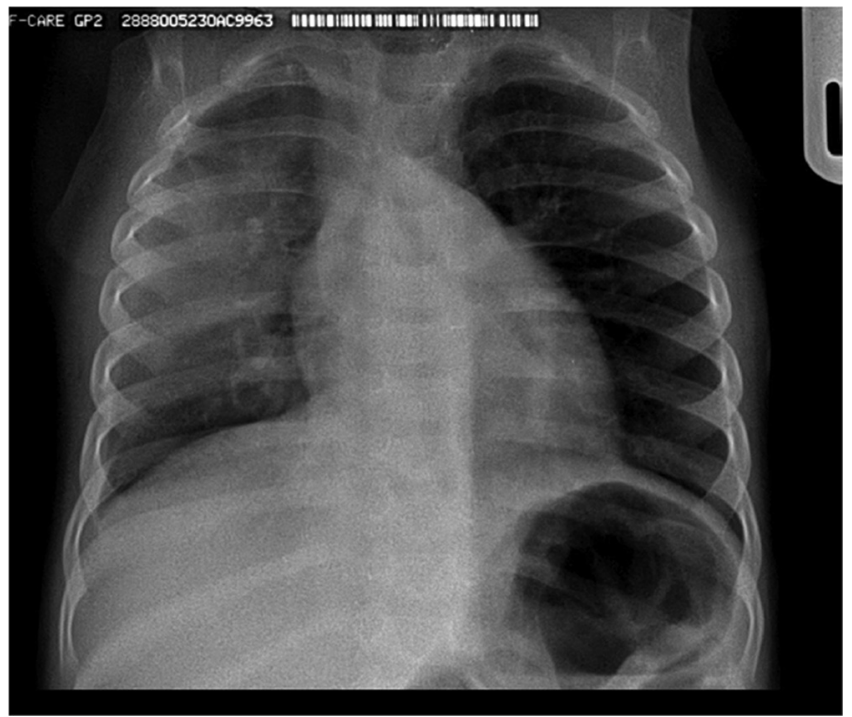

FIG 1 Posteroanterior chest radiograph of an 11-month-old infant showing right-sided pneumonia caused by $H$. influenzae type b (copyright 2020 Grant Mackenzie).

presentation of invasive Hib disease $(34,35)$. The incidence of Hib pneumonia in HIVpositive infants aged $<1$ year was $822 / 100,000$ compared to $48 / 100,000$ in HIV-negative infants (relative risk, 18.0; $95 \% \mathrm{Cl}, 6.9$ to 47.1) (34). In addition to patients with HIV, patients with asplenia, sickle cell disease (SCD), and possibly malignancies were also at a higher risk of developing invasive Hib infections (18).

Hib was also the most common cause of acute epiglottitis, which usually presented in older children aged 2 to 4 years, but it was rarely seen in Indigenous children in Australia (36) or in Native Alaskan and Canadian Inuit children (19), where the greatest burden of invasive $H$. influenzae disease was found in those aged $<18$ months. Other manifestations of invasive Hib infection include bacteremia without a focus of infection, orbital and periorbital cellulitis, facial cellulitis, and skeletal infections (1). The annual incidence of all invasive Hib disease before the introduction of Hib vaccine ranged from 67 to $131 / 100,000$ in the United States (18), 58/100,000 in Australia (37), 52/ 100,000 in Finland (38), 24 to 36/100,000 in the United Kingdom (16), 34/100,000 in Israel (39) and 18.8/100,000 in children aged $<5$ years in Japan (40).

\section{Hib POLYSACCHARIDE VACCINE}

The original Hib vaccine was a PRP plain polysaccharide vaccine. A large field trial recruiting 100,000 children aged 3 months to 5 years in Finland demonstrated an agedependent response to PRP but failed to show any impact on nasopharyngeal carriage and therefore no interruption of transmission (17). The PRP vaccine did not induce protective levels of anti-PRP antibodies in children aged $<18$ months, but it was $90 \%$ efficacious in those aged $\geq 18$ months. Polysaccharides are T-cell-independent antigens which lead primarily to IgM responses with little isotype switching to lgG antibody in infants aged $<18$ months. Plain polysaccharide vaccines fail to induce immunologic memory and also fail to elicit a booster response on repeated exposure $(2,41)$.

\section{Hib PROTEIN CONJUGATE VACCINES}

To address the reduced immunogenicity of polysaccharide vaccines in infants, conjugated protein-polysaccharide (glycoconjugate) vaccines were developed (Fig. 2).

Antibody responses to proteins are $T$ cell dependent and can be elicited from a very young age, resulting in high-affinity antibodies with isotype switching, affinity maturation, and the generation of immunologic memory. Subsequent exposure to the 


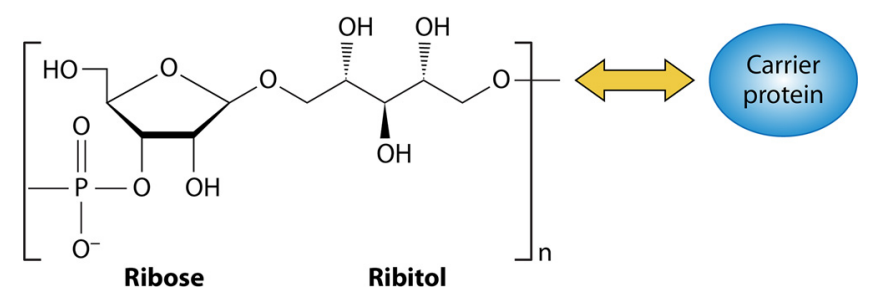

FIG 2 Cartoon illustrating Hib conjugate vaccine. Polyribosyl ribitol phosphate (PRP) [composed of repeating units of 5 -D-ribitol-(1 $\rightarrow 1)-\beta$-D-ribose-3-phosphate] covalently linked to a carrier protein (chemical structure kindly provided by Neni Nurainy, Biofarma, Indonesia).

antigen results in a significant booster response. Hib PRP-protein conjugate vaccines, which activate a T-cell-dependent response with high levels of protective antibodies in infants from 2 months of age, were developed in the late 1980s (42). Hib nasopharyngeal carriage is reduced in those who are vaccinated, thereby interrupting transmission of Hib to susceptible unvaccinated children and adults (i.e., herd protection) (43). Initially, four different monovalent Hib protein conjugate vaccines were produced. Different carrier proteins, various lengths of PRP saccharide, and different protein-polysaccharide conjugation techniques were used. The four protein carriers were tetanus toxoid (PRP-TT), diphtheria toxoid (PRP-D), Neisseria meningitidis outer membrane complex (PRP-OMP), and a nontoxic mutant Corynebacterium diphtheriae protein $\mathrm{CRM}_{197}$ (PRP-CRM). The Hib protein conjugate vaccines had different immunologic properties, resulting in different antibody titers, avidity maturation, rapidity of response, and idiotypic expression of the antibody response following vaccination (44-47). A doubleblind RCT of the four Hib protein conjugate vaccines administered at 2, 4, and 6 months found that only $29 \%$ of infants achieved the putative long-term protective concentration of Hib antibodies ( $\geq 1 \mu \mathrm{g} / \mathrm{ml}$ ) after three doses of PRP-D, compared with $55 \%, 75 \%$, and $83 \%$ of infants who had received PRP-OMP, PRP-CRM, and PRP-T, respectively (48). The PRP-OMP vaccine stimulated the highest antibody concentration after the first dose in infants aged as young as 2 months (49), with $57 \%$ of infants achieving an antibody concentration of $\geq 1.0 \mu \mathrm{g} / \mathrm{ml}$ at age 4 months. However, PRPOMP did not produce significant increases in antibody concentration when further doses of vaccine were administered at 4 and 6 months of age. Despite this, PRP-OMP was the first vaccine used in Indigenous populations in North America and Australia, where a high burden of disease existed in very young infants $(19,20,33)$. Over time, PRP-D was withdrawn, and Hib protein conjugate vaccines have since been incorporated into a range of combination bivalent (Hib/meningococcal serogroup C $[\mathrm{MenC}]$ ), pentavalent (diphtheria-tetanus-acellular pertussis [DTaP]/inactivated poliovirus [IPV]/ $\mathrm{Hib})$, and hexavalent (DTaP/IPV/Hib/hepatitis B [HepB]) vaccines.

\section{IMPACT OF Hib PROTEIN CONJUGATE VACCINES ON INVASIVE Hib DISEASE}

The inclusion of Hib glycoconjugate vaccines in NIPs has led to a significant and sustained decline in invasive Hib disease across all age groups, through direct and indirect (herd) protection $(50,51)$. Routine use of Hib protein conjugate vaccine has consistently reduced the incidence of invasive Hib disease by $\geq 90 \%$ in high-income countries (51). The inclusion of Hib protein conjugate vaccines in the NIPs of low and middle-income countries has been generally much slower than its introduction in high-income countries. This was due to several factors, including limited local data on the burden of Hib infections as a result of high rates of antimicrobial therapy before specimen collections for culture and difficulties in growing this fastidious organism, as well as the associated vaccine costs (14). By 2004, few low-income countries had adopted Hib vaccines. The World Health Organization (WHO) and the Global Alliance for Vaccines and Immunization (GAVI) sought to address this problem in several ways. Vaccine probe studies (28-30) and the WHO Hib rapid assessment tool (HibRAT) (52) 
provided a prompt and timely assessment of Hib disease burden in many countries. In 2005, the GAVI Alliance established the Hib Initiative to accelerate the introduction of Hib protein conjugate vaccine into GAVI-eligible countries (53). In 2006, the WHO advocated the global introduction of Hib protein conjugate vaccines (54), enabling GAVI-eligible countries to apply for Hib vaccine introduction without needing to generate data on local disease burden. For GAVI-eligible countries, free vaccine was initially provided through the GAVI Alliance with cofinancing guidelines offering a financial commitment to cover vaccine costs until 2015, together with a small copayment by each country to address concerns regarding the long-term sustainability of the program. As a result of these endeavors, the number of countries implementing Hib immunization increased from 89/193 (46\%) in 2004 to 158/193 (82\%) in 2009 (55). As of 2020, all countries in the world, except China and the Russian Federation (where Hib vaccine is recommended for certain risk groups), have included Hib protein conjugate vaccines in their routine NIPs (see Tables 1 to 6).

A substantial reduction in Hib disease burden has been seen wherever the vaccine has been used. In an updated analysis of data from the year 2000, Hib was estimated to have caused approximately 8.13 million (uncertainty range [UR], 7.33 to 13.2 million) cases of serious disease and 371,000 deaths (UR, 247,000 to 527,000) per year in children aged $<5$ years (31). Between 2000 and 2015, the estimated global burden of Hib meningitis, pneumonia, and nonpneumonic bacteremia in HIV-negative children aged $<5$ years had declined to 340,000 cases (UR, 196,000 to 669,000 ) and 29,800 deaths (UR, 18,600 to 41,100) (56). From 2000 to 2015, Hib-related deaths declined by $90 \%$ (UR, 78\% to 96\%) (56). Most Hib deaths occurred in just four countries, India $(15,600$ deaths; UR, 9,800 to 21,500), Nigeria (3,600 deaths; UR, 2,200 to 51,000), China $(3,400$ deaths; UR, 2,300 to 4,600), and South Sudan (1,000 deaths; UR, 600 to 1,400) (56).

\section{CURRENT EPIDEMIOLOGY OF INVASIVE H. INFLUENZAE DISEASE}

The burden of invasive Hib disease is limited currently to a small number of countries where Hib immunization is either not freely available or has been incorporated only recently into the NIP. Reducing invasive Hib disease to the lowest possible level depends on maintaining high vaccine coverage and maintaining good surveillance systems for Hib disease.

Initially, concerns were raised that other capsulated serotypes of $H$. influenzae might occupy the ecologic niche formerly occupied by Hib and emerge as significant causes of invasive disease once Hib vaccination had been introduced. In general, this has not happened in many parts of the world, with an important exception of the Indigenous communities of North America, where Hia is an emerging pathogen $(57,58)$. There has also been a slight increase in invasive $H$. influenzae serotype e (Hie) and $H$. influenzae serotype $f(H i f)$ cases in Europe $(9,59)$. In contrast, the numbers of cases of invasive NTHi infections have increased significantly in multiple regions of the world $(60,61)$. In the following sections, the current epidemiology in the different WHO-designated regions is described (Fig. 3) (62).

\section{Region of the Americas}

All countries in the WHO Region of the Americas have introduced Hib vaccine. In 2020 , the average coverage of three doses of Hib vaccine was $85 \%$ (63).

The data on individual countries in the Region of the Americas are shown in Table 1.

North America. Hib was a major cause of invasive bacterial infection in young children in the United States and Canada before the introduction of Hib vaccine. Population-based surveillance studies in the United States and Canada reported 10,000 to 20,000 cases annually of Hib meningitis and other serious invasive infections, with a CFR of $3 \%$ to $5 \%$ and long-term sequelae in as many as $25 \%$ of meningitis survivors (8). Much higher incidence rates of invasive Hib disease were observed in Alaska Native (64), White Mountain Apache (65), and Navajo Indian (66) children, with reported annual incidence rates of 700/100,000, 214/100,000, and 254/100,000 children aged $<5$ years, respectively. In North America, Hib infection occurred at a younger age 


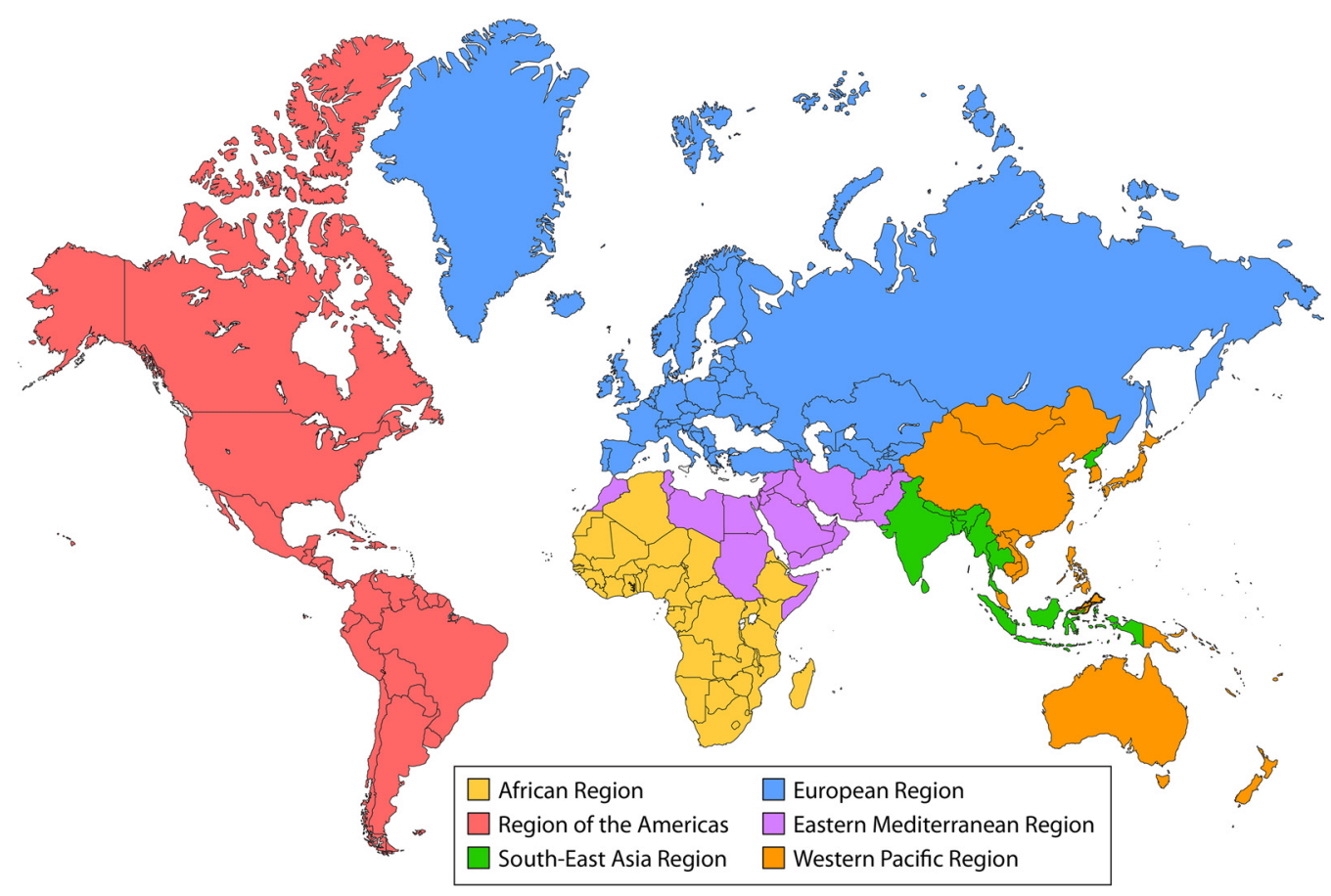

FIG 3 The six designated World Health Organization regions.

in Indigenous than non-Indigenous children. The peak incidence of Hib meningitis in Navajo children was at age 4 to 8 months (66), and that in White Mountain Apache children was at 4 to 7 months of age (65). In Alaska Native children, $23 \%$ of cases were in infants aged $<6$ months (64), whereas in North American non-Indigenous children, the peak rate of Hib meningitis was at 6 to 11 months of age (8). Although most cases in North American Indigenous children presented with meningitis, CFRs in Navajo Indian and Alaska Native children were lower than in the U.S. general population, $4 \%$ and $3 \%$ versus $5 \%$, respectively $(8,64,66)$. However, $16 \%$ of Navajo children who survived meningitis suffered neurologic sequelae (66). Carriage of Hib in Indigenous children began at a very young age (66), with asymptomatic carriers acting as a major reservoir and source of disease transmission.

Hib immunization was initiated in Alaska in 1991 using PRP-CRM and then changed to PRP-OMP, as this vaccine elicited protective antibody levels after a single dose (49). The incidence of invasive Hib disease in Alaska Native children aged $<5$ years fell from $309.4 / 100,000$ in 1980 to 1991 to $18.3 / 100,000$ in 1992 to 1995 (67). The PRP-OMP vaccine was used in Alaska until 1996, when it was replaced by a combination vaccine with a PRP-CRM component. Cases of Hib disease in rural Alaska Native children increased over the next year to $91.1 / 100,000$ children aged $<5$ years, and in 1997, Alaska adopted a sequential Hib vaccine policy for Alaska Native children, with an initial dose of PRP-OMP and PRP-CRM for the rest of the schedule. In 2001, Alaska reintroduced a schedule using PRP-OMP alone or a combined hepatitis B/PRP-OMP vaccine (67). Although Hib disease is largely controlled, the rate of disease in this age group is still higher among rural Alaska Native children $(5.4 / 100,000)$ than in non-Native Alaska and other non-Indigenous U.S. children $(0.09 / 100,000)(67,68)$.

In 1990, Hib protein conjugate vaccine was added to the routine infant immunization program in the United States (69). The program had a dramatic impact, and by 1995 , invasive Hib disease incidence in children aged $<5$ years had declined by more than $95 \%$ (8). Ongoing active surveillance of invasive $H$. influenzae disease has continued in the Active Bacterial Core (ABC) surveillance sites coordinated by the Centers for Disease Control and Prevention (CDC). This surveillance system encompasses a 
TABLE 1 Implementation of Hib vaccine in countries of the WHO Region of the Americas ${ }^{a}$

\begin{tabular}{|c|c|c|c|c|c|c|}
\hline Country & $\begin{array}{l}\text { Yr of } \\
\text { introduction }\end{array}$ & NIP & Formulation in 2019 & Schedule in 2019 & $\begin{array}{l}\text { Coverage of } \\
\text { Hib3 in } \\
2019(\%)\end{array}$ & $\begin{array}{l}\text { Yr in which } \\
\text { coverage } \\
\text { reached } \geq 50 \%\end{array}$ \\
\hline Antigua and Barbuda & 2000 & Yes & DTwP/Hib/HepB & $2,4,6 \mathrm{mo}$ & 99 & 2001 \\
\hline Argentina & & & DTaP/Hib/HepB/IPV & $\begin{array}{l}2,4,6 \text { mo for } \\
\text { premature } \\
\text { neonates }\end{array}$ & & \\
\hline \multirow{2}{*}{ The Bahamas } & & & DTwP/Hib/HepB & $2,4,6 \mathrm{mo}$ & & \\
\hline & & & DTwP/Hib & $15 \mathrm{mo}$ & & \\
\hline \multirow[t]{2}{*}{ Barbados } & 2000 & Yes & DTwP/Hib/HepB & $2,4,6 \mathrm{mo}$ & 90 & 2002 \\
\hline & & & $\begin{array}{l}\mathrm{DTaP} / \mathrm{Hib} / \mathrm{HepB} / \mathrm{IPV} \\
\quad \text { (infants of } \mathrm{HIV}^{+} \\
\text {mother) }\end{array}$ & $2,4,6 \mathrm{mo}$ & & \\
\hline \multirow[t]{2}{*}{ Brazil } & 1999 & Yes & DTwP/Hib/HepB & $2,4,6 \mathrm{mo}$ & 80 & 2000 \\
\hline & & & $\mathrm{Hib}$ & Special population & & \\
\hline Canada & 1986 & Yes & DTaP/Hib/HepB/IPV & $2,4,6,18 \mathrm{mo}$ & 96 & 1996 \\
\hline Chile & 1996 & Yes & DTaP/Hib/HepB/IPV & $2,4,6,18 \mathrm{mo}$ & 96 & 1996 \\
\hline Colombia & 1998 & Yes & DTwP/Hib/HepB & $2,4,6 \mathrm{mo}$ & 92 & 1998 \\
\hline Costa Rica & 1998 & Yes & DTaP/Hib/HepB/IPV & $2,4,6,15 \mathrm{mo}$ & 94 & 1999 \\
\hline \multirow[t]{2}{*}{ Cuba } & 1999 & Yes & DTwP/Hib/HepB & $2,4,6,18 \mathrm{mo}$ & 99 & 1999 \\
\hline & & & $\begin{array}{l}\text { Hib (children of } \\
\mathrm{HepB}^{+} \text {women) }\end{array}$ & $2,4,6,18 \mathrm{mo}$ & & \\
\hline Dominica & 2006 & Yes & DTwP/Hib/HepB & $2,4,6 \mathrm{mo}$ & 99 & 2007 \\
\hline Dominican Republic & 2002 & Yes & DTwP/Hib/HepB & $2,4,6 \mathrm{mo}$ & 79 & 2003 \\
\hline Ecuador & 2003 & Yes & DTwP/Hib/HepB & $2,4,6 \mathrm{mo}$ & 85 & 2003 \\
\hline Mexico & 1999 & Yes & DTaP/Hib/HepB/IPV & $2,4,6,18 \mathrm{mo}$ & 82 & 2000 \\
\hline Nicaragua & 1999 & Yes & DTwP/Hib/HepB & $2,4,6 \mathrm{mo}$ & 98 & 1999 \\
\hline \multirow[t]{2}{*}{ Panama } & 2000 & Yes & DTaP/Hib/HepB/IPV & $2,4,6 \mathrm{mo}$ & 88 & 2001 \\
\hline & & & DTwP/Hib & $18 \mathrm{mo}$ & & \\
\hline \multirow[t]{2}{*}{ Paraguay } & 2002 & Yes & DTwP/Hib/HepB & $2,4,6 \mathrm{mo}$ & 86 & 2003 \\
\hline & & & $\begin{array}{l}\text { Hib ( }<5 \text { yrs; scheduled } \\
\text { splenectomy, } \text { HIV }^{+}, \\
\text {immunodeficiencies, } \\
\text { and not fully } \\
\text { vaccinated) }\end{array}$ & $\begin{array}{l}\text { 1st contact and } 2 \\
\text { mo later }\end{array}$ & & \\
\hline \multirow[t]{2}{*}{ Peru } & 2005 & Yes & DTwP/Hib/HepB & $2,4,6 \mathrm{mo}$ & 88 & 2004 (introduced \\
\hline & & & $\begin{array}{r}\text { Hib (if pentavalent } \\
\text { contraindicated) }\end{array}$ & $4,6 \mathrm{mo}$ & & $\begin{array}{l}\text { in part of the } \\
\text { country) }\end{array}$ \\
\hline Saint Kitts and Nevis & 2000 & Yes & DTwP/Hib/HepB & $4,6 \mathrm{mo}$ & 97 & 2001 \\
\hline Saint Lucia & 2002 & Yes & DTwP/Hib/HepB & $2,4,6 \mathrm{mo}$ & 92 & 2003 \\
\hline $\begin{array}{l}\text { Saint Vincent and the } \\
\text { Grenadines }\end{array}$ & 2003 & Yes & DTwP/Hib/HepB & $2,4,6 \mathrm{mo}$ & 97 & 2005 \\
\hline
\end{tabular}


TABLE 1 (Continued)

\begin{tabular}{|c|c|c|c|c|c|c|}
\hline Country & $\begin{array}{l}\text { Yr of } \\
\text { introduction }\end{array}$ & NIP & Formulation in 2019 & Schedule in 2019 & $\begin{array}{l}\text { Coverage of } \\
\text { Hib3 in } \\
2019(\%)\end{array}$ & $\begin{array}{l}\text { Yr in which } \\
\text { coverage } \\
\text { reached } \geq 50 \%\end{array}$ \\
\hline Suriname & 2005 & Yes & DTwP/Hib/HepB & $2,4,6 \mathrm{mo}$ & 77 & 2005 \\
\hline Trinidad and Tobago & 1999 & Yes & $\begin{array}{l}\text { DTwP/Hib/HepB } \\
\text { Hib (given to children } \\
\text { born overseas who are } \\
\text { over the age for } \\
\text { pentavalent) }\end{array}$ & $\begin{array}{l}2,4,6 \mathrm{mo} \\
>12 \mathrm{mo}\end{array}$ & 93 & 2000 \\
\hline United States & 1991 & Yes & $\begin{array}{l}\text { DTaP/Hib/HepB/IPV } \\
\text { Hib }\end{array}$ & $\begin{array}{l}2,4,6,12 \mathrm{mo} \\
2,4,6,12 \mathrm{mo}\end{array}$ & 91 & 1995 \\
\hline Uruguay & 1994 & Yes & $\begin{array}{l}\text { DTwP/Hib/HepB } \\
\text { Hib (if pertussis } \\
\text { contraindicated) }\end{array}$ & $\begin{array}{l}2,4,6,15 \mathrm{mo} \\
2,4,6,15 \mathrm{mo}\end{array}$ & 94 & 1997 \\
\hline $\begin{array}{l}\text { Bolivarian Republic of } \\
\text { Venezuela }\end{array}$ & 2000 & Yes & DTwP/Hib/HepB & $2,4,6,18 \mathrm{mo}, 5 \mathrm{yrs}$ & 64 & 2002 \\
\hline
\end{tabular}

aAnnual birth cohort, 14.7 million. Children aged <5 years, 73.3 million. Eighty-five percent of target population was immunized with three doses of Hib (Hib3) in 2019 (based on WHO-UNICEF estimates) (63). NIP, national immunization program. Abbreviations of vaccine antigens: $D$, diphtheria; T, tetanus; aP, acellular pertussis; wP, wholecell pertussis; Hib, Haemophilus influenzae type b; HepB, hepatitis B virus surface antigen; IPV, inactivated poliovirus.

population of over 42 million in five states and five metropolitan areas across the United States (70). It showed that invasive Hib disease continued to decline, and from 2009 to 2015, only 77 cases of invasive Hib disease were reported from the $A B C$ sites, with a median patient age of 49 years (68). Of the 77 cases, only 23 (29.9\%) occurred in children of $<5$ years of age, and in the 22 with available clinical information, nine presented with meningitis, six with bacteremic pneumonia, three with bacteremia, and four with other presentations. Only five $(21.7 \%)$ of the children had been age appropriately vaccinated, including two aged 3 months who were eligible for only their first vaccine dose. None had reported underlying comorbidities. Of the remaining 54/77 (70.1\%) Hib patients of $>5$ years of age, 9 (16.7\%) were aged 5 to 17 years, $28(51.9 \%)$ were 18 to 64 years, and 17 (31.5\%) were $\geq 65$ years of age.

The $A B C$ surveillance network also reported that between 2009 and 2015, there were 545 cases of invasive $H$. influenzae infection in children aged $<5$ years, with an incidence of 2.84/100,000 children $<5$ years and 8.45/100,000 infants aged $<1$ year (68). Of the 317 cases in infants $<1$ year, 140 (44.2\%) were in the first month of life, and of these, $127 / 140(90.7 \%)$ were in the first week of life, with 109/127 (77.9\%) presenting at birth. Most who developed infection in the first month of life were preterm and lowbirthweight infants, and $113(80.7 \%)$ of these infections were from bacteremia, with $111(98.5 \%)$ caused by NTHi. The incidence of invasive $H$. influenzae infection was substantially higher in Alaska Native and American Indian children (15.19/100,000 children $<5$ years and $34.36 / 100,000$ infants $<1$ year of age) (68). In these children, infections with non-b serotypes, principally Hia, had the highest incidence. During 2009 to 2015 , the risk of invasive $H$. influenzae infection in U.S. adults of $\geq 65$ years increased with age, with incidences of 3.48/100,000, 4.65/100,000, 6.48/100,000, 8.56/100,000, and $13.56 / 100,000$ in those aged 65 to 69 years, 70 to 74 years, 75 to 79 years, 80 to 85 years, and $\geq 85$ years, respectively (68). Most infections in $\geq 65$-year-old patients were caused by NTHi (79.3\%) or non-b serotypes (19.9\%; with serotype $f$ the most frequent). Only $0.08 \%$ of cases were due to Hib. Bacteremic pneumonia was the most common presentation in this age group (73.4\%), and $74.0 \%$ had at least one underlying comorbidity. The overall incidence of invasive $H$. influenzae disease was 1.70 / 100,000 population, with a CFR of $14.5 \%$. NTHi had a higher incidence $(1.22 / 100,000)$ and CFR (16\%) than Hib $(0.03 / 100,000$ and $4 \%$, respectively) and non-b capsulated $(0.45 / 100,000$ and $11 \%$, respectively) $H$. influenzae serotypes.

From 2002 to 2015, the estimated overall incidence of invasive $H$. influenzae infections in the United States increased by $2 \%$ per year $(68,71)$. The annual incidence of NTHi and Hia invasive infections increased by $3 \%$ and $13 \%$, respectively. The incidence 
of all other non-b serotypes declined or remained the same. The NTHi and Hia infection CFRs were $16.1 \%$ and $8.3 \%$, respectively. Among the non-b encapsulated serotypes, Hia affected predominantly children $<5$ years of age, Hif had the highest overall incidence $(0.27 / 100,000)$, and Hie exhibited a high CFR (18.4\%). While Hid was detected rarely, its CFR (50.0\%) was the highest recorded.

(i) Invasive $H$. influenzae disease and HIV. From 2017 to 2018, invasive NTHi infections in HIV-infected men who had sex with men increased in metropolitan Atlanta, Georgia (72). The incidence of invasive NTHi infection in HIV-positive individuals (41.7/ 100,000 ) in 2017 to 2018 was significantly greater than that in HIV-positive individuals from 2008 to $2016(9.9 / 100,000 ; P<0.001)$ and in those without HIV from 2008 to 2018 $(1.1 / 100,000 ; P<0.001)$. Comparing NTHi infections in 2017 to 2018 to those in 2008 to 2016, HIV-positive adults aged 18 to 55 years with NTHi infection in 2017 to 2018 were significantly more likely to be male (94\% versus $49 \%$; $P<0.001$ ), AfricanAmerican (100\% versus 53\%; $P<0.001$ ), and to have septic arthritis (35\% versus $1 \%$; $P<0.001)$ than HIV-negative adults with NTHi infection in 2008 to 2016. Whole-genome sequencing confirmed two distinct but genetically related clonal lineages of NTHi. Among 38 cases of NTHi infection in persons with HIV, 32 (84\%) lived in close geographic proximity, while all were male African-Americans with a median age of 34.5 years and 31 (82\%) reported having sex with men.

(ii) Invasive $H$. influenzae infections and sickle cell disease. There is an increased risk of invasive infections caused by encapsulated bacteria, including $\mathrm{Hib}$, in children with sickle cell disease (SCD). Before the introduction of Hib conjugate vaccine, children with SCD in the United States had a 4-fold increased risk of developing Hib bacteremia (73). In a Kenyan study of bacteremic episodes in children with SCD, 13/108 (12\%) were due to Hib (74). In Africa, children with invasive Hib infections had 13times-higher odds of having SCD (75).

In the United States, antibiotic prophylaxis and $\mathrm{Hib}$ and pneumococcal conjugate vaccines have led to a marked decline in the overall rates of invasive infections in SCD, including Hib infections. A retrospective review of the medical records of 815 children with SCD at the Children's Hospital of Philadelphia conducted from 2000 to 2010 in the era of Hib conjugate vaccination did not find a single case of Hib bacteremia (76). In one study in a pediatric tertiary care center in Atlanta, Georgia, there were eight episodes of $\mathrm{H}$. influenzae bacteremia over a 17-year period (2000 to 2017): $5 \mathrm{Hif}, 2 \mathrm{NTHi}$, and $1 \mathrm{Hia}$ (77). Seven of the eight infections occurred in children aged $<5$ years, with an incidence of $1.6 / 1,000$ person-years in this age group. Although uncommon, the possibility of non-Hib $\mathrm{H}$. influenzae bacteremia should therefore also be considered in children with SCD.

(iii) Strain replacement: Hia in the United States. In the pre-Hib vaccine era, Hia as a cause of invasive $H$. influenzae disease was overshadowed by Hib, and epidemiologic data on Hia disease prior to 2000 are very limited. However, during the last decade, Hia has been recognized increasingly as a clinically significant pathogen causing severe disease and high CFRs in certain geographic areas and populations (58). Based on experiments with an infant rat septicemia model (78), Hia was found to be the second most virulent serotype after Hib (79). Indeed, Hia and Hib share many similarities: both serotypes cause invasive disease preferentially in young children, and both pathogens are characterized by serious infections, including meningitis, bacteremic pneumonia, and septic arthritis (58). Whereas at present invasive Hia disease is extremely uncommon in Europe or Asia, it has been reported consistently from Alaska, the North American Arctic, Western Canada, North Western Ontario, Manitoba, and South Western parts of the United States, where Indigenous people comprise a high proportion of the population, with concerning trends toward increasing incidence rates in some of these regions $(58,80)$. Hia has emerged as a significant pathogen in Utah $(81$, 82) and North and South Dakota (83). In a study in Utah from 1998 to 2008, 28\% of all invasive $H$. influenzae disease in children aged $<5$ years was due to $\mathrm{Hia}$, while just $18 \%$ was from Hib. Fifty percent of the Hia cases presented as meningitis. However, unlike 
in other parts of North America, Hia and Hib did not occur predominantly in American Indian children in these states. A recent study from Utah described 51 cases of invasive Hia disease in children over the 10-year period from 2007 to 2017 (82). Meningitis was the most common clinical presentation (53\%), with pneumonia and septic arthritis each accounting for $14 \%$ of cases; $43 \%$ of children required admission to an intensive care unit, and one child died (82).

The incidence of invasive Hia disease in the United States has been increasing by an average of $11.1 \%$ annually, from 0.05 to $0.14 / 100,000$ population overall between 2008 and 2017 (84). The overall greatest burden of disease was observed in Alaska Native and American Indian children, with an estimated incidence of $8.29 / 100,000$ in those aged $<5$ years, compared to $0.49 / 100,000$ in those $<5$ years of age in all other races combined; for infants $<1$ year of age, the incidence rates were $17.78 / 100,000$ and 1.28 / 100,000 , respectively (84).

The highest incidence rates of invasive Hia disease have been reported from Alaska, where no Hia disease was identified before 2002, but since then, the incidence has been increasing annually by an average of $4.9 \%$ (85) and outbreaks have occurred, with the biggest disease burden borne by Alaska Native children (86). The average annual incidence rates of invasive Hia disease in Alaska Native children were 27.74/ 100,000 in those aged $<5$ years and $82.39 / 100,000$ in infants aged $<1$ year (2008 to 2017) (84). Between 2002 and 2014, 42\% of pediatric Hia cases in Alaska presented as meningitis with a high prevalence of unfavorable outcomes, including death $(11 \%)$ or neurologic sequelae (14\%) (87). All but two of 36 (94\%) affected children were Alaska Natives, and 32 (89\%) were $<18$ months of age (87).

From 2011 to 2015, review of the medical records of 169 patients with Hia infection in the $A B C$ sites demonstrated the severity of invasive Hia disease: $96.0 \%$ were admitted to hospital, $25.3 \%$ required ventilatory support, $47.5 \%$ needed intensive care, and $6.2 \%$ died during hospitalization (88). In children aged $<1$ year, meningitis was the most common clinical presentation (71.4\%). Overall, $17.7 \%$ of patients had adverse sequelae following discharge from hospital, as did 17.8\% 1 year after the onset of the infection. Patients with meningitis had the highest proportion of sequelae $(48.5 \%)$, including deafness and developmental and/or speech delay, with all adverse outcomes documented in children aged $<5$ years (88).

(iv) Strain replacement: Hia in Canada. In Canada, the highest incidence rates of invasive Hia are reported from the Nunavut and Nunavik territories in Northern Canada, which are populated mainly by Inuit people, where Hia epidemiology is very similar to that in Alaska. In these Canadian territories, Hia affects mainly young Indigenous children, has severe clinical presentation, such as meningitis with high CFRs, and causes outbreaks when the incidence can reach $300 / 100,000$ in children aged $<1$ year $(80,89)$. In addition, Hia disease has been reported consistently from northern parts of the Canadian provinces of Manitoba, Ontario, and Quebec, regions largely inhabited by Indigenous peoples $(58,80,90)$. Thus, invasive Hia disease is now prevalent in populations of North American Indigenous people, where several outbreaks have occurred since 2002, although sporadic cases have been reported from countries outside this continent. The emergence of Hia as a significant cause of invasive disease has prompted moves to develop a conjugated Hia vaccine (91), which if effective could prevent the high rates of morbidity and mortality seen with invasive Hia disease in addition to saving health care systems millions of dollars in both acute and long-term care (91).

\section{Latin America and the Caribbean}

Before Hib protein conjugate vaccines were introduced, the estimated incidence rate in children aged $<5$ years in 16 countries of this region for Hib meningitis was 35/ 100,000 , and for all invasive Hib disease, it was 60/100,000 (92). The first country in Latin America to introduce large-scale immunization with Hib protein conjugate vaccines was Uruguay in 1994 (93). By 2006, all countries and territories in this region, except Haiti (94), had incorporated Hib vaccines into their NIPs (Table 1). Haiti 
subsequently introduced pentavalent vaccine (diphtheria-tetanus-whole-cell pertussis [DTwP]/HepB/Hib) in 2012 (95). As in other regions, cases of Hib meningitis have declined substantially with the use of Hib vaccines (96). Surveillance in four countries suggested that high vaccine coverage resulted in a low incidence of Hib meningitis and low rates of Hib nasopharyngeal carriage in countries that used a three-dose primary course with (Uruguay and Argentina) or without (Colombia and Chile) a booster dose in the second year of life (93). In Mexico, a cross-sectional study (97) undertaken in 2007 found that only $40 \%$ to $50 \%$ of 110 children aged 12 to 23 months of age had anti-PRP antibody titers of $>1 \mu \mathrm{g} / \mathrm{ml}$, the putative concentration required for longterm protection, despite $92 \%$ of these children having been fully immunized with three doses of Hib combination vaccine given at 2, 4, and 6 months of age. As a result, Mexico introduced a booster dose of an acellular pertussis pentavalent vaccine (DTaP/ $\mathrm{Hib} / \mathrm{IPV}$ ) in 2007 (97).

Strain replacement: Hia in Central and South America. Hia infections have also been recorded in several Caribbean and South American countries, including Colombia, Venezuela, Argentina, and Cuba, with most reports coming from Brazil (80). Routine Hib immunization was introduced in Brazil in 1999. The incidence rates of Hia meningitis increased 8-fold, from 0.02/100,000 person-years in 1996 to 0.16 cases/ 100,000 person-years in 2000 (98). In Paraguay, invasive Hib infections in children $<5$ years of age declined following the introduction of Hib vaccine but was associated with an increase in invasive NTHi infections in older children and adults (99).

\section{European Region}

Almost all nations in the WHO European Region have included Hib vaccine in their recommended NIPs. In the Russian Federation, Hib vaccines are recommended for certain risk groups but are not yet included in the NIP. In 2019, the average coverage of three doses of Hib vaccine in the WHO European Region was $85 \%$ (100). It was estimated that the incidence of all invasive Hib infections in the WHO European Region in 2000 was 304/100,000 (UR, 274 to 491) in children aged <5years (31). By 2015, the estimated incidence had declined to $41 / 100,000$ (UR, 37 to 67) in children aged $<5$ years (56). These two studies only reported data on invasive Hib infections and did not analyze data on infections due to NTHi or other serotypes.

The data for individual countries in the European Region are shown in Table 2.

Invasive $\boldsymbol{H}$. influenzae infections in Western Europe. The mean annual incidence of Hib meningitis among children $<5$ years of age in Europe was 23/100,000 before Hib vaccination was implemented (101). By 2005, all countries in the European Union (EU) and European Economic Area (EEA) had introduced Hib vaccine (Table 2). In 2018, the overall incidence of all invasive $H$. influenzae infections in the EU/EEA had declined to $0.8 / 100,000$ population, with the highest incidence in infants $<1$ year of age (4.0/ $100,000)$ and adults $>65$ years of age $(2.4 / 100,0000)(102)$. NTHi accounted for $78 \%$ of infections overall. The most common serotype was Hif. From 1996 to 2006, surveillance of invasive $H$. influenzae infections in Western Europe was undertaken by the European Union Invasive Bacterial Infection Surveillance (EU-IBIS) network (funded by the European Commission DG SANCO) $(9,103)$. In 2007, coordination of the network was transferred to the European Centre for Disease Prevention and Control (ECDC) (103). Data from this network collected from 1996 to 2006 (9) and from 2007 to 2014 (10) have been reported separately. Between 1996 and 2006, 14 countries reported 10,081 cases of invasive $H$. influenzae infection, and serotype data were reported for 9,117 $(80.5 \%)$ of the isolates: $44 \%$ were due to $\mathrm{NTHi}, 28 \%$ were $\mathrm{Hib}$, and $7.9 \%$ were from other capsulated serotypes. Some isolates were "non-Hib" but were not fully serotyped, and others were not submitted to the reference laboratory. By 2006, national reference laboratories in 14 European countries with an annual denominator population of 150 million persons routinely serotyped all invasive $H$. influenzae isolates (9).

From 2007 to 2014, 12 European countries reported 10,624 cases of invasive $H$. influenzae infection (10). Serotyping data were reported for $8,781(83 \%)$ isolates. A total of 6,853 (78\%) were NTHi, 828 (9\%) were Hif, 239 (3\%) were Hie, and 811 (9\%) were 
TABLE 2 Implementation of Hib vaccine in countries of the WHO European Region ${ }^{a}$

\begin{tabular}{|c|c|c|c|c|c|c|}
\hline Country & $\begin{array}{l}\text { Yr of } \\
\text { introduction }\end{array}$ & NIP & Formulation in 2019 & Schedule in 2019 & $\begin{array}{l}\text { Coverage of } \\
\text { Hib3 in } \\
2019(\%)\end{array}$ & $\begin{array}{l}\text { Yr in which } \\
\text { coverage } \\
\text { reached } \geq 50 \%\end{array}$ \\
\hline Albania & 2009 & Yes & DTwP/Hib/HepB & $2,4,6 \mathrm{mo}$ & 99 & 2009 \\
\hline Armenia & 2009 & Yes & $\begin{array}{l}\text { DTwP/Hib/HepB } \\
\text { DTaP/Hib/HepB/IPV }\end{array}$ & $\begin{array}{l}6,12,18 \mathrm{wks} \\
18 \mathrm{mo}\end{array}$ & 92 & 2011 \\
\hline Austria & 1994 & Yes & DTaP/Hib/HepB/IPV & $2,4,11 \mathrm{mo}$ & 85 & 1999 \\
\hline Belgium & 1993 & Yes & DTaP/Hib/HepB/IPV & $8,12,16$ wks, $15 \mathrm{mo}$ & 97 & 1999 \\
\hline Bosnia and Herzegovina & 2008 & Yes & DTaP/Hib/IPV & $\begin{array}{l}2,4,10 \text { mo }(3,4,18, \\
24 \text { mo in Republic } \\
\text { of Srpska/Brcko } \\
\text { District) }\end{array}$ & 62 & 2005 \\
\hline Czech Republic & 2001 & Yes & DTaP/Hib/HepB/IPV & $3,5,11 \mathrm{mo}$ & 97 & 2002 \\
\hline Denmark & 1993 & Yes & $\mathrm{DTaP} / \mathrm{Hib} / \mathrm{IPV}$ & $3,5,12 \mathrm{mo}$ & 97 & 1993 \\
\hline Estonia & 2005 & Yes & $\begin{array}{l}\text { DTaP/Hib/HepB/IPV } \\
\text { Hib (for children with } \\
\text { contraindication } \\
\text { for pertussis) }\end{array}$ & $\begin{array}{l}3,4,5,6 \mathrm{mo}, 2 \mathrm{yrs} \\
3,4,6 \mathrm{mo}, 2 \mathrm{yrs}\end{array}$ & 91 & 2006 \\
\hline Finland & 1986 & Yes & $\mathrm{DTaP} / \mathrm{Hib} / \mathrm{IPV}$ & $3,5,12 \mathrm{mo}$ & 91 & 1992 \\
\hline France & 1992 & Yes & DTaP/Hib/HepB/IPV & $2,4,11 \mathrm{mo}$ & 95 & 1998 \\
\hline Georgia & 2010 & Yes & DTaP/Hib/HepB/IPV & $2,3,4 \mathrm{mo}$ & 94 & 2010 \\
\hline Germany & 1990 & Yes & DTaP/Hib/HepB/IPV & $2,3,4,11-14 \mathrm{mo}$ & 92 & 1991 \\
\hline Greece & 2000 & Yes & $\begin{array}{l}\text { Hib (in various } \\
\text { combination } \\
\text { vaccines) }\end{array}$ & $2,4,6,15-18 \mathrm{mo}$ & 99 & 1997 \\
\hline Kazakhstan & 2008 & Yes & $\begin{array}{l}\text { DTaP/Hib/HepB/IPV } \\
\text { DTaP/Hib/IPV }\end{array}$ & $\begin{array}{l}2,4 \mathrm{mo} \\
3,18 \mathrm{mo}\end{array}$ & 97 & 2009 \\
\hline Kyrgyzstan & 2009 & Yes & DTwP/Hib/HepB & $2,3,5 \mathrm{mo}$ & 94 & 2010 \\
\hline Latvia & 1994 & Yes & $\begin{array}{l}\text { DTaP/Hib/HepB/IPV } \\
\text { DTaP/Hib/IPV } \\
\quad \text { (infants who } \\
\text { receive } \\
\text { monovalent HepB } \\
\text { due to HepB risk } \\
\text { from mother) }\end{array}$ & $\begin{array}{l}2,4,6,12-15 \mathrm{mo} \\
2,4,6 \mathrm{mo}\end{array}$ & 99 & 1999 \\
\hline Lithuania & 2004 & Yes & $\mathrm{DTaP} / \mathrm{Hib} / \mathrm{IPV}$ & $2,4,6,18 \mathrm{mo}$ & 92 & 2005 \\
\hline Luxembourg & 1994 & Yes & $\begin{array}{l}\text { DTaP/Hib/HepB/IPV } \\
\text { DTaP/Hib/IPV }\end{array}$ & $\begin{array}{l}2,3,13 \mathrm{mo} \\
4 \mathrm{mo}\end{array}$ & 99 & 1997 \\
\hline Malta & 1996 & Yes & DTaP/Hib/HepB/IPV & $6-8 \mathrm{wks}, 3,4,18 \mathrm{mo}$ & 97 & 1997 \\
\hline Monaco & 1992 & Yes & $\mathrm{Hib}$ & $2,4,11 \mathrm{mo}$ & 99 & 1999 \\
\hline Montenegro & 2006 & Yes & $\begin{array}{l}\text { DTaP/Hib/IPV } \\
\text { Hib }\end{array}$ & $\begin{array}{l}9,17,23 \text { wks } \\
18 \mathrm{mo}\end{array}$ & 86 & 2006 \\
\hline Netherlands & 1993 & Yes & DTaP/Hib/HepB/IPV & $2,3,4-11 \mathrm{mo}$ & 94 & 1997 \\
\hline North Macedonia & 2008 & Yes & $\begin{array}{l}\text { DTaP/Hib/HepB/IPV } \\
\text { DTaP/Hib/IPV }\end{array}$ & $\begin{array}{l}2,6 \mathrm{mo} \\
3,5,18 \mathrm{mo}\end{array}$ & 92 & 2009 \\
\hline Norway & 1992 & Yes & DTaP/Hib/HepB/IPV & $3,5,12 \mathrm{mo}$ & 97 & 1996 \\
\hline
\end{tabular}


TABLE 2 (Continued)

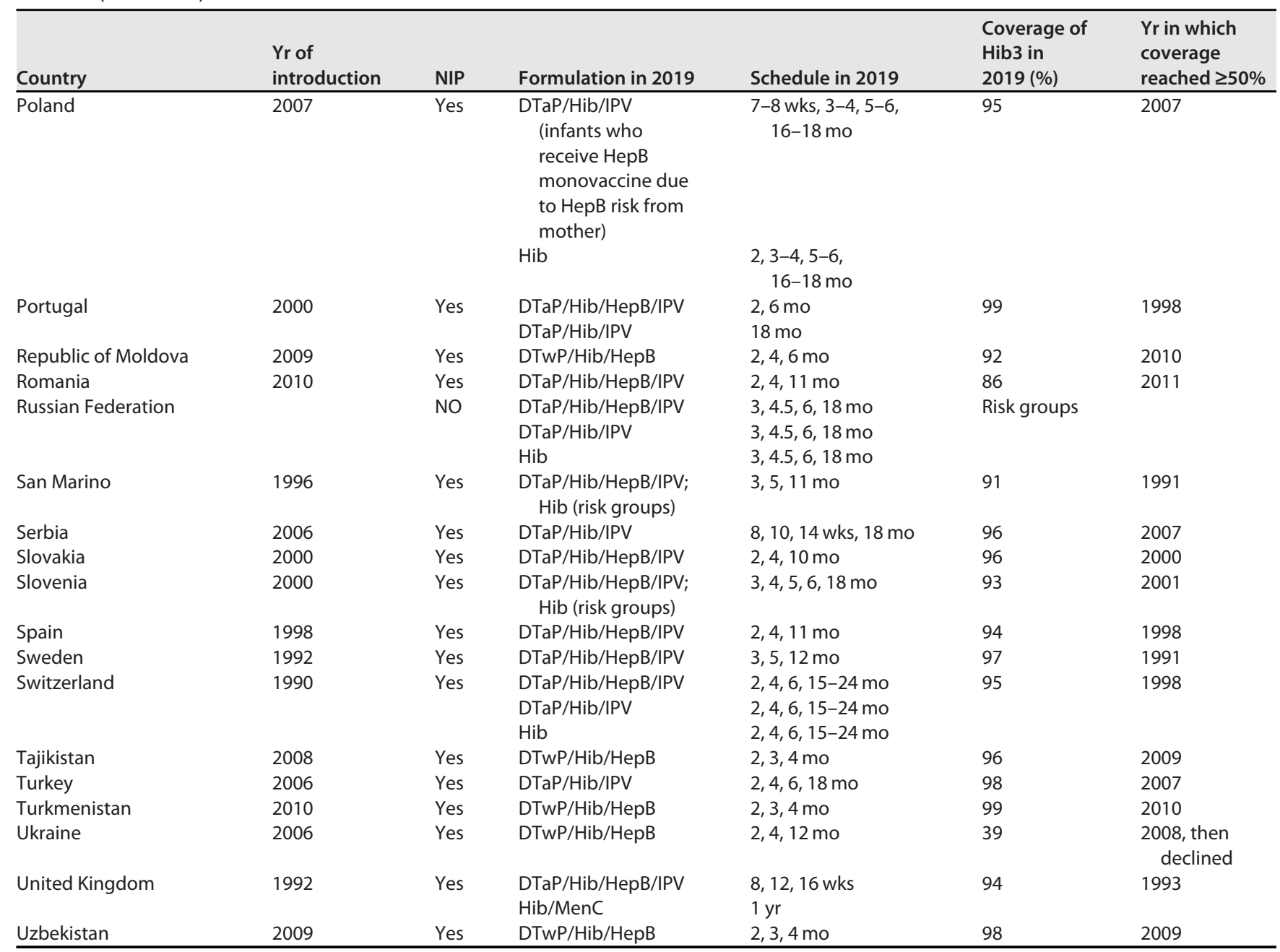

${ }^{a}$ Annual birth cohort, 11.1 million. Children aged $<5$ years, 56.4 million. Seventy-nine percent of target population was immunized with three doses of Hib (Hib3) in 2019 (based on WHO-UNICEF estimates) (100). NIP, national immunization program. Abbreviations of vaccine antigens: D, diphtheria; T, tetanus; aP, acellular pertussis; wP, whole-cell pertussis; Hib, Haemophilus influenzae type b; HepB, hepatitis B virus surface antigen; IPV, inactivated poliovirus; MenC, meningococcal serogroup C.

Hib. By 2014, the notification rates for invasive Hib in children aged $<1$ year and 1 to 4 years had declined to $0.65 / 100,000$ and $0.18 / 100,000$, respectively (10). The notification rates for all invasive $H$. influenzae infections gradually increased from $0.27 / 100,000$ in 1999 to $0.56 / 100,000$ in 2014 , driven by increases in the incidence of NTHi and to a lesser extent by non-b capsulated serotypes, following the introduction of Hib vaccine. The incidence of invasive $H$. influenzae infections in adults aged $\geq 65$ years increased from $0.53 / 100,000$ in 1999 to $1.55 / 100,000$ in 2014. Invasive NTHi infections occurred more frequently in older patients than Hib infections (median age, 58 years versus 5 years $[P<0.0001])$ and were associated with a higher CFR (12\% versus $4 \%$ $[P<0.001])$. Invasive NTHi infections also occur in neonates, where the increased CFR of NTHi compared to that of Hib was especially marked $(17 \%$ versus $3 \%[P<0.001])$ (104). Non-b serotypes were almost exclusively Hif (72\%) and Hie (21\%) with an overall CFR of $9 \%$.

The United Kingdom. In 1992, the Hib protein conjugate vaccine was introduced in the United Kingdom, with a 2-, 3-, and 4-month schedule and no booster in the second year of life (105). Simultaneously, a catch-up program offered Hib vaccine to all children aged $<4$ years. There was a rapid and sustained decline in invasive Hib disease in children < $<$ years of age from $23.8 / 100,000$ in 1991 to 1992 to $1.8 / 100,000$ in 1993 to 1994 . The decline in the vaccinated age group was soon followed by a decline in other age 


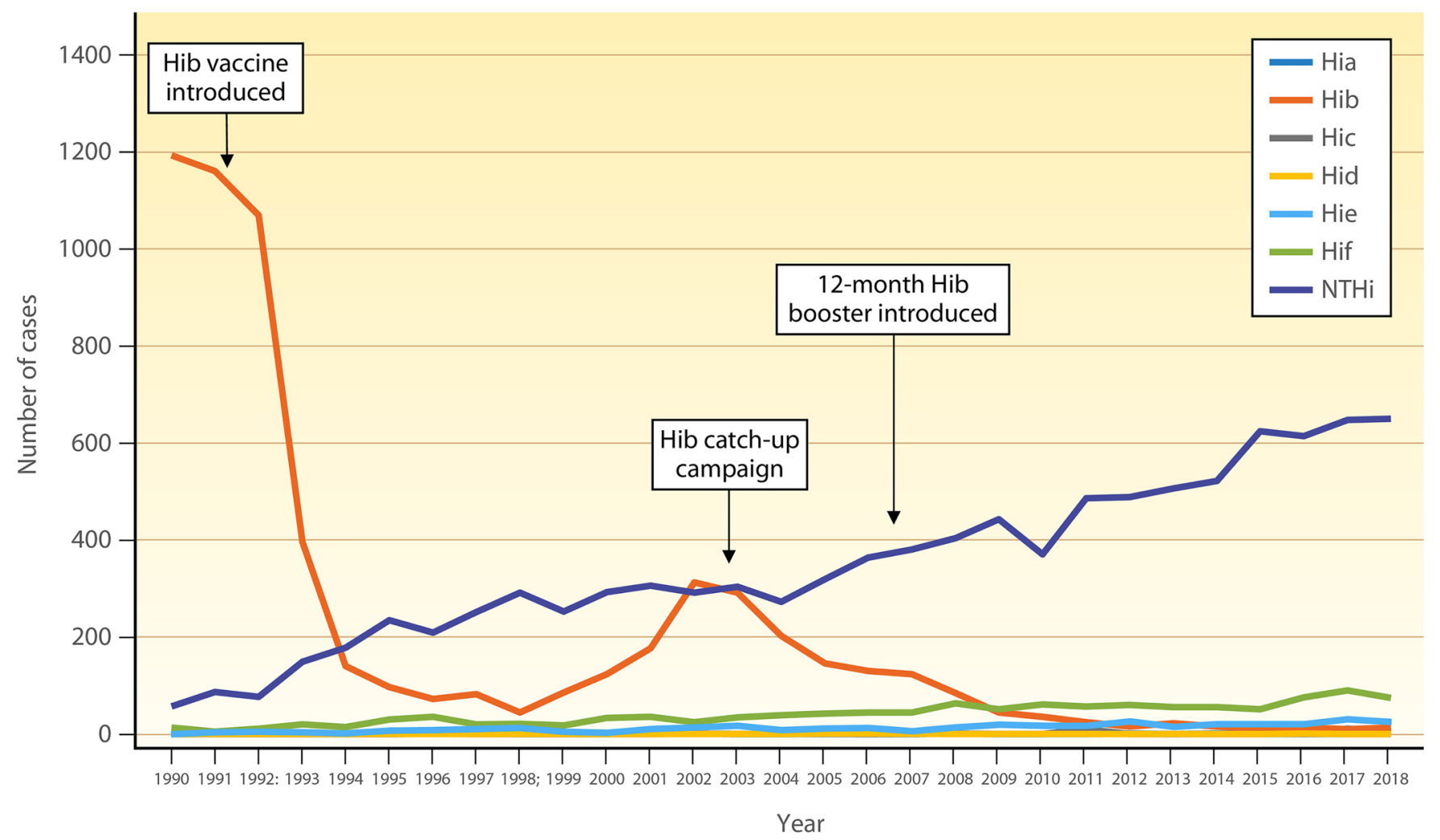

FIG 4 Number of cases of invasive Haemophilus influenzae infections in England, 1990 to 2018, by serotype (unpublished data from Public Health England, with permission from Shamez Ladhani).

groups through herd protection (106). This continued until 1998, when the estimated incidence of Hib disease in children aged $<5$ years was $0.63 / 100,000$ (106). However, after 1999, cases of invasive Hib infection in children increased (107), with 134 cases in children aged <5 years in 2002 compared with 22 cases in 1998 (Fig. 4) (0.63/100,000 in 1998 to $4.60 / 100,000$ in 2002) (105).

There were several reasons for this resurgence (105). First, immunization in infancy resulted in a lower than expected vaccine effectiveness (VE), which was also lower than the VE in children who had been given one dose of Hib vaccine at an older age in the catch-up program. The VE in those immunized in infancy declined over time, reaching zero after 1 year. This became apparent only after the direct and indirect protection provided by the catch-up program had waned. By 1998, all children aged $<5$ years had only received Hib vaccine in infancy. Next, a shortage of the combination vaccine used in the United Kingdom at that time, which had a whole-cell pertussis component (DTwP/Hib) resulted in utilization of an alternative combination vaccine containing an acellular component (DTaP/Hib). This vaccine was given to approximately $50 \%$ of infants (108). The Hib component of some DTaP/Hib vaccines can be less immunogenic, particularly when administered in an early, accelerated schedule, as was the case in the United Kingdom (109). A third possible reason was the introduction of meningococcal group C protein conjugate vaccine (MenC) in 1999, which was coadministered with the Hib vaccine. The MenC vaccine used was mainly CRM based, and there is evidence that the MenC/CRM vaccine given with $\mathrm{DTaP} / \mathrm{Hib}$ also reduces the immunogenicity of the Hib component (110).

Control of the resurgence was achieved by providing a single dose of Hib vaccine to all children aged 6 months to 4 years in 2003. In 2004, a booster dose at 12 months of Hib vaccine was added to the NIP. This resulted in a prompt decline in incidence of Hib infections $(4.60 / 100,000$ in 2002 to $1.1 / 100,000$ in children aged $<5$ years in 2004) (111). In 2007, there was a second campaign administering a preschool booster to 
children who were too old for the 12-month booster but too young for the campaign in 2003. These actions led to a further decline in Hib disease, with only six cases reported in the United Kingdom for the period 2007 to 2010 (105). The United Kingdom experience indicated that protective levels of serum anti-PRP antibodies at the time of nasopharyngeal acquisition of Hib are necessary to prevent infection and that immunologic memory alone will not prevent colonization. By giving a booster dose of vaccine in the second year of life, serum anti-PRP antibody titers are maintained above the protective threshold in children $<5$ years of age.

In contrast, between 2001 and 2010, there were annual increases in England and Wales of $11.0 \%$ and $7.4 \%$ in Hif and Hie infections, respectively. Hif incidence was 0.09 (95\% Cl, 0.07 to 1.10$) / 100,000$ persons, and Hie incidence was 0.03 ( $95 \% \mathrm{Cl}, 0.02$ to $0.04) / 100,000$ persons in 2009 to 2010, with the majority of cases occurring in infants and older adults (59). There were 1,275 invasive $H$. influenzae infections reported in 2009 to 2010, comprising 715 (56.1\%) NTHi, 99 (7.8\%) Hif, 69 (5.4\%) Hib, and 33 (2.6\%) Hie cases. In the remaining 359 (28.2\%) cases, the serotype was unknown.

Of the 132 cases of Hif and Hie infection, 25 (18.9\%) were in children aged $<15$ years (59). Ten of these 25 cases ( $7 \mathrm{Hif}, 3 \mathrm{Hie}$ ) were in previously healthy infants aged $<1$ year, nine of whom had meningitis and the one remaining infant had Hif septic arthritis. Of the three infant cases of Hie meningitis, one died and the two survivors had long-term sequelae. All seven infants with Hif infection survived without sequelae. At the other end of the age spectrum, approximately half of the cases (52 Hif, $14 \mathrm{Hie}$ ) occurred in adults of $\geq 65$ years of age. In contrast to the infants, 50/52 (96.2\%) adults aged $\geq 65$ years with Hif infections had underlying comorbidities (including 11 with cancer), and their most frequent presentation was pneumonia (35/50 [70\%]), followed by sepsis (9/50 [18\%]). The CFR in these patients was 54\% (27/50). Similarly, 13/14 (93.9\%) patients aged $\geq 65$ years with Hie infections had comorbidities, and again pneumonia (10/14 [71.4\%]) was the most common presentation. There were no cases of Hie or Hif meningitis in adults $\geq 65$ years of age. Eight of the 14 Hie patients aged $\geq 65$ years $(57.1 \%)$ died. Hie and Hif invasive infections are comparable to invasive NTHi infections by generally presenting as pneumonia in older adults with underlying comorbidities. However, Hie causes more cases of meningitis and has a higher CFR than Hif.

From 2012 to 2016, a low incidence of invasive Hib disease in all age groups was reported in England (0.05/100,000 population), with just 67 cases of Hib reported (112). In contrast, during this period, there were 2,451 cases of NTHi (85.0\%), 274 (9.5\%) of Hif, and 85 (2.9\%) of Hie invasive disease. There were only four cases of Hia and just two cases of $\mathrm{H}$. influenzae serotype $\mathrm{d}(\mathrm{Hid})$. Indeed, the incidence of NTHi increased 10-fold, from $0.12 / 100,000$ in 2012 to $1.2 / 100,000$ in 2016. Hia caused only five invasive infections in England from 2008 to 2015 but caused 10 infections in the 12 months between December 2016 and December 2017 (113). More recent data (2017 to 2018) from England (114) reported that $76.7 \%$ of all invasive $H$. influenzae infections were due to $\mathrm{NTHi}$, and Hif was the most prevalent capsulated serotype (8.3\%). Other capsulated serotypes caused $2.7 \%(\mathrm{Hie}), 1.2 \%(\mathrm{Hib})$, and $0.8 \%(\mathrm{Hia})$ of the invasive $H$. influenzae infections.

Rest of Western Europe. In a detailed analysis of 4,044 invasive $H$. influenzae infections in Germany, in 2001 to 2016, NTHi caused 1,545/1,902 (81\%) infections (115). Among the capsulated strains, $69 \%$ were Hif and $17 \%$ were Hib. Moreover, NTHi and Hif infections in those aged $<5$ years and $\geq 60$ years, respectively, and ampicillin resistance in NTHi increased significantly after the introduction of Hib vaccine. Data for 2017 to 2018 (116) reported that $84.5 \%$ of invasive infections were due to NTHi. Hif was the most prevalent capsulated serotype (9.8\%), followed by Hib and Hie ( $2.4 \%$ each) and Hia $(0.5 \%)$.

From 2016 to 2018, there were 231 cases of invasive $H$. influenzae infection in Finland (117), with an annual incidence of 1.3 to $1.6 / 100,000$ population. Most of the cases were caused by NTHi (79.2\%), followed by Hif (12.6\%), Hib (3.5\%), and Hie (3.0\%). 
All Hie infections, $86 \%$ of Hif infections, and $63 \%$ of Hib infections occurred in adults aged 27 to 79 years of age.

In Italy, the annual incidence of invasive $H$. influenzae disease in 2017 to 2018 was $0.28 / 100,000$ population, with an incidence of $0.77 / 100,000$ in children aged $<5$ years (118). Most of the cases were due to NTHi (76.1\%), with $11.5 \%$ and $4.6 \%$ caused by Hib and Hif, respectively.

In a Swedish Arctic region, between 1986 to 1991 and 2010 to 2015, invasive $H$. influenzae infections declined by $89.1 \%(P<0.01)$ from $41 / 100,000$ to $1.1 / 100,000$, respectively, including $H$. influenzae meningitis by $95.3 \%(P<0.01 ; 28$ to $1.1 / 100,000)$ and "all-cause" bacterial meningitis by $82.3 \%(P<0.01 ; 37$ to $3.4 / 100,00)$ in children aged 0 to 4 years following the introduction in 1992 of infant Hib vaccination (119).

In Portugal, 260 invasive $H$. influenzae isolates received from 2011 to 2018 were characterized (120): NTHi, 206 (79.2\%); Hib, 35 (13.5\%); Hif, 8 (3.1\%); Hia, 7 (2.7\%); and Hie, 4 (1.5\%). The NTHi strains were isolated mainly from adults (161/260 [78.2\%]), especially among those $\geq 65$ years of age (103/161 [64.0\%]), whereas $56.3 \%$ of $H$. influenzae infections in children were due to NTHi. Most of the capsulated strains causing infection were from preschool-aged children (35/54 [64.8\%]): $25 \mathrm{Hib}, 7 \mathrm{Hia}, 2 \mathrm{Hif}$, and 1 Hie. Six cases of Hib infection were in infants too young to have received the Hib vaccine, 15 were aged 10 months to 5 years, and 4 were older ( 6 to 16 years). All seven cases of Hia infection occurred in children aged $<2$ years and were isolated from 2016 onwards.

Persistence of Hib infections and Hib vaccine failures. Bajanca-Lavado et al. (121) reported on 29 cases of Hib infection identified in Portugal between 2010 and 2018. Half of the cases occurred in 2017 to 2018, and 72\% were in preschool-aged children. Eighteen were Hib vaccine failures: three were infants, seven were aged between 13 and 47 months, and eight were $\geq 4$ years of age. Only one child had an underlying comorbidity.

In France, a country with high Hib vaccine coverage (95\% to $98 \%$ over the last decade) (122), the number of invasive Hib cases almost doubled in 2018 from $<10$ per year in previous years (123). Most cases were in children aged $<5$ years, and there were at least 10 vaccine failures. After a change in the Hib immunization program from $3+1$ to $2+1$ doses in 2013, mean anti-PRP IgG titers were lower and peaked at 6 to 11 months rather than at 2 years of age, as seen with a $3+1$ schedule. Antibody titers also declined to $<1 \mu \mathrm{g} / \mathrm{ml}$ at a much younger age (4 to 5 years versus 20 years).

Eastern Europe and Central Asia. Data on invasive Hib disease incidence in Eastern Europe and Central Asia are limited. The data that exist suggest that the prevaccine incidence was low. For example, Hib meningitis incidence in children aged $<5$ years in Bulgaria and Moscow was 6.7/100,000 (124) and 5.7/100,000, respectively (125). One factor contributing to low incidence figures is the high proportion of culture-negative cases of purulent meningitis, possibly reflecting prior antimicrobial therapy or limited laboratory capacity. One approach, advocated by the WHO, is to allocate culture-negative cases to bacterial pathogens in the same proportions as microbiologically confirmed cases (52). Using this approach, Griffiths and colleagues (126) adjusted the incidence of $\mathrm{Hib}$ meningitis prior to introducing $\mathrm{Hib}$ conjugate vaccine in Belarus and Uzbekistan upwards to $10.8 / 100,000$ and 18.7/100,000, respectively. In 2006, Ukraine was the first country in Eastern Europe to incorporate Hib protein conjugate vaccine into its infant NIP. Between 2007 and 2009, hospitalized children <2 years of age in Ukraine with radiographically confirmed pneumonia were significantly less likely to have been immunized with Hib vaccine than age-matched controls $151 \%$ of cases versus $67 \%$ of controls $[P<0.001])$ (127). A retrospective study in a tertiary hospital in Budapest, Hungary, undertaken between 2004 and 2017 identified 34 adult invasive $H$. influenzae infections (128). Most cases presented as pneumonia (62\%) due to NTHi (79\%), followed by Hif (11\%), Hia (5\%), and Hib (5\%). One-third of patients were aged $\geq 65$ years with underlying comorbidities, including cardiovascular disease, diabetes mellitus, and malignancy. 
TABLE 3 Implementation of Hib vaccine in countries of the WHO Eastern Mediterranean Region ${ }^{a}$

\begin{tabular}{|c|c|c|c|c|c|c|}
\hline Country & $\begin{array}{l}\text { Yr of } \\
\text { introduction }\end{array}$ & NIP & Formulation in 2019 & Schedule in 2019 & $\begin{array}{l}\text { Coverage of } \\
\text { Hib3 in } 2019(\%)\end{array}$ & $\begin{array}{l}\text { Yr in which } \\
\text { coverage } \\
\text { reached } \geq 50 \%\end{array}$ \\
\hline Afghanistan & 2009 & Yes & DTwP/Hib/HepB & $6,10,14$ wks & 66 & 2009 \\
\hline Bahrain & 1998 & Yes & $\begin{array}{l}\text { DTaP/Hib/HepB/IPV } \\
\text { DTwP/Hib/HepB } \\
\text { Hib (for SCD, asplenia, } \\
\text { post-BMT, and post- } \\
\text { cancer chemotherapy) }\end{array}$ & $\begin{array}{l}2,4 \mathrm{mo} \\
6,18 \mathrm{mo} \\
<5 \mathrm{yrs}\end{array}$ & 99 & 1998 \\
\hline Djibouti & 2007 & Yes & DTwP/Hib/HepB & $6,10,14 \mathrm{wks}$ & 85 & 2008 \\
\hline Egypt & 2014 & Yes & $\begin{array}{l}\text { DTwP/Hib/HepB } \\
\text { Hib }\end{array}$ & $\begin{array}{l}\text { 2, 4, } 6 \text { mo } \\
\text { 2, 4, } 6 \text { mo (previous } \\
\text { adverse reaction } \\
\text { after pertussis } \\
\text { vaccination) }\end{array}$ & 95 & 2014 \\
\hline Islamic Republic of Iran & 2014 & Yes & $\begin{array}{l}\text { DTwP/Hib/HepB } \\
\text { Hib }\end{array}$ & $\begin{array}{l}\text { 2, 4, } 6 \text { mo } \\
\text { 2, 4, } 6 \text { mo (previous } \\
\text { adverse reaction } \\
\text { after pertussis } \\
\text { vaccination) }\end{array}$ & 99 & 2015 \\
\hline Iraq & 2012 & Yes & DTaP/Hib/HepB & $2,4,6 \mathrm{mo}$ & 84 & 2013 \\
\hline Jordan & 2001 & Yes & $\begin{array}{l}\text { DTaP/Hib/HepB/IPV } \\
\text { Hib }\end{array}$ & $\begin{array}{l}3,4,5 \mathrm{mo} \\
3,4,5 \mathrm{mo}\end{array}$ & 89 & 2001 \\
\hline Kuwait & 1998 & Yes & DTwP/Hib/HepB & $2,4,6,18 \mathrm{mo}$ & 91 & 1998 \\
\hline Lebanon & 2003 & Yes & DTwP/Hib/HepB & $2,4,6,18 \mathrm{mo}$ & 85 & 2003 \\
\hline Libya & 2007 & Yes & $\begin{array}{l}\text { DTaP/Hib/HepB/IPV } \\
\text { DTaP/Hib/IPV }\end{array}$ & $\begin{array}{l}2,4,6 \mathrm{mo} \\
18 \mathrm{mo}\end{array}$ & 73 & 2007 \\
\hline Morocco & 2007 & Yes & DTwP/Hib/HepB & $2,3,4 \mathrm{mo}$ & 99 & 2007 \\
\hline Oman & 2001 & Yes & $\begin{array}{l}\text { DTaP/Hib/HepB/IPV } \\
\text { DTwP/Hib/HepB; Hib } \\
\text { (immunocompromised) }\end{array}$ & $\begin{array}{l}2,4 \mathrm{mo} \\
6 \mathrm{mo}\end{array}$ & 99 & 2002 \\
\hline Pakistan & 2009 & Yes & DTwP/Hib/HepB & $6,10,14$ wks & 75 & 2009 \\
\hline Qatar & 1996 & Yes & $\begin{array}{l}\text { DTaP/Hib/HepB/IPV } \\
\text { DTwP/Hib/HepB }\end{array}$ & $\begin{array}{l}2,4 \mathrm{mo} \\
6 \mathrm{mo}\end{array}$ & 98 & 1997 \\
\hline Saudi Arabia & 2002 & Yes & DTaP/Hib/HepB/IPV & $2,4,6 \mathrm{mo}$ & 96 & 2002 \\
\hline Somalia & 2013 & Yes & DTwP/Hib/HepB & $6,10,14$ wks & 42 & \\
\hline Sudan & 2008 & Yes & DTwP/Hib/HepB & $6,10,14 \mathrm{wks}$ & 93 & 2008 \\
\hline Syrian Arab Republic & 2001 & Yes & DTwP/Hib/HepB & $8,16,24 \mathrm{wks}, 18 \mathrm{mo}$ & 54 & $\begin{array}{l}2001 \\
\quad \text { (fell to } \\
<50 \% \text { after } \\
2012 \text { ) }\end{array}$ \\
\hline Tunisia & 2011 & Yes & DTwP/Hib/HepB & $2,3,6 \mathrm{mo}$ & 92 & 2012 \\
\hline United Arab Emirates & 1999 & Yes & $\begin{array}{l}\text { DTaP/Hib/HepB/IPV } \\
\text { DTwP/Hib/HepB } \\
\text { DTaP/Hib/IPV; Hib } \\
\text { (high-risk groups) }\end{array}$ & $\begin{array}{l}2,4 \mathrm{mo} \\
6 \mathrm{mo} \\
18 \mathrm{mo}\end{array}$ & 99 & 1999 \\
\hline Yemen & 2005 & Yes & DTwP/Hib/HepB & $6,10,14$ wks & 73 & 2006 \\
\hline
\end{tabular}

${ }^{a}$ Annual birth cohort, 17.3 million. Children aged $<5$ years, 85.3 million. Eighty-two percent of target population was immunized with three doses of Hib (Hib3) in 2019 (based on WHO-UNICEF estimates) (129). Abbreviations of vaccine antigens: D, diphtheria; T, tetanus; aP, acellular pertussis; wP, whole-cell pertussis; Hib, Haemophilus influenzae type b; HepB, hepatitis B virus surface antigen; IPV, inactivated poliovirus. NIP, national immunization program; SCD, sickle cell disease; BMT, bone marrow transplant.

\section{Eastern Mediterranean Region}

All countries in the WHO Eastern Mediterranean Region have introduced Hib vaccine. In 2019, the average coverage of three doses of Hib vaccine was $82 \%$ (129). Data on individual countries are shown in Table 3. Reports on invasive Hib disease before Hib vaccination was initiated are limited to a few countries (130). Prevaccine data from Egypt showed that Hib was the most common cause of meningitis (39\%) in children $<6$ years of age with a CFR of $27 \%$ (131). In Jordan, $32 \%$ of cases of bacterial meningitis in children aged 2 months to 12 years were due to $H$. influenzae, with $95 \%$ of Hib meningitis occurring in children $<2$ years of age (132). In Qatar, a prevaccine study 
recorded the incidence of bacterial meningitis as $2.24 / 100,000$, with the highest rate observed in infants aged $<1$ year and where Hib accounted for $24 \%$ of cases (133). In Pakistan, a prospective study of bacterial meningitis in children conducted in 2004, before Hib vaccines were introduced (134), estimated incidences of Hib meningitis of $7.6 / 100,000$ in children $<5$ years of age and 38.1/100,000 in children aged $<1$ year. In Saudi Arabia, Hib meningitis incidence was $16.9 / 100,000$ in those aged $<5$ years but with marked regional variation (135). Pre- and postvaccine introduction incidence data are available in this region only from Oman. Before Hib vaccines were introduced in Oman, their highest incidence of Hib meningitis was in infants aged $<1$ year (23/ 100,000 in 1999). After Hib immunization was introduced in 2001, the incidence declined to $4 / 100,000$ by 2003 (130). All countries in this region have now introduced Hib vaccines, with Bahrain being the first country, in 1998, and Egypt and Iran the last, in 2014.

Currently, there are few data on the emergence of NTHi or non-b serotypes of $H$. influenzae causing invasive disease in this region.

\section{African Region}

Hib conjugate vaccines have been introduced into the NIPs of all 47 member states in the WHO African Region, and the average coverage of three doses of Hib vaccine was $73 \%$, with wide variation between countries (136). Data on individual countries are shown in Table 4. The Gambia introduced the Hib protein conjugate vaccine in 1997, being the first African country to do so. Several other African countries followed suit, although 15 years elapsed before all countries in the region had introduced the vaccine. An important study in The Gambia established Hib as a significant cause of pediatric pneumonia, something that had not been appreciated previously (28). This trial showed vaccine efficacy of $21 \%$ against radiographic pneumonia, $36 \%$ efficacy against hypoxic pneumonia, and 95\% efficacy against invasive Hib disease. Before The Gambia introduced routine Hib vaccination, Hib meningitis incidence was 297/100,000 in infants $<1$ year of age and 60/100,000 in children aged $<5$ years (137).

The GAVI Alliance and the Hib Initiative have been major players in providing subsidized vaccines for low-income countries in Africa. All studies from African countries indicate that with the sole exception of South Africa, Hib vaccination has led to a $>90 \%$ decline in Hib meningitis or invasive disease. However, in South Africa, 5 years after vaccine introduction, Hib disease rates were only reduced approximately $65 \%$ in the <1-year age group (11), and a decade after Hib vaccination was implemented, cases were reported to have increased from 0.7 to $1.3 / 100,000$ in children aged $<5$ years (138). To some extent, the increase was due to low vaccine coverage and waning immunity of a 3-dose primary schedule without a booster, with Hib vaccine failure occurring in both HIV-positive and -negative children. South Africa introduced enhanced surveillance of invasive $H$. influenzae infections in 1999 following the introduction of Hib vaccination (138). During the first 10 years of Hib immunization, there was no significant increase in other capsulated serotypes or NTHi (138). From 2003 to $2009,135 / 263$ (51\%) cases of invasive Hib disease occurred in fully immunized children and $55 \%$ of the Hib vaccine failures were in children aged $\geq 18$ months (138). South Africa introduced an 18-month booster dose of Hib vaccine in 2009 in a pentavalent vaccine (DTaP/Hib/IPV). Invasive Hib disease in infants aged $<1$ year then declined significantly from 5.2 cases/100,000 in 2010 to 1.6 cases/100,000 in $2017(P<0.001)$ and remained $<0.2 / 100,000$ in children aged 1 to 4 years from 2013 to 2018 (139).

In 2018, the ongoing surveillance program in South Africa (GERMS) identified 327 cases of invasive $H$. influenzae infection, of which 201 provided isolates for typing (139). Seventeen percent (34/201) were Hib, and 64\% (129/201) were NTHi. There were 25 isolates $(12 \%)$ of other capsulated serotypes. Hib isolates were more likely than NTHi isolates to be from cases of meningitis (8/34 [24\%] versus 15/129 [12\%], $P=0.01$ ). The highest incidence of invasive $H$. influenzae infection (all types) was in children aged $<5$ years, with a second peak in adults aged 25 to 44 years. NTHi incidence was 
TABLE 4 Implementation of Hib vaccine in countries of the WHO African Region ${ }^{a}$

\begin{tabular}{|c|c|c|c|c|c|c|}
\hline Country & Yr of Introduction & NIP & Formulation in 2019 & Schedule in 2019 & $\begin{array}{l}\text { Coverage of } \\
\text { Hib3 in } 2019(\%)\end{array}$ & $\begin{array}{l}\text { Yr in which } \\
\text { coverage reached } \\
\geq 50 \%\end{array}$ \\
\hline Algeria & 2008 & Yes & DTaP/HepB/Hib/IPV & $2,4,12 \mathrm{mo}$ & 91 & 2008 \\
\hline Benin & 2005 & Yes & DTwP/HepB/Hib & $6,10,14$ wks & 76 & 2006 \\
\hline Botswana & 2011 & Yes & DTwP/HepB/Hib & $2,3,4 \mathrm{mo}$ & 95 & 2011 \\
\hline Burkina Faso & 2006 & Yes & DTwP/HepB/Hib & $8,12,16$ wks & 91 & 2006 \\
\hline Cabo Verde & 2010 & Yes & DTwP/HepB/Hib & $2,4,6,18 \mathrm{mo}$ & 97 & 2011 \\
\hline $\begin{array}{l}\text { The Central African } \\
\text { Republic }\end{array}$ & 2008 & Yes & DTwP/HepB/Hib & 6,1014 wks & 47 & \\
\hline Chad & 2008 & Yes & DTwP/HepB/Hib & $6,10,14$ wks & 50 & \\
\hline Comoros & 2009 & Yes & DTwP/HepB/Hib & $6,10,14$ wks & 91 & 2009 \\
\hline The Congo & 2009 & Yes & DTwP/HepB/Hib & $6,10,14$ wks & 79 & 2009 \\
\hline Equatorial Guinea & 2013 & Yes & DTwP/HepB/Hib & $6,10,14$ wks & 53 & 2016 \\
\hline Eritrea & 2008 & Yes & DTwP/HepB/Hib & $6,10,14$ wks & 95 & 2008 \\
\hline Ethiopia & 2007 & Yes & DTwP/HepB/Hib & $6,10,14$ wks & 68 & 2008 \\
\hline Gabon & 2010 & Yes & DTwP/HepB/Hib & $6,10,14$ wks & 70 & 2010 \\
\hline The Gambia & 1997 & Yes & DTwP/HepB/Hib & $2,3,4 \mathrm{mo}$ & 88 & 1998 \\
\hline Ghana & 2002 & Yes & DTwP/HepB/Hib & $6,10,14$ wks & 97 & 2002 \\
\hline Guinea & 2008 & Yes & DTwP/HepB/Hib & $6,10,14$ wks & 45 & $2009(<50 \%$ in 2014$)$ \\
\hline Guinea-Bissau & 2008 & Yes & DTwP/HepB/Hib & $6,10,14$ wks & 84 & 2009 \\
\hline Kenya & 2001 & Yes & DTwP/HepB/Hib & $6,10,14$ wks & 92 & 2002 \\
\hline Lesotho & 2008 & Yes & DTwP/HepB/Hib & $6,10,14$ wks & 87 & 2009 \\
\hline Liberia & 2008 & Yes & DTwP/HepB/Hib & $6,10,14$ wks & 74 & 2008 \\
\hline Madagascar & 2008 & Yes & DTwP/HepB/Hib & $6,10,14$ wks & 79 & 2008 \\
\hline $\begin{array}{l}\text { Sao Tome and } \\
\text { Principe }\end{array}$ & 2009 & Yes & DTwP/HepB/Hib & $6,10,14$ wks & 95 & 2010 \\
\hline Senegal & 2005 & Yes & DTwP/HepB/Hib & $6,10,14$ wks & 93 & 2006 \\
\hline Seychelles & 2010 & Yes & DTwP/HepB/Hib & $3,4,5 \mathrm{mo}$ & 99 & 2010 \\
\hline Sierra Leone & 2007 & Yes & DTwP/HepB/Hib & $6,10,14$ wks & 95 & 2007 \\
\hline South Africa & 1999 & Yes & DTaP/HepB/Hib/IPV & $6,10,14$ wks, $18 \mathrm{mo}$ & 77 & 2000 \\
\hline South Sudan & 2014 & Yes & DTwP/HepB/Hib & $6,10,14$ wks & 49 & \\
\hline Eswatini (Swaziland) & 2009 & Yes & DTwP/HepB/Hib & $6,10,14$ wks & 90 & 2009 \\
\hline Togo & 2008 & Yes & DTwP/HepB/Hib & $6,10,14$ wks & 84 & 2009 \\
\hline Uganda & 2002 & Yes & DTwP/HepB/Hib & $6,10,14$ wks & 93 & 2004 \\
\hline $\begin{array}{l}\text { The United Republic } \\
\text { of Tanzania }\end{array}$ & 2009 & Yes & DTwP/HepB/Hib & $6,10,14 \mathrm{wks}$ & 89 & 2009 \\
\hline Zambia & 2004 & Yes & DTwP/HepB/Hib & $6,10,14$ wks & 88 & 2004 \\
\hline Zimbabwe & 2008 & Yes & DTwP/HepB/Hib & $6,10,14$ wks & 90 & 2008 \\
\hline
\end{tabular}

${ }^{a}$ Annual birth cohort, 35.7 million. Children aged $<5$ years, 170.2 million. Seventy-three percent of target population was immunized with three doses of Hib (Hib3) in 2019 (based on WHO-UNICEF estimates) (136). NIP, national immunization program. Abbreviations of vaccine antigens: D, diphtheria; T, tetanus; aP, acellular pertussis; wP, whole-cell pertussis; Hib, Haemophilus influenzae type b; HepB, hepatitis B virus surface antigen; IPV, inactivated poliovirus.

highest in infants, with a second peak in adults aged $>65$ years $(2.9 / 100,000$ and $0.3 /$ 100,000, respectively) (Fig. 5).

In contrast to South Africa, long-term surveillance in Kenya has demonstrated the effectiveness of a 3-dose primary schedule of Hib vaccine and no booster dose in the 


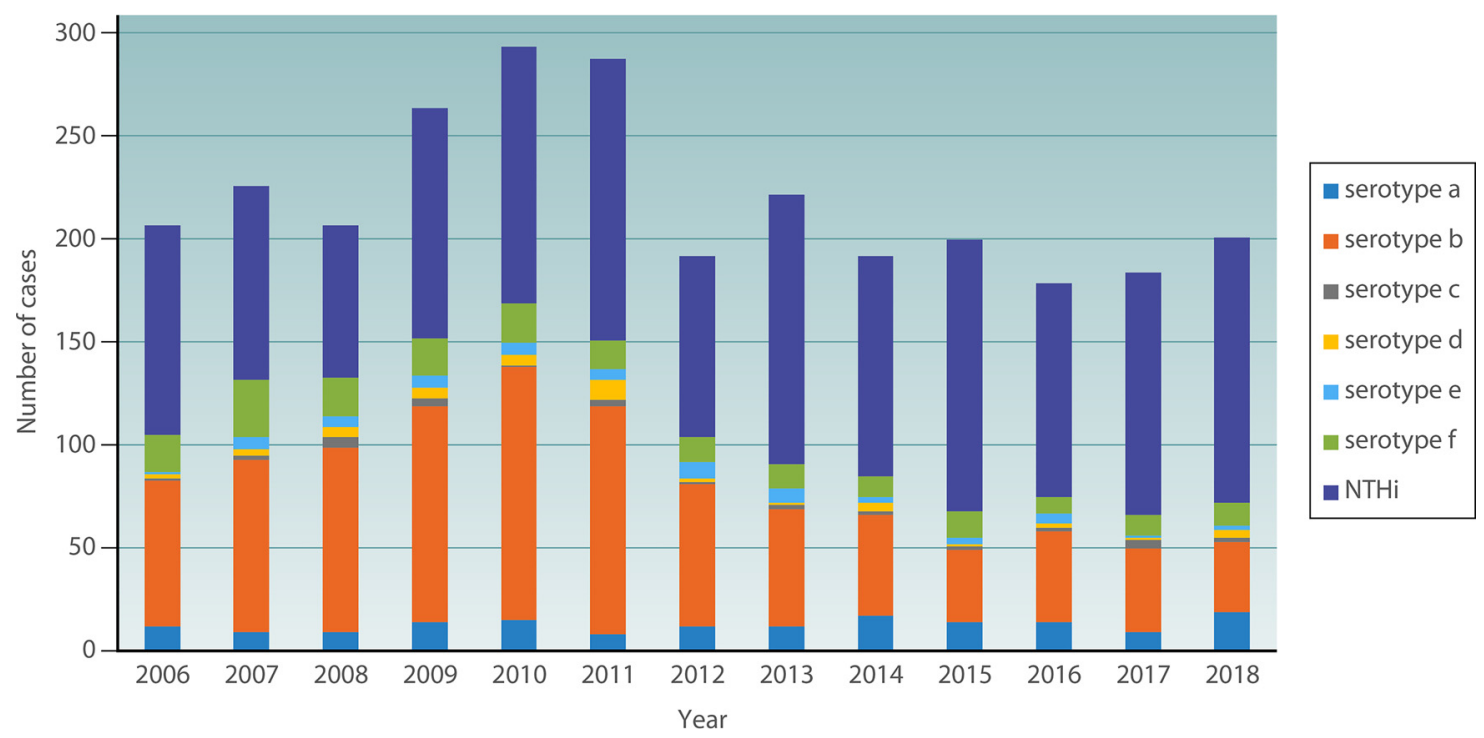

FIG 5 Number of cases of invasive Haemophilus influenzae infection, by serotype, reported to National Institute of Communicable Diseases (NICD), South Africa, 2006 to 2018 (from GERMS-SA Annual Reports, 2006 to 2018, with permission from Anne von Gottberg, NICD, Johannesburg, South Africa) (139, 227-237).

second year of life $(140,141)$. In Kenya, there has not been an increase in invasive infections by other serotypes or NTHi (140). The reasons why a booster dose is necessary to achieve control in some settings but not in others remain unclear (see discussion below).

The Gambia also uses a 3-dose primary series of Hib immunization without a booster dose. This resulted in excellent control of invasive Hib disease for 14 years after the vaccine was introduced, with consistently high coverage, low carriage rates, and high levels of protective antibodies (142). In order to measure the impact of pneumococcal conjugate vaccine introduction, surveillance for meningitis, sepsis, and pneumonia was established in Eastern Gambia (in Basse in 2008 and in Fuladu West in 2011). This surveillance identified increased Hib infections in Eastern Gambia between 2011 and 2013, despite high vaccine coverage. In 2013, the annual incidences of invasive Hib disease in this region were $90 / 100,000$ in infants aged $<1$ year and $26 / 100,000$ in children $<5$ years of age (143). The primary reasons for Hib infection were vaccine failure (39\%) and onset of infection in infants before receipt of two doses of Hib vaccine (39\%). At least two doses of Hib vaccine are required for high vaccine effectiveness ( $\geq 85 \%$ ) (144). HIV infection did not appear to be a factor (143). The surveillance in Eastern Gambia identified 57 cases of invasive H. influenzae infection: 24 (42\%) Hib, 17 (30\%) NTHi, 10 (18\%) Hia, $2 \mathrm{Hic}$, Hid, Hie, or Hif, 2 isolates that failed to grow on subculture, and 2 isolates that could not be retrieved. Fourteen of the Hib infections (58\%) were cases of meningitis, whereas NTHi presented principally as bacteremic pneumonia (12/17 [71\%]). The CFRs were 17\% (4/24) for Hib and $21 \%(5 / 17)$ for NTHi (143). It is also noteworthy that molecular studies of lung aspirate specimens collected in The Gambia more than 10 years after the introduction of Hib vaccines indicate that $H$. influenzae (mostly NTHi) may still cause up to $23 \%$ of cases of radiographic pneumonia. In this study, there was sufficient DNA for full multilocus sequence typing in 4/12 samples, with 3 samples yielding NTHi, whereas 1 sample in a child with HIV contained Hib (145).

Data on pediatric bacterial meningitis have been generated in 26 Sub-Saharan African countries by the WHO's Invasive Bacterial Vaccine-Preventable Diseases Surveillance Network (IB-VPD) (146-154). During 2011 to 2016, 1,670/49,844 (3.3\%) meningitis cases in children aged $<5$ years were laboratory confirmed, of which $H$. influenzae $(232 / 1,670$ [13.9\%]) was the least common organism identified (146). While most were Hib infections, 
cases of Hia, Hic, Hie, and NTHi were also reported. Interestingly, Boni-Cisse et al. noted that NTHi had become a significant cause of meningitis in Côte d'Ivoire (154).

Several West African countries participating in the IB-VPD network reported bacterial meningitis cases in children aged $<5$ years in the years 2010 to 2016. In Lomé, Togo, there were 23 cases of $H$. influenzae meningitis, and 20 of the isolates were available for serotyping. There were 9 cases of Hib meningitis, with the number declining by year, with only 1 case in 2015, while 2/2 cases of Hic occurred in 2012 and 5/7 cases of Hie were in 2015 (151). In Nigeria, 19/153 (12\%) pediatric bacterial meningitis cases were due to $H$. influenzae (150). Serotyping was performed on $16 / 19$, with Hib being the predominant serotype $(11 / 16,69 \%)$. In contrast to the findings in Togo, the number of Hib isolates increased from one in 2012, two in 2013, to eight in 2016. Hia and Hic caused three and two infections, respectively, in 2015 (150). In Senegal, H. influenzae was responsible for 10/115 (9\%) of cases, with serotyping data available for five cases. Hib was the causative serotype in 4/5 (2 in 2014 and 2 in 2016). There was also one case of Hic (148). In The Gambia, H. influenzae was responsible for $11 / 69$ cases of meningitis (15.9\%), with Hib causing 6/11 (54\%) cases (149). In Ghana, 5/73 (6.8\%) microbiologically confirmed cases of bacterial meningitis were caused by $\mathrm{H}$. influenzae: $1 \mathrm{Hib}, 1 \mathrm{Hic}, 2 \mathrm{Hie}$, and $1 \mathrm{NTHi}$ (152). It is of note that although Hib vaccine was introduced in The Gambia and Senegal in 1997 and 2005, respectively, Hib continues to cause pediatric bacterial meningitis, albeit at a low rate. Although the number of cases is small, the identification of Hia, Hic, and Hie as causative agents of pediatric bacterial meningitis underlines the importance of continuing surveillance and serotyping of isolates.

In Sub-Saharan Africa, in countries with a high prevalence of SCD and low rates of Hib vaccine coverage, invasive Hib infections remain one of the most frequent causes of bacteremia in children with SCD (155). Improving uptake of Hib vaccine should result in a significant decline in invasive Hib infections in these children. However, SCD children will remain at potential risk of bacteremia from non-type $b$ strains.

Apart from South Africa and The Gambia, countries in Sub-Saharan Africa using schedules of three primary doses of Hib vaccine and no booster dose have not seen a resurgence of invasive Hib infection. A lack of robust surveillance in many countries may mask potential limitations of the vaccine's impact in populations with high HIV prevalence or limited vaccine coverage. To fully appreciate the ongoing burden of Hib meningitis in Africa, surveillance using molecular methods is needed. The difficulty of making an etiologic diagnosis of pneumonia may also mask the role of NTHi and Hib as ongoing causes of pneumonia with consolidation. There are only limited data on other $\mathrm{H}$. influenzae serotypes or NTHi. With respect to Hib disease, the primary challenges for NIPs in Sub-Saharan Africa are optimizing the timeliness of the primary series of doses and increasing coverage in displaced or migrating subpopulations.

\section{South East Asia Region}

Hib immunization was introduced throughout the WHO South East Asia Region after 2009. An exception was Thailand, where although Hib vaccine had been added to the NIP in 2019 as a 3-dose primary course without a booster dose, the vaccine had been available in the private market since the late 1990s. In 2019, the average coverage of three doses of Hib vaccine in the South East Asian Region was 89\%, although rates between countries are highly variable (156). Data for individual countries in the region are shown in Table 5. Data on the incidence of invasive disease and pneumonia across the region are limited. In 1998, Miller (157) estimated that there were 135,000 deaths annually due to $\mathrm{Hib}$ and $92 \%$ of these occurred in three countries in this WHO region: India, Bangladesh, and Indonesia. In India, most deaths were from meningitis and pneumonia (158), although the incidence of severe Hib pneumonia is most likely to have been substantially underestimated (159). This is probably true for other countries in the region. The reported incidence rates for Hib meningitis vary widely from an estimate of $9.5 / 100,000$ in Thailand $(160)$ to 75 to $100 / 100,000$ in children aged $<5$ years in India (161), and there are no reliable data for the incidence of pneumonia and bacteremia or sepsis. However, it is likely that the true incidence of meningitis 
TABLE 5 Implementation of Hib vaccine in countries of the WHO South East Asia Region ${ }^{a}$

\begin{tabular}{|c|c|c|c|c|c|c|}
\hline Country & $\begin{array}{l}\text { Yr of } \\
\text { introduction }\end{array}$ & NIP & $\begin{array}{l}\text { Formulation } \\
\text { in } 2019\end{array}$ & $\begin{array}{l}\text { Schedule } \\
\text { in } 2019\end{array}$ & $\begin{array}{l}\text { Coverage of } \\
\text { Hib3 in } \\
2019(\%)\end{array}$ & $\begin{array}{l}\text { Yr in which } \\
\text { coverage } \\
\text { reached } \geq 50 \%\end{array}$ \\
\hline Bangladesh & 2009 & Yes & DTwP/Hib/HepB & $6,10,14$ wks & 98 & 2009 \\
\hline $\begin{array}{c}\text { Democratic People's } \\
\text { Republic of Korea }\end{array}$ & 2012 & Yes & DTwP/Hib/HepB & $6,10,14$ wks & 97 & 2013 \\
\hline India & 2015 & Yes & DTwP/Hib/HepB & $6,10,14 \mathrm{wks}$ & 89 & 2016 \\
\hline Myanmar & 2012 & Yes & DTwP/Hib/HepB & $2,4,6 \mathrm{mo}$ & 91 & 2013 \\
\hline Nepal & 2009 & Yes & DTwP/Hib/HepB & $6,10,14$ wks & 91 & 2011 \\
\hline Sri Lanka & 2008 & Yes & DTwP/Hib/HepB & $2,4,6 \mathrm{mo}$ & 99 & 2010 \\
\hline Thailand & 2019 & Yes & DTwP/Hib/HepB & $2,4,6 \mathrm{mo}$ & ND & ND \\
\hline Timor-Leste & 2012 & Yes & DTwP/Hib/HepB & $6,10,14$ wks & 83 & 2013 \\
\hline
\end{tabular}

reported for Thailand may also have been underestimated due to antimicrobial use prior to admission and before blood or cerebrospinal fluid samples for culture were collected $(160,162)$.

In India, with the largest population of any country in this region, the decision was made to introduce Hib immunization in 2011, but by 2015, only 8 of 29 Indian states had initiated Hib immunization in the public sector. Therefore, given the recent introduction of the vaccine, the earlier availability of the vaccine through the private sector, the widespread use of antibiotics, and the lack of access to reliable diagnostic laboratories, it is very difficult to determine the impact of Hib immunization on the epidemiology of $H$. influenzae disease in this region. A study modeling the national, regional, and state-level burden of Hib infections in children throughout India from 2000 to 2015 (163) estimated that Hib deaths in children aged $<5$ years fell from 82,600 (UR, 52,300 to 112,000 ) to 15,600 (UR, 9,800 to 21,500 ), representing an $81 \%$ decline in death rates. The mortality rate varied between states, with Uttar Pradesh (9,300 [UR 5,900 to 12,700]) and Odisha (1,100 [UR, 700 to 1,500]) reporting the highest number of deaths in 2015. It is of note that Hib mortality had declined before nationwide implementation of Hib conjugate vaccine, reflecting child survival trends in India (164) as a result of improved maternal and child health provision throughout the country. Introduction of $\mathrm{Hib}$ vaccine in several states corresponded with a more rapid reduction in morbidity and mortality associated with Hib infection (163). The recent establishment of hospitalbased sentinel surveillance for invasive bacterial diseases in India (HBSSPIBD) (165) will be of great benefit in determining the local impact of Hib and pneumococcal conjugate vaccine immunization programs.

Generally, there are few data on the impact of introducing Hib vaccines on invasive H. influenzae disease in the WHO South East Asian Region. Two sentinel studies have demonstrated that the burden of invasive Hib disease should be reduced after Hib vaccine has been used in NIPs for many years. The first, a large vaccine probe trial conducted in Lombok, Indonesia, reported a significant reduction in Hib meningitis incidence, but it did not prevent pneumonia in children $<5$ years of age (29). This study also revealed that contrary to the previously widely held belief, the incidence of Hib disease was high in the region and potentially the incidence of vaccine-preventable clinical meningitis was as much as $158 / 100,000$, while vaccine-preventable pneumonia was $1,467 / 100,000$ (29). The second was a case-control study in children aged $<2$ years from Bangladesh, where preventable fractions of radiographically confirmed pneumonia and Hib meningitis were $17 \%(95 \% \mathrm{Cl}, 10 \%$ to $38 \%)$ and $89 \%(95 \% \mathrm{Cl}, 28 \%$ to $100 \%$ ), respectively, when community controls were used and $35 \%(95 \% \mathrm{Cl}, 13 \%$ to 
$52 \%$ ) and $93 \%$ (95\% Cl, 53\% to 100\%), respectively, when controls were recruited from hospitals (166). To date, there are no published data on the impact of Hib immunization on bacteremic pneumonia in this region.

Given the relative lack of data, it is important that surveillance networks are established not only to monitor the impact of vaccination on Hib disease but also to monitor the effect on $\mathrm{H}$. influenzae epidemiology, given the resurgence of disease by non-type b strains seen elsewhere in Europe, North America, and Australia.

\section{Western Pacific Region}

According to the WHO, the Western Pacific Region has an annual birth cohort of almost 24 million, with 121 million children aged < 5 years. Both Australia and New Zealand incorporated Hib vaccine in their NIPs in 1993 and 1994, respectively. However, other countries within the region have included Hib vaccines in their NIPS only within the last 10 to 15 years. The notable exception is China, which so far has not adopted Hib vaccines for its 17 million infants born annually. In China, Hib vaccines are available in the private market, with only approximately $55 \%$ coverage for the full immunization schedule (167). Consequently, despite 19/26 countries reporting $\geq 90 \%$ completion rates of the third Hib vaccine dose during infancy, in 2019 just $24 \%$ of infants in this WHO region received three primary doses of Hib vaccine by 1 year of age (168).

The data for individual countries in the region are shown in Table 6. In 2015, in the Western Pacific Region, there were an estimated 370,000 cases of invasive Hib disease and 3,800 deaths (56). This compares with estimates of 1.5 million cases and 27,200 deaths in the year 2000 for this region (31). Meanwhile, the proportion of Hib-related deaths in the region attributed to China has almost doubled from $40 \%$ in 2000 to $74 \%$ in 2015 (56). Data on H. influenzae disease incidence in China are limited, although one study estimated that $29 \%$ of pediatric pneumonia was due to Hib (169). One study in Hefei City estimated that $30 \%$ to $50 \%$ of bacterial meningitis was from Hib, with an annual incidence of Hib meningitis of $10.4 / 100,000$ in children aged $<5$ years (170), whereas the incidence of all invasive Hib infections in Hong Kong was estimated to be 2.7/100,000 (171). In contrast, neighboring Mongolia, which introduced Hib vaccines in 2000, has had a $93 \%$ reduction in Hib meningitis cases and no Hib-related deaths since $2012(6,56)$. The annual incidence of Hib meningitis in Mongolia declined from 28/ 100,000 in children aged $<5$ years in 2002 to 2005 to $2 / 100,000$ in 2008 to 2010 ( $P<$ $0.0001)(6)$.

Following the introduction of Hib vaccine into the Australian NIP in 1993, annual invasive Hib disease rates declined from 40 to 60/100,000 in non-Indigenous children aged $<5$ years in 1993 to $0.07 / 100,000$ in 2010 and from 580/100,000 in Indigenous children aged $<5$ years to $1.4 / 100,000$ over the same time period (172). Recent surveys have not found a subsequent increase in replacement disease by encapsulated non-b strains $(173,174)$. A review of 238 invasive $H$. influenzae cases in South Australia and the Northern Territory between 2001 and 2011 reported an annual incidence rate in the Indigenous population of 9.0/100,000 compared to $0.7 / 100,000$ in non-Indigenous people (173). Indigenous children aged $<5$ years had the highest rates of invasive $H$. influenzae disease. This included $\mathrm{Hia}$, whose annual incidence of 10.5/100,000 was stable and outranked that of Hib, NTHi, and other non-b serotypes in this age group. Another recent review of 737 invasive cases from the state of Queensland found that the incidence of Hib and encapsulated non-b strains between 2000 and 2013 did not change significantly (174). The highest observed rates for encapsulated types were for $\mathrm{Hia}$ and $\mathrm{Hib}$ in Indigenous populations. However, across age groups, invasive NTHi infections predominated year-to-year and the incidence increased significantly during the study. The highest annual disease incidence rates for NTHi of 14.8 and 16.5/ 100,000 were in infants and in those aged $>90$ years, respectively.

In 2018, the age of administration of the Hib booster dose in Australia was moved from 12 months to 18 months (7). To assess the likely impact of this change, incidence rate ratios (IRR) and vaccine failure trends were calculated using Hib case surveillance 
TABLE 6 Implementation of Hib vaccine in countries of the WHO Western Pacific Region ${ }^{a}$

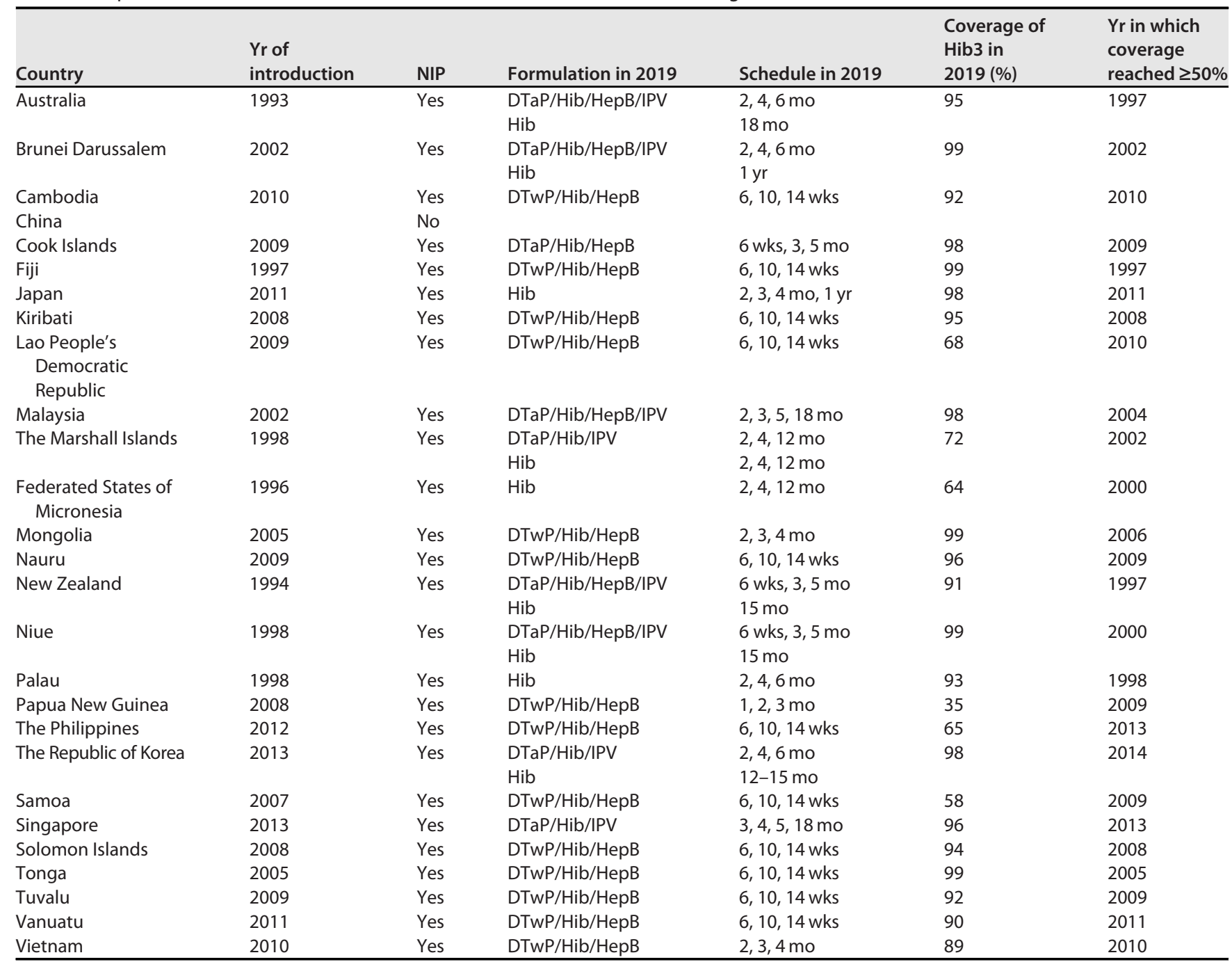

${ }^{a}$ Annual birth cohort, 23.2 million. Children aged $<5$ years, 119.8 million. Twenty-four percent of target population was immunized with three doses of Hib (Hib3) in 2019 (based on WHO-UNICEF estimates) (168). NIP, national immunization program. Abbreviations of vaccine antigens: D, diphtheria; T, tetanus; aP, acellular pertussis; WP, whole-cell pertussis; Hib, Haemophilus influenzae type b; HepB, hepatitis B virus surface antigen; IPV, inactivated poliovirus.

scheme data from 2000 to 2017, where 153/345 (44\%) cases were in children born after 2000, and 51/153 (33\%) occurred in Indigenous Australian children. The IRR for Indigenous children was $8.34(95 \% \mathrm{Cl}, 5.83$ to 11.79$)$ in comparison with nonIndigenous children with no evidence of a decline over these years. There was also no evidence of an increase in vaccine failures during the study period. Between 2000 and 2017, invasive Hib disease declined by $55 \%$, with a persistent marked disparity between Indigenous and non-Indigenous children (7). These results indicate the need to monitor any potential impact of moving the booster dose to 18 months of age, particularly in Indigenous children.

After Hib vaccine introduction in New Zealand, hospital admissions for Hib meningitis and epiglottitis in children aged $<15$ years decreased sharply (175). From 1993 to 1995 , meningitis rates declined by $82 \%$ from $8.63 / 100,000$ in 1993 to $1.58 / 100,000$ in 1995. Epiglottitis rates fell similarly by $87 \%$ from $3.67 / 100,000$ in 1993 to $0.48 / 100,000$ in 1995. In the period between 1991 and 2014, annual invasive Hib disease rates in this age group fell to as low as $0.12 / 100,000$. There was a similarly declining trend in Hib bacteremia hospitalization rates (175). Moreover, hospitalization rates for Indigenous Māori and non-Māori children for Hib disease were comparable. 
In Japan, Hib vaccine was introduced on a voluntary basis in 2008 and was then incorporated into the NIP in 2013. Active population-based surveillance of culture-proven pediatric invasive $H$. influenzae infections was conducted from 2008 to 2017 in 10 prefectures in Japan (approximately 23\% of the total Japanese population) (176). Over the 10 years of the study, 566 cases of invasive $H$. influenzae infection, including 336 meningitis cases, were identified. From 2013 to 2017, invasive $H$. influenzae infections among children $<5$ years of age declined by $93 \%$ (IRR, $0.07 ; 95 \% \mathrm{Cl}, 0.05$ to 0.10 ; $P<0.001])$ compared with cases in 2008 to 2012. The annual incidence of invasive $H$. influenzae disease in children $<5$ years of age declined from 12.5/100,000 in 2012 to 0.9/100,000 in 2017 (176). However, since 2014, in the post-Hib vaccine era, NTHi and Hif invasive infections have been identified in children $<5$ years of age. NTHi is now the major cause of invasive $H$. influenzae disease in Japan (177).

\section{WHO IS NOW AT RISK OF INVASIVE Hib DISEASE?}

In countries that have established infant NIPs, including Hib protein conjugate vaccine, invasive $\mathrm{Hib}$ infections are no longer a major cause of bacterial meningitis in young children, but cases of invasive Hib disease do still occur. Collins and colleagues investigated the epidemiology of all cases of invasive Hib disease in England and Wales from 2009 to 2012 (178). The incidence of invasive Hib disease in children aged $<5$ years was $0.06 / 100,000$ (two cases) compared with an incidence of 35.5/100,000 prior to routine Hib immunization. All 106 cases of invasive Hib infection that occurred between 2009 and 2012 were followed up. The median age at disease onset was 49.4 years (interquartile range, 16.9 to 67.5 ). Seventy-three percent of the cases occurred in adults, presenting with pneumonia (56\%), many of whom had underlying comorbidities (77\%): chronic heart disease $(n=17$, particularly in those of $>65$ years of age) and chronic lung disease ( $n=17$, mainly among those of $>45$ years of age) being the most frequently reported. The Hib-associated mortality was $9.4 \%$ (10/106). Data from the United States show a similar pattern (68). Between 2009 and 2015, the ABC surveillance sites identified 77 patients with invasive Hib disease whose median age was 49 years (interquartile range, 4 to 62 ). Of the 54 adults, 37 (82.2\%) presented with bacteremic pneumonia, with underlying comorbidities in $62.9 \%$, including chronic obstructive pulmonary disease (COPD), chronic heart disease, diabetes, and obesity. The shift of invasive Hib disease from young children to adults could be due to the absence of natural boosting from exposure to Hib organisms before Hib vaccines were introduced (179).

There is an increased risk of invasive Hib disease in patients with primary immunodeficiency disorders (e.g., agammaglobulinemia, early complement component deficiencies), those with anatomical or functional asplenia, those with HIV infection, and patients undergoing radiotherapy or chemotherapy for malignancy or post-hematopoietic stem cell transplantation (180). In the United States, a single booster dose of Hib vaccine is recommended for these high-risk groups whenever a primary course has not been completed (180). Hib vaccination is not recommended for HIV-infected adults.

\section{IS A BOOSTER DOSE OF Hib VACCINE NEEDED?}

Evidence of waning immunity following the introduction of a primary immunization series, without a booster dose, prompted three countries, the United Kingdom, South Africa, and Mexico, to add a booster dose. Worldwide, 50/83 high-income countries, as defined by the World Bank (181), recommend a booster dose at 11 to 18 months. In contrast, booster doses are used only by 19/56 upper middle-income countries and 5/ 50 lower middle-income countries. All 29 low-income countries employ a 3-dose primary series of Hib vaccine (at 6, 10, and 14 weeks of age) without a booster dose, as recommended by the WHO Expanded Program on Immunization (EPI) schedule (182) and adopted by the Vaccine Alliance (GAVI) (183) when it began supporting Hib vaccine introduction in the poorest countries globally in 2000. In many countries, Hib vaccine is included in a pentavalent or hexavalent vaccine, and the existing schedule for 
diphtheria, tetanus, and pertussis vaccine (DTP) has often been a deciding factor in the timing of Hib vaccination.

A meta-analysis of 20 RCTs, which had been conducted in 15 countries (United States, Canada, Chile, Guatemala, Belgium, Austria, Germany, Greece, France, Sweden, Netherlands, Turkey, The Gambia, Niger, China) compared different Hib vaccination schedules $(3+0,3+1$, and $2+1)$ and different intervals between the primary schedule and the primary and booster dose schedule (184). There was no difference between the schedules in terms of prevention of invasive Hib disease, clinical effectiveness, or immunologic response. The authors concluded that a two-dose primary schedule plus a booster $(2+1), 3+1$, and $3+0$ schedules all protected against Hib infection and that the choice would depend on the local epidemiology. Three doses in the first 6 months of life would be more appropriate when the greatest burden of Hib infection is in the first year of life, as in Sub-Saharan Africa. In countries where the burden of infection occurs at a later age, the third dose could be given in the second year of life. Where there had been a resurgence of infection following the use of a $3+0$ schedule, as in the United Kingdom, then a fourth dose as a booster in the second year of life may be required. A further meta-analysis of RCTs reported that 3- and 2-dose primary immunization courses of Hib vaccine in infancy showed similar vaccine efficacies (185). A 3-dose primary schedule had a vaccine efficacy of $82 \%$ compared to $79 \%$ for a 2 dose primary series. A systematic review and meta-analysis of observational data (144) considered the number of doses of vaccine, age at which the vaccination schedule was initiated, the interval between doses, and coadministration with other vaccines in the NIP. The authors concluded that $\geq 2$ doses of Hib vaccine are needed to achieve high levels of effectiveness (>85\%) and a booster could be beneficial, especially if the primary course was incomplete, but there were insufficient data to clearly show superiority of any particular schedule. A modeling study estimated that a primary series plus a booster dose within 1 year would result in greater reduction in the incidence of Hib disease than a primary series without a booster dose (186). However, this assumed high vaccine coverage of 90 to $100 \%$, which has not yet been achieved in many countries. The model also looked at delaying the booster dose for 2 years after the primary vaccination series and found that this had little impact on direct vaccine-induced protection against invasive Hib disease in children who have received Hib vaccine (186). A study in four South American countries (93) concluded that high Hib vaccine coverage resulted in a sustained low incidence of Hib meningitis and nasopharyngeal carriage of Hib with a three-dose primary series of Hib vaccine with or without a booster dose of vaccine in the second year of life.

Children with HIV may, however, require a booster dose of Hib vaccine. In a systematic review of Hib infection in HIV-infected children (35), the effectiveness of one or more doses of Hib vaccine was $55 \%$ (95\% Cl, 5\% to $80 \%$ ) in HIV-positive children and $91 \%(95 \% \mathrm{Cl}, 79 \%$ to $96 \%)$ in HIV-negative children.

It is unclear why a booster dose appears to be necessary in some settings but not in others. Among the factors that may be of importance are the type of vaccine used. Almost all countries now use combination vaccines which include Hib and either a whole-cell or acellular pertussis component. Some DTaP/Hib vaccines were reported to be associated with reduced Hib immunogenicity, but the clinical significance of this finding is unclear. Almost all countries currently using a Hib-acellular pertussis combination vaccine do include a booster dose in their schedule, but this may reflect national income rather than issues with the vaccine. Use of DTaP/Hib or DTaP/Hib/IPV does not significantly alter the immunogenicity and antibody functionality of the individual vaccine components (187), and in Germany, the use of DTaP-Hib combination vaccines produced protective levels of anti-PRP antibodies and high VE (188). The protein carrier used for the Hib component does not appear to be a factor. Tetanus toxoid (TT)-conjugated Hib vaccine has been adopted widely by low-income countries, both in those with sustained control, such as Kenya (141), and in others with evidence 
of waning immunity, such as The Gambia (143), so this seems to be an unlikely explanation.

It is difficult to determine the long-term impact of a primary immunization series without a booster dose in countries where high-quality population-based surveillance is not in place and sustained high coverage over a prolonged period has not yet been achieved.

The impact of changes to the timing of a booster dose has been reported from France, where a $3+1$ schedule of Hib vaccine was used from 1992 to 2012, with vaccine given at 2,3 , and 4 months and a booster dose at 16 to 18 months. In 2013 , the schedule was changed to a $2+1$ schedule, with a 2-dose primary course at 2 and 4 months plus a booster dose at 11 months. In 2018, cases of invasive Hib disease increased, with several examples of vaccine failure in children aged $<5$ years (123). This $2+1$ schedule was associated with a decline in anti-PRP antibodies to $<1 \mu \mathrm{g} / \mathrm{ml}$ by the age of 4 to 5 years. Although these are only preliminary data, it does suggest that a booster dose administered in the second year of life rather than before the first birthday may achieve sustained high levels of anti-PRP antibodies.

\section{INVASIVE NONTYPEABLE H. INFLUENZAE DISEASE}

Few reports exist describing the epidemiology of non-Hib disease prior to routine Hib immunization. A prospective, enhanced population-based surveillance of all invasive $H$. influenzae infections, conducted in six regions in England and Wales over the 2 years before routine Hib immunization was introduced, indicated that the majority (approximately 90\%) were caused by Hib, while approximately $10 \%$ were due to nontypeable $H$. influenzae (NTHi) (16). Other serotypes of $H$. influenzae accounted for $<1 \%$ of invasive infections. Twenty-three percent of NTHi cases were in children $<5$ years of age, and $62 \%$ occurred in adults, including $39 \%$ in adults aged $>65$ years. The annual attack rate of NTHi was $14.9 / 100,000$ in neonates and $0.39 / 100,000$ in those $>65$ years of age. Bacteremia without a detectable focus was the predominant presentation of invasive NTHi disease, being present in $37 \%$ of cases, while pneumonia accounted for $27 \%$ and meningitis for $12 \%$ of cases.

When Hib protein conjugate vaccines were first introduced in the early 1990s, there was concern that as these vaccines reduced nasopharyngeal carriage of Hib, other $H$. influenzae serotypes might replace Hib in the vacated ecological niche in the nasopharynx and cause more invasive disease. Indeed, as described above, NTHi is now responsible for the majority of invasive $H$. influenzae disease in every age group in countries where Hib vaccination programs are well established $(60,68,189,190)$. This is most probably due to multiple factors, such as the increased number and survival of preterm and extremely preterm infants (111), the increasing number of patients with underlying chronic medical disorders and immunocompromising conditions, and an aging population $(60,191)$.

Between 1992 and 2006, the Health Protection Agency in the United Kingdom coordinated surveillance data from Europe and other regions as part of the EU-IBIS program $(9,103)$. The incidence of invasive NTHi infections increased from $0.22 / 100,000$ population in 1996 to $0.28 / 100,000$ in 2006 , a small but statistically significant increase of $3.5 \%$ (95\% Cl, $2.1 \%$ to $5.2 \%$ ) year-to-year in 14 countries (9). Overall, $97 \%$ of invasive non-b $H$. influenzae infections were caused by NTHi (9). Since 2007, European data collation has been undertaken by the ECDC (192). In 2008 and 2009, the overall incidence of invasive NTHi disease from 29 reporting countries was $0.41 / 100,000$ and $0.36 / 100,000$, respectively, with higher incidence rates reported in Sweden $(1.78 / 100,000$ and 1.58/100,000, respectively) and Norway $(1.58 / 100,000$ and $1.48 / 100,000$, respectively) than in other European countries. The increase in NTHi infections was particularly notable among adults aged $\geq 60$ years (10). In Italy during 2017 to 2018 , the majority of invasive $H$. influenzae infections were caused by NTHi (76.1\%) (118). Similar increases in NTHi infections have been reported from other European countries, including Greece (193), Germany (194), England (114), Poland (195), and Finland (117). 
NTHi is now the major cause of invasive $H$. influenzae disease in all age groups in the United States, with a substantial disease burden, particularly in neonates, pregnant/postpartum women, and older adults (196). Surveillance in the CDC ABC sites from 2009 to 2015 reported that the highest incidence $(1.22 / 100,000)$ and highest CFRs (16\%) were for NTHi compared to Hib $(0.03 / 100,000$ and $4 \%$, respectively) and other capsulated serotypes $(0.45 / 100,000$ and $11 \%$, respectively) (68). The incidence of all invasive $H$. influenzae disease had increased by $16 \%$, compared with that in 2002 to 2008, driven by increases in NTHi and Hia disease (68). The highest incidence rates of invasive NTHi disease were in children aged $<1$ year $(3.18 / 100,000)$ and those aged $>65$ years $(4.47 / 100,000)$. These age groups also had the highest CFRs (68).

\section{NTHi Infections in Neonates and Pregnancy}

Early-onset neonatal NTHi infections are well described in studies from Europe (197-199), the United States (200), and Australia (201), with an incidence of 0.9/100,000 ( $95 \% \mathrm{Cl}, 0.9$ to 1.6$)$ in infants born at term rising to $342 / 100,000$ ( $95 \% \mathrm{Cl}, 234$ to 483 ) in infants born at $<28$ weeks gestation $(104,197,199,202)$ accounting for approximately $5 \%$ of all neonatal sepsis episodes (104). The European EU-IBIS study reported a 10-foldhigher incidence of invasive NTHi disease than with Hib in neonates, with $81 \%$ of cases occurring in the first 7 days of life (9). Neonatal NTHi sepsis develops rapidly (usually within the first $24 \mathrm{~h}$ after birth) and has a fulminant course with a CFR of $19 \%$, especially in preterm infants. Each additional gestational week reduced the CFR by $21 \%$ (OR, 0.79; $95 \% \mathrm{Cl}, 0.69$ to 0.90$)$. NTHi can colonize the female genital tract, and an ascending infection can cause both maternal and fetal infection, with maternal sepsis, septic abortion, preterm delivery, and increased complications during labor as possible consequences $(196,198,203)$. In the EU-IBIS study, for example, NTHi caused more infections in women than in men aged 25 to 44 years, and there may be an increased risk of invasive NTHi infection in women of childbearing age. Between 2008 and 2017, the ABC surveillance network identified NTHi invasive infection in 390 women of childbearing age. Of these, $86 / 390$ (27.8\%) were pregnant or postpartum. Pregnant/postpartum women were also more likely to have NTHi bacteremia than nonpregnant women of childbearing age (91\% versus $56.1 \% ; P<0.001)$ and less likely to have $\geq 1$ underlying comorbidity $(31.4 \%$ versus $67.7 \% ; P<0.001$ ). Three mother/infant pairs with invasive NTHi at delivery were identified. The neonatal isolate had the same sequence type as that of the corresponding maternal isolate (196). Of the 188 neonates with invasive NTHi infection identified in this study, 152 (81\%) were diagnosed in the first $24 \mathrm{~h}$ of life and 134 (71\%) were preterm. The average annual incidences among neonates and preterm infants were 43/100,000 and 320/100,000, respectively.

There is increasing evidence that NTHi invasive infection in early pregnancy may be associated with fetal loss, but as this diagnosis relies on postmortem placental and fetal samples, it is likely to be underrecognized. In a retrospective survey of all postmortem samples at $<24$ weeks gestation, NTHi was identified in $20 \%$ of cases with histologically confirmed chorioamnionitis and matched fetal and placental samples (198).

\section{NTHi Infections in Older Adults}

In countries with mature Hib vaccination programs, the median age at onset of invasive $H$. influenzae disease has now moved from early childhood to late adulthood, since the majority of invasive infections are now due to NTHi, which has a median age at disease onset of approximately 60 years (9). The majority of invasive NTHi cases in children $(40 \%$ to $70 \%)$ and adults $(60 \%$ to $80 \%)$ are seen in those with underlying comorbidities, notably chronic respiratory disease and impaired immunity (104, 204-206). While only 38\% of cases in a recent Swedish study had identified comorbidities (207), one-third of patients in that study were aged $>80$ years. Interestingly, the authors found B-cell immunity disorders, including chronic lymphatic leukemia and multiple myeloma, to be common among patients with invasive NTHi, suggesting that humoral immunity may have an important protective role to play (207). The authors also speculated that immunosenescence with age-related decline in B-cell function 
might explain the increasing incidence of invasive NTHi infections. Nevertheless, NTHi invasive disease can also occur in previously healthy individuals.

The clinical presentation of invasive NTHi disease varies with age. While meningitis is more commonly seen in older infants and children, it is uncommon in adults. Overall, pneumonia is the most frequent presentation, with invasive NTHi disease and NTHi pneumonia incidence increasing with age, particularly in older adults with underlying respiratory tract comorbidities, such as COPD and emphysema $(204,208)$. Other clinical presentations, such as epiglottitis (once a characteristic of invasive Hib disease) and skeletal and soft tissue infections, are uncommon, but cholecystitis (209) and urolithiasis (210) appear to be a particular feature of invasive NTHi infection in adults. The morbidity rate of invasive NTHi infections is high in older adults. In a Swedish study, $48 \%$ of 101 invasive NTHi cases developed severe sepsis or septic shock and $20 \%$ required intensive care (207).

In the United States, 4,683 cases of invasive NTHi disease were reported from 2008 to 2017 in the $A B C$ surveillance system (196). The overall average annual incidence of invasive NTHi infection was $1.29 / 100,000$, with an overall CFR of $15.6 \%$ and considerable variation between different age groups. While in children aged $<1$ year the average annual incidence was $5.94 / 100,000$, with a CFR of $8.3 \%$, in adults aged $\geq 80$ years the average annual incidence was $10.08 / 100,000$, with a CFR of $25.2 \%$.

Several studies have reported that invasive NTHi infection causes significant mortality, with CFRs of $12 \%$ to $22 \%(196,204,211)$. Moreover, CFRs for invasive NTHi disease have also been reported to be higher in studies with an extended follow-up after the initial NTHi infection, suggesting that NTHi may preferentially target those in poor health who, even if they survive the initial infection, may subsequently succumb to their underlying illness. The 28-day CFR for invasive NTHi disease in the Swedish study was $8 \%$, but 1 year postinfection, it had risen to $29 \%$ (207).

In countries with limited surveillance, or where serotyping of clinical isolates is incomplete, detecting an increase in NTHi infections will be difficult. Several factors may be responsible for the increase in NTHi infections, and it is possible that all have contributed to some extent. One possible explanation is strain replacement disease following the successful implementation of Hib immunization programs, although the evidence for this is limited (212). In England and Wales, invasive NTHi infections in children aged $<15$ years increased by $3 \%$ to $4 \%$ per year from 1994 to 2008 , but there was no detectable effect on NTHi epidemiology during the resurgence of invasive Hib infections from 2000 to 2003 (111). It is also well described that vulnerable populations, such as preterm infants, older adults, and individuals with underlying cardiac and respiratory comorbidities, malignancy, and immunosuppression, are particularly susceptible to invasive NTHi infection (111). In recent years, medical advances have increased the survival rates for these groups, resulting in a larger number of individuals susceptible to invasive NTHi infections. Other possible reasons for the increase may be the result of increased awareness of NTHi infections, alterations in clinical practice, and improved diagnostic testing, including the use of automated blood culture systems and molecular typing of isolates, together with more comprehensive epidemiologic surveillance.

\section{NTHi Vaccine Strategies}

In marked contrast to capsulated $H$. influenzae strains, NTHi strains are highly heterogeneous and there is no obvious vaccine candidate (191). One outer membrane protein, protein D, is highly conserved and produced by almost all strains (213). It is the protein carrier for eight of the pneumococcal polysaccharide antigens in the 10-valent pneumococcal protein conjugate vaccine (Synflorix; GlaxoSmithKline). Use of an 11-valent prototype of this vaccine resulted in a 35.3\% reduction in NTHi acute otitis media in children (214), but to date, the licensed vaccine has failed to show any significant effectiveness against invasive NTHi infections and has no effect on carriage (215). A multicomponent NTHi vaccine, containing protein $D$, protein $E$, and a fusion protein of another surface-exposed protein, PilA, is under investigation as a possible vaccine to 
prevent NTHi infections in adults with COPD (216). Other routes of vaccine administration have also been under consideration. Oral NTHi vaccination has been proposed for patients with recurrent exacerbations of COPD. A Cochrane review (217) concluded that oral administration of an NTHi vaccine did not yield consistent reductions in NTHimediated exacerbations but did demonstrate a significant reduction in the number of antibiotic courses prescribed. Subject age and gender were significant confounding factors in these studies (218).

\section{Invasive Disease and Haemophilus quentini}

Albritton et al. described a "cryptic genospecies of Haemophilus biotype IV" isolated from genitourinary tract specimens (219). Quentin et al. (220) further investigated these strains, which have been designated Haemophilus quentini. These strains can be differentiated from other NTHi strains by DNA hybridization, 16S rRNA gene sequencing, and multilocus enzyme electrophoresis (221). There have been case reports of $H$. quentini as a cause of neonatal bacteremia (222) and bacteremia in an adult with multiple myeloma (223). H. quentini has also been isolated from urine and urethral cultures in adult males (224). Between 2016 and 2018, the Public Health Ontario laboratory in Toronto identified seven cases of invasive $H$. quentini infection (225). Two of the isolates were from neonates, three were from adult females of childbearing age ( 2 were known to be pregnant), and one was from an elderly female. There was also an atypical $H$. quentini biotype III from an elderly male with varices. $H$. quentini strains were identified as nontypeable, biotype IV, possessed sodC, and lacked fucK, with detection of the H. quentini-specific 16S rRNA gene and near-full-length 16S rRNA gene sequencing, tests which require referral to a reference laboratory. Given the need for testing not generally available in routine diagnostic laboratories, $H$. quentini may well be an underrecognized pathogen in adults, especially in pregnant women (225).

\section{CONCLUSIONS}

The sustained low incidence of invasive Hib infection in all age groups in all countries that have introduced Hib protein conjugate vaccine illustrate the remarkable success of routine Hib vaccination programs that have provided both direct and indirect protection to vaccine recipients and their communities, respectively (226). Vaccine failures in fully immunized children are rare, and Hib vaccines are safe and well tolerated. The coverage of the third dose of Hib vaccine ranges from $76 \%$ in the WHO African and European Regions $(100,136)$ to $82 \%$ in the Eastern Mediterranean Region (129) and to $87 \%$ in the Region of the Americas and South East Asian Region $(63,156)$. The overall coverage in the Western Pacific Region is only 23\% (168), reflecting that China has yet to include Hib vaccines in their NIP. Most invasive Hib cases now occur mainly in older adults with underlying comorbidities. The continuing identification of cases of invasive $\mathrm{Hib}$ disease stresses the importance of maintaining Hib immunization with high rates of coverage in all countries to ensure that this pathogen does not reemerge as an important agent of serious pediatric infections.

In the prevaccine era, NTHi was an infrequent cause of invasive infection, but it is now acknowledged as the major contributor to invasive $H$. influenzae disease in countries with good surveillance mechanisms and full typing capabilities. The low rates of invasive NTHi infections reported in some countries is more likely due to the low proportion of strains referred to reference laboratories and highlights the need to improve ascertainment of such cases. NTHi infections occur predominantly in infants, particularly neonates, older adults, those who are immunosuppressed or who have underlying comorbidities, and women of childbearing age. Several studies have shown an increased burden of NTHi in these vulnerable individuals, resulting in frequent intensive care admission, high CFRs, and many sequelae in those who survive the infection. The reporting rate of NTHi infections in neonates is particularly striking, with most cases presenting as early-onset sepsis, especially in those born preterm where maternal infection has induced early labor and preterm delivery. Furthermore, NTHi infections in neonates are likely to be underestimated, although the increasing notification 
rates in this age group suggest an increasing awareness and reporting of these infections. NTHi immunization of pregnant women could protect both the mother and her baby. However, the development of an NTHi vaccine is difficult because of the genetic diversity of unencapsulated NTHi strains needing identification of multiple vaccine targets. Despite these challenges, investigations of potential NTHi vaccine candidates are ongoing.

Hia has emerged as a serious problem among the Indigenous populations of North America, to the extent that an Hia conjugate vaccine may be required to control these infections. In contrast, Hif is now the most frequently isolated capsulated serotype of $H$. influenzae causing invasive disease in the European Region, but the number of cases remains relatively small. Hie infections have also been recognized increasingly, principally in the European Region. Like NTHi, both Hie and Hif often target the elderly, and a high proportion of cases occur in patients with underlying comorbidities. Hie appears to be more virulent than Hif.

Hib conjugate vaccines were the first glycoprotein vaccines developed. The use of these vaccines over the last 30 years has proven extremely successful, to the extent that young pediatricians in high-income countries may never see cases of acute epiglottitis or acute meningitis caused by Hib. Valuable lessons have been learned about the use of these glycoprotein vaccines, which have aided the development of this type of vaccine for other major bacterial pathogens, including Neisseria meningitidis, Streptococcus pneumoniae, and Salmonella enterica serovar Typhi. The changing epidemiology of invasive $H$. influenzae infections, exemplified by the increasing incidence of Hia in Indigenous populations in North America and NTHi globally, together with alterations in the age groups affected, emphasizes the importance of ongoing surveillance. National Reference Centers, with sufficient resources, should establish comprehensive epidemiologic and microbiologic surveillance of all $H$. influenzae serotypes and NTHi infections, with accurate identification and typing of invasive isolates using molecular methods together with data on age groups affected, underlying comorbidities, risk factors, clinical presentations, and outcomes of the infections. Such systems should be implemented both before and for many years after a new vaccine has been introduced to establish its potential impact. Continuous surveillance is essential to inform future vaccination strategies and to detect vaccine "escape mutants" or replacement disease and vaccine failures. Indeed, as Hib disease has declined, surveillance systems have identified the increasing importance of NTHi, and in some regions of non-b serotypes, so that these species may themselves become future vaccine targets.

\section{ACKNOWLEDGMENTS}

We thank Kate O'Brien, WHO Geneva, Adam Cohen, WHO Geneva, and Kirthini Muralidharan, Johns Hopkins University, for their helpful advice. We also thank Shamez Ladhani, Public Health England (PHE), for permission to use PHE surveillance data of invasive $H$. influenzae infections in England and Anne von Gottberg, National Institute for Communicable Diseases (NICD), Johannesburg, South Africa, for permission to use data of cases of invasive $H$. influenzae infection in South Africa reported to the NICD.

M.P.E.S. has received personal fees from GSK, Pfizer, AstraZeneca, and Sanofi Pasteur as a speaker at international meetings and as a member of advisory boards (unrelated to the submitted work).

A.W.C. is a member of the Seqirus Australia (Parkville, Victoria, Australia) Pneumococcal Advisory Board and the Merck \& Co., Inc. (Kenilworth, NJ, USA), Global Pneumococcal Advisory Board (unrelated to the submitted work).

K.G., M.U., and G.A.M. have no conflicts of interest to declare.

\section{REFERENCES}

1. Moxon ER. 1995. Haemophilus influenzae, p 2039-2050. In Mandell GL, Bennett JE, Dolin R (ed), Mandell, Douglas and Bennett's principles and practice of infectious disease, 4th ed, vol 2. Churchill Livingstone, New York, NY.
2. Käyhty H, Peltola H, Karanko V, Mäkelä PH. 1983. The protective level of serum antibodies to the capsular polysaccharide of Haemophilus influenzae type b. J Infect Dis 147:1100. https://doi.org/10.1093/infdis/147.6 .1100 . 
3. Käyhty H, Karanko V, Peltola H, Mäkelä PH. 1984. Serum antibodies after vaccination with Haemophilus influenzae type b capsular polysaccharide and responses to reimmunization: no evidence of immunologic tolerance or memory. Pediatrics 74:857-865.

4. Anderson P. 1984. The protective level of serum antibodies to the capsular polysaccharide of Haemophilus influenzae type b. J Infect Dis 149:1034-1035. https://doi.org/10.1093/infdis/149.6.1034.

5. Peltola H. 2000. Worldwide Haemophilus influenzae type b disease at the beginning of the 21st century: global analysis of the disease burden 25 years after the use of the polysaccharide vaccine and a decade after the advent of conjugates. Clin Microbiol Rev 13:302-317. https://doi.org/10 .1128/CMR.13.2.302.

6. Scott S, Altanseseg D, Sodbayer D, Nymadawa P, Bulgan D, Mendsaikhan J, Watt JP, Slack MP, Carvalho MG, Hajjeh R, Edmond KM. 2013. Impact of Haemophilus influenzae type b conjugate vaccine in Mongolia: prospective population-based surveillance, 2002-2010. J Pediatr 163:S8-S11. https://doi.org/10.1016/j.jpeds.2013.03.024.

7. Maguire JE, Beard F, Meder K, Dey A, Macartney K, Mclntyre P. 2020. Australian vaccine preventable disease epidemiological review series: invasive Haemophilus influenzae type b disease, 2000-2017. Commun Dis Intell (2018) 17:44. https://doi.org/10.33321/cdi.2020.44.11.

8. Wenger JD. 1998. Epidemiology of Haemophilus influenzae type b disease and impact of Haemophilus influenzae type b conjugate vaccines in the United States and Canada. Pediatr Infect Dis J 17:S132-S136. https:// doi.org/10.1097/00006454-199809001-00008.

9. Ladhani S, Slack MP, Heath PT, von Gottberg A, Chandra M, Ramsay ME, European Union Invasive Bacterial Infection Surveillance Participants. 2010. Invasive Haemophilus influenzae Disease, Europe, 1996-2006. Emerg Infect Dis 16:455-463. https://doi.org/10.3201/eid1603.090290.

10. Whittaker R, Economopoulou A, Dias JG, Bancroft E, Ramliden M, Celentano LP, European Centre for Disease Prevention and Control Country Experts for Invasive Haemophilus influenzae Disease. 2017. Epidemiology of Invasive Haemophilus influenzae Disease, Europe, 20072014. Emerg Infect Dis 23:396-404. https://doi.org/10.3201/eid2303 .161552 .

11. von Gottberg A, de Gouveia L, Madhi SA, Du Plessis M, Quan V, Soma K, Huebner R, Flannery B, Schuchat A, Klugman K. 2006. Impact of conjugate Haemophilus influenzae type $\mathrm{b}(\mathrm{Hib})$ vaccine introduction in South Africa. Bull World Health Organ 84:811-818. https://doi.org/10.2471/blt .06 .030361 .

12. Mäkelä PH, Takala AK, Peltola H, Eskola J. 1992. Epidemiology of invasive Haemophilus influenzae type b Disease. J Infect Dis 165:S2-S6. https:// doi.org/10.1093/infdis/165.Supplement_1-S2.

13. Wilfert CM. 1990. Epidemiology of Haemophilus influenzae type b infections. Pediatrics 85:631-635.

14. World Health Organization. 2008. Progress introducing Haemophilus influenzae type b vaccine in low-income countries, 2004-2008. https:// www.who.int/wer/2008/wer8307/en/.

15. World Health Organization. 2002. Haemophilus influenzae type b (Hib) meningitis in the pre-vaccine era: a global review of incidence, age distributions, and case-fatality rates. World Health Organization, Geneva, Switzerland. https://apps.who.int/iris/handle/10665/67572.

16. Anderson EC, Begg NT, Crawshaw SC, Hargreaves RM, Howard AJ, Slack MP. 1995. Epidemiology of invasive Haemophilus influenzae infections in England and Wales in the pre-vaccination era (1990-2). Epidemiol Infect 115:89-100. https://doi.org/10.1017/s0950268800058155.

17. Peltola H, Käyhty H, Virtanen M, Mäkelä PH. 1984. Prevention of Hemophilus influenzae type $\mathrm{b}$ bacteremic infections with the capsular polysaccharide vaccine. N Engl J Med 310:1561-1566. https://doi.org/10.1056/ NEJM198406143102404.

18. Broome CV. 1987. Epidemiology of Haemophilus influenzae type b infections in the United States. Pediatr Infect Dis J 6:779-782. https://doi.org/ 10.1097/00006454-198708000-00036.

19. Ward Jl, Margolis HS, Lum MK, Fraser DW, Bender TR, Anderson P. 1981. Haemophilus influenzae disease in Alaskan Eskimos: characteristics of a population with an unusual incidence of invasive disease. Lancet 1:1281-1285. https://doi.org/10.1016/S0140-6736(81)92458-2.

20. Hammond GW, Rutherford BE, Malazdrewicz R, MacFarlane N, Pillay N, Tate RB, Nicolle LE, Postl BD, Stiver HG. 1988. Haemophilus influenzae meningitis in Manitoba and the Keewatin District, NWT: potential for mass vaccination. CMAJ 139:743-747.

21. Hansman D, Hanna J, Morey F. 1986. High prevalence of invasive Haemophilus influenzae disease in central Australia, 1986. Lancet 2:927. https:// doi.org/10.1016/s0140-6736(86)90451-4.
22. Baraff LJ, Lee SI, Schriger DL. 1993. Outcomes of bacterial meningitis in children: a meta-analysis. Pediatr Infect Dis J 12:389-394. https://doi.org/ 10.1097/00006454-199305000-00008.

23. Grimwood K, Anderson VA, Bond L, Catroppa C, Hore RL, Keir EH, Nolan T, Roberton DM. 1995. Adverse outcomes of bacterial meningitis in school-age survivors. Pediatrics 95:646-656.

24. Goetghebuer T, West TE, Wermenbol V, Cadbury AL, Milligan P, LloydEvans N, Adegbola RA, Mulholland EK, Greenwood BM, Weber MW. 2000. Outcome of meningitis caused by Streptococcus pneumoniae and Haemophilus influenzae type b in children in the Gambia. Trop Med Int Health 5:207-213. https://doi.org/10.1046/j.1365-3156.2000.00535.x.

25. D'Angio CT, Froehlke RG, Plank GA, Meehan DJ, Aguilar CM, Lande MB, Hugar L. 1995. Long-term outcome of Haemophilus influenzae meningitis in Navajo Indian children. Arch Pediatr Adolesc Med 149:1001-1008. https://doi.org/10.1001/archpedi.1995.02170220067009.

26. Letson GW, Gellin BG, Bulkow LR, Parks DJ, Ward J. 1992. Severity and frequency of sequelae of bacterial meningitis in Alaska Native infants. Correlation with a scoring system for severity of sequelae. Am J Dis Child 146:560-566. https://doi.org/10.1001/archpedi.1992.02160170040013.

27. Anderson V, Anderson P, Grimwood K, Nolan T. 2004. Cognitive and executive function 12 years after childhood bacterial meningitis: effect of acute neurologic complications and age of onset. J Pediatr Psychol 29:67-81. https://doi.org/10.1093/jpepsy/jsh011.

28. Mulholland K, Hilton S, Adegbola R, Usen S, Oparaugo A, Omosigho $C$, Weber M, Palmer A, Schneider G, Jobe K, Lahai G, Jaffar S, Secka O, Lin K, Ethevenaux C, Greenwood B. 1997. Randomised trial of Haemophilus influenzae type-b tetanus protein conjugate vaccine [corrected] for prevention of pneumonia and meningitis in Gambian infants. Lancet 349:1191-1197. https://doi.org/10.1016/s0140-6736(96)09267-7.

29. Gessner BD, Sutanto A, Linehan M, Djelantik IG, Fletcher T, Gerudug IK, Ingerani Mercer D, Moniaga V, Moulton LH, Moulton LH, Mulholland $\mathrm{K}$, Nelson C, Soemohardjo S, Steinhoff M, Widjaya A, Stoeckel P, Maynard J, Arjoso S. 2005. Incidences of vaccine-preventable Haemophilus influenzae type b pneumonia and meningitis in Indonesian children: hamletrandomised vaccine-probe trial. Lancet 365:43-52. https://doi.org/10 .1016/s0140-6736(04)17664-2.

30. Levine OS, Lagos R, Muñoz A, Villaroel J, Alvarez AM, Abrego P, Levine MM. 1999. Defining the burden of pneumonia in children preventable by vaccination against Haemophilus influenzae type b. Pediatr Infect Dis J 18:1060-1064. https://doi.org/10.1097/00006454-199912000-00006.

31. Watt JP, Wolfson LJ, O'Brien KL, Henkle E, Deloria-Knoll M, McCall N, Lee E, Levine OS, Hajjeh R, Mulholland K, Cherian T, Hib and Pneumococcal Global Burden of Disease Study Team. 2009. Burden of disease caused by Haemophilus influenzae type $b$ in children younger than 5 years: global estimates. Lancet 374:903-911. https://doi.org/10.1016/S0140 -6736(09)61203-4.

32. Lehmann D. 1992. Epidemiology of acute respiratory tract infections, especially those due to Haemophilus influenzae, in Papua New Guinean Children. J Infect Dis 165:S20-S25. https://doi.org/10.1093/infdis/165 -Supplement_1-S20.

33. Hanna JN. 1990. The epidemiology of invasive Haemophilus influenzae infections in children under five years of age in the Northern Territory: a three-year study. J Paediatr Child Health 152:234-240. https://doi.org/10 .5694/j.1326-5377.1990.tb120916.x.

34. Madhi SA, Petersen K, Khoosal M, Huebner RE, Mbelle N, Mothupi R, Saloojee H, Crewe-Brown H, Klugman KP. 2002. Reduced effectiveness of Haemophilus influenzae type b conjugate vaccine in children with a high prevalence of human immunodeficiency virus type 1 infection. Pediatr Infect Dis J 21:315-321. https://doi.org/10.1097/00006454-200204000 $-00011$.

35. Mangtani P, Mulholland K, Madhi SA, Edmond K, O'Loughlin R, Hajjeh R. 2010. Haemophilus influenzae type $b$ disease in HIV-infected children: $a$ review of the disease epidemiology and effectiveness of Hib conjugate vaccines. Vaccine 28:1677-1683. https://doi.org/10.1016/j.vaccine.2009 .12 .011 .

36. Hanna JN, Wild BE, Sly PD. 1992. The epidemiology of acute epiglottitis in children in Western Australia. J Paediatr Child Health 28:459-464. https://doi.org/10.1111/j.1440-1754.1992.tb02718.x.

37. Gilbert GL, Clements DA, Broughton SJ. 1990. Haemophilus influenzae type b infections in Victoria, Australia, 1985 to 1987. Pediatr Infect Dis J 9:252-257. https://doi.org/10.1097/00006454-199004000-00006.

38. Takala AK, Eskola J, Peltola H, Mäkelä PH. 1989. Epidemiology of invasive Haemophilus influenzae type b disease among children in Finland before 
vaccination with Haemophilus influenzae type b conjugate vaccine. Pediatr Infect Dis J 8:297-302.

39. Dagan R. 1993. Epidemiology of invasive Haemophilus influenzae type b (Hib) disease in Israel. Vaccine 11:S43-S45. https://doi.org/10.1016/0264 -410X(93)90159-U.

40. Nakamura R, Togashi T. 2013. Population-based incidence of invasive Haemophilus influenzae and pneumococcal diseases before the introduction of vaccines in Japan. Pediatr Infect Dis J 32:1394-1396. https://doi .org/10.1097/INF.0b013e3182a14971.

41. O'Brien KL, Steinhoff MC, Edwards K, Keyserling H, Thoms ML, Madore D. 1996. Immunologic priming of young children by pneumococcal glycoprotein conjugate, but not polysaccharide, vaccines. Pediatr Infect Dis J 15:425-430. https://doi.org/10.1097/00006454-199605000-00009.

42. Anderson P, Pichichero ME, Insel RA. 1985. Immunization of 2-month-old infants with protein-coupled oligosaccharides derived from the capsule of Haemophilus influenzae type b. J Pediatr 107:346-351. https://doi.org/ 10.1016/s0022-3476(85)80504-7.

43. Barbour ML, Booy R, Crook DW, Griffiths H, Chapel HM, Moxon ER, Mayon-White D. 1993. Haemophilus influenzae type b carriage and immunity four years after receiving the Haemophilus influenzae oligosaccharide-CRM197 (HbOC) conjugate vaccine. Pediatr Infect Dis J 12:478-484. https://doi.org/10.1097/00006454-199306000-00005.

44. Granoff DM, Anderson EL, Osterholm MT, Holmes SJ, McHugh JE, Belshe RB, Medley F, Murphy TV. 1992. Differences in the immunogenicity of three Haemophilus influenzae type b conjugate vaccines in infants. J Pediatr 121:187-194. https://doi.org/10.1016/s0022-3476(05)81186-2.

45. Granoff DM, Holmes SJ, Belshe RB, Osterholm MT, McHugh JE, Anderson EL. 1994. Effect of carrier protein priming on antibody responses to Haemophilus influenzae type b conjugate vaccines in infants. JAMA 272:1116-1121. https://doi.org/10.1001/jama.1994.03520140046036.

46. Schlesinger Y, Granoff DM, Murphy TV, Osterholm MT, McHugh JE, Anderson R, Esbenshade J, Blatter M, Reisinger KS, Keyserling H, Guito K, Meschievitz CK, the Vaccine Study Group. 1992. Avidity and bactericidal activity of antibody elicited by different Haemophilus influenzae type b conjugate vaccines. The Vaccine Study Group. JAMA 267:1489-1494. https://doi.org/10.1001/jama.267.11.1489.

47. Heath PT. 1998. Haemophilus influenzae type b conjugate vaccines: a review of efficacy data. Pediatr Infect Dis J 17:S117-S122. https://doi .org/10.1097/00006454-199809001-00005.

48. Decker MD, Edwards KM, Bradley R, Palmer P. 1992. Comparative trial in infants of four conjugate Haemophilus influenzae type b vaccines. J Pediatr 120:184-189. https://doi.org/10.1016/s0022-3476(05)80424-x.

49. Bulkow LR, Wainwright RB, Letson GW, Chang SJ, Ward JI. 1993. Comparative immunogenicity of four Haemophilus influenzae type b conjugate vaccines in Alaska Native infants. Pediatr Infect Dis J 12:484-492. https:// doi.org/10.1097/00006454-199306000-00006.

50. Swingler G, Fransman D, Hussey G. 2007. Conjugate vaccines for preventing Haemophilus influenzae type b infections. Cochrane Database Syst Rev 2007:CD001729. https://doi.org/10.1002/14651858.CD001729 .pub2.

51. Watt JP, Levine OS, Santosham M. 2003. Global reduction of Hib disease: what are the next steps? Proceedings of the meeting Scottsdale, Arizona, September 22-25, 2002. J Pediatr 143:S163-S187. https://doi.org/10 .1067/s0022-3476(03)00576-6.

52. Feikin DR, Nelson CB, Watt JP, Mohsni E, Wenger JD, Levine OS. 2004. Rapid assessment tool for Haemophilus influenzae type b disease in developing countries. Emerg Infect Dis 10:1270-1276. https://doi.org/10 .3201/eid1007.030737.

53. Hajjeh RA, Privor-Dumm L, Edmond K, O'Loughlin R, Shetty S, Griffiths UK, Bear AP, Cohen AL, Chandran A, Schuchat A, Mulholland EK, Santosham M. 2010. Supporting new vaccine introduction decisions: lessons learned from the Hib Initiative experience. Vaccine 28:7123-7129. https://doi.org/10.1016/j.vaccine.2010.07.028.

54. World Health Organization. 2006. WHO position paper on Haemophilus influenzae type b conjugate vaccines. Wkly Epidemiol Rec 81:445-452.

55. Ojo LR, O'Loughlin RE, Cohen AL, Loo JD, Edmond KM, Shetty SS, Bear AP, Privor-Dumm L, Griffiths UK, Hajjeh R. 2010. Global use of Haemophilus influenzae type b conjugate vaccine. Vaccine 28:7117-7122. https:// doi.org/10.1016/j.vaccine.2010.07.074.

56. Wahl B, O'Brien KL, Greenbaum A, Majumder A, Liu L, Chu Y, Luksic I, Nair H, McAllister DA, Campbell H, Rudan I, Black R, Knoll MD. 2018. Burden of Streptococcus pneumoniae and Haemophilus influenzae type b disease in children in the era of conjugate vaccines: global, regional, and national estimates for 2000-15. Lancet Glob Health 6:e744-e757. https://doi.org/ 10.1016/S2214-109X(18)30247-X.

57. Brown VM, Madden S, Kelly L, Jamieson FB, Tsang RS, Ulanova M. 2009. Invasive Haemophilus influenzae disease caused by non-type b strains in Northwestern Ontario, Canada, 2002-2008. Clin Infect Dis 49:1240-1243. https://doi.org/10.1086/605671.

58. Ulanova M, Tsang R. 2014. Haemophilus influenzae serotype a as a cause of serious invasive infections. Lancet Infect Dis 14:70-82. https://doi.org/ 10.1016/S1473-3099(13)70170-1.

59. Ladhani SN, Collins S, Vickers A, Litt DJ, Crawford C, Ramsay ME, Slack MP. 2012. Invasive Haemophilus influenzae serotype e and f disease, England and Wales. Emerg Infect Dis 18:725-732. https://doi.org/10.3201/ eid1805.111738.

60. Van Eldere J, Slack MP, Ladhani S, Cripps AW. 2014. Non-typeable Haemophilus influenzae, an under-recognised pathogen. Lancet Infect Dis 14:1281-1292. https://doi.org/10.1016/S1473-3099(14)70734-0.

61. Collins S, Vickers A, Ladhani SN, Flynn S, Platt S, Ramsay ME, Litt DJ, Slack MP. 2016. Clinical and molecular epidemiology of childhood invasive nontypeable Haemophilus influenzae disease in England and Wales. Pediatr Infect Dis J 35:e76-e84. https://doi.org/10.1097/INF.0000000000000996.

62. World Health Organization. 2021. Definition of regional groupings. www .who.int/healthinfo/global_burden_disease/definition_regions/en/.

63. World Health Organization. 2019. Regional immunization profile: region of the Americas. https://www.who.int/immunization/monitoring surveillance/data/AMR/en/.

64. Ward J, Lum MK, Hall DB, Silimperi DR, Bender TR. 1986. Invasive Haemophilus influenzae type $\mathrm{b}$ disease in Alaska: background epidemiology for a vaccine efficacy trial. J Infect Dis 153:17-26. https://doi.org/10.1093/ infdis/153.1.17.

65. Losonsky GA, Santosham M, Sehgal VM, Zwahlen A, Moxon ER. 1984. Haemophilus influenzae disease in the White Mountain Apaches: molecular epidemiology of a high risk population. Pediatr Infect Dis 3:539-547. https://doi.org/10.1097/00006454-198411000-00012.

66. Coulehan JL, Michaels RH, Hallowell C, Schults R, Welty TK, Kuo JS. 1984. Epidemiology of Haemophilus influenzae type b disease among Navajo Indians. Public Health Rep 99:404-409.

67. Singleton R, Hammitt L, Hennessy T, Bulkow L, DeByle C, Parkinson A, Cottle TE, Peters H, Butler JC. 2006. The Alaska Haemophilus influenzae type $b$ experience: lessons in controlling a vaccine-preventable disease. Pediatrics 118:e421-e429. https://doi.org/10.1542/peds.2006-0287.

68. Soeters HM, Blain A, Pondo T, Doman B, Farley MM, Harrison LH, Lynfield R, Miller L, Petit S, Reingold A, Schaffner W, Thomas A, Zansky SM, Wang $X$, Briere EC. 2018. Current epidemiology and trends in invasive Haemophilus influenzae disease-United States, 2009-2015. Clin Infect Dis 67:881-889. https://doi.org/10.1093/cid/ciy187.

69. Centers for Disease Control. 1991. Haemophilus b conjugate vaccines for prevention of Haemophilus influenzae type $b$ disease among infants and children two months of age and older: recommendations of the Immunization Practices Advisory Committee (ACIP), on Centers for Disease Control. https://www.cdc.gov/mmwr/preview/mmwrhtml/00041736.htm.

70. Schuchat A, Hilger T, Zell E, Farley MM, Reingold A, Harrison L, Lefkowitz L, Danila R, Stefonek K, Barrett N, Morse D, Pinner R, Active Bacterial Core Surveillance Team of the Emerging Infections Program Network. 2001. Active bacterial core surveillance of the emerging infections program network. Emerg Infect Dis 7:92-99. https://doi.org/10.3201/eid0701.010114.

71. MacNeil JR, Cohn AC, Farley M, Mair R, Baumbach J, Bennett $N$, Gershman K, Harrison LH, Lynfield R, Petit S, Reingold A, Schaffner W, Thomas A, Coronado F, Zell ER, Mayer LW, Clark TA, Messonnier NE. 2011. Current epidemiology and trends in invasive Haemophilus influenzae disease-United States, 1989-2008. Clin Infect Dis 53:1230-1236. https://doi.org/10.1093/cid/cir735.

72. Collins LF, Havers FP, Tunali A, Thomas S, Clennon JA, Wiley Z, TobinD'Angelo M, Parrott T, Read TD, Satola SW, Petit RA, Farley MM. 2019. Invasive nontypeable Haemophilus influenzae infection among adults with HIV in metropolitan Atlanta, Georgia, 2008-2018. JAMA 322:2399-2410. https:// doi.org/10.1001/jama.2019.18800.

73. Powars D, Overturf G, Turner E. 1983. Is there an increased risk of Haemophilus influenzae septicemia in children with sickle cell anemia? Pediatrics 71:927-931.

74. Williams TN, Uyoga S, Macharia A, Ndila C, McAuley CF, Opi DH, Mwarumba S, Makani J, Komba A, Ndiritu MN, Sharif SK, Marsh K, Berkley JA, Scott JA. 2009. Bacteraemia in Kenyan children with sickle-cell anaemia: a retrospective cohort and case-control study. Lancet 374:1364-1370. https://doi.org/10.1016/S0140-6736(09)61374-X. 
75. Ramakrishnan M, Moisi JC, Klugman KP, Iglesias JM, Grant LR, MpoudiEtame M, Levine OS. 2010. Increased risk of invasive bacterial infections in African people with sickle-cell disease: a systematic review and metaanalysis. Lancet Infect Dis 10:329-337. https://doi.org/10.1016/S1473 -3099(10)70055-4.

76. Ellison AM, Ota KV, McGowan KL, Smith-Whitley K. 2013. Epidemiology of bloodstream infections in children with sickle cell disease. Pediatr Infect Dis J 32:560-563. https://doi.org/10.1097/INF.0b013e318286c75b.

77. Yee ME, Bakshi N, Graciaa SH, Lane PA, Jerris RC, Wang YF, Yildirim I. 2019. Incidence of invasive Haemophilus influenzae infections in children with sickle cell disease. Pediatr Blood Cancer 66:e27642. https://doi.org/ $10.1002 / p b c .27642$.

78. Moxon ER, Glode MP, Sutton A, Robbins JB. 1977. The infant rat as a model of bacterial meningitis. J Infect Dis 136(Suppl):S186-S190. https:// doi.org/10.1093/infdis/136.supplement.s186.

79. Zwahlen A, Kroll JS, Rubin LG, Moxon ER. 1989. The molecular basis of pathogenicity in Haemophilus influenzae: comparative virulence of genetically-related capsular transformants and correlation with changes at the capsulation locus cap. Microb Pathog 7:225-235. https://doi.org/10 .1016/0882-4010(89)90058-2.

80. Tsang RSW, Ulanova M. 2017. The changing epidemiology of invasive Haemophilus influenzae disease: emergence and global presence of serotype a strains that may require a new vaccine for control. Vaccine 35:4270-4275. https://doi.org/10.1016/j.vaccine.2017.06.001.

81. Bender MA, Kumarasamy N, Mayer KH, Wang B, Walensky RP, Flanigan T, Schackman BR, Scott CA, Lu Z, Freedberg KA. 2010. Invasive Haemophilus influenzae disease in Utah children: an 11-year population-based study in the era of conjugate vaccine. Clin Infect Dis 50:e41-e46. https://doi .org/10.1086/651165.

82. Crandall H, Christiansen J, Varghese AA, Russon A, Korgenski EK, Bengtson EK, Dickey M, Killpack J, Knackstedt ED, Daly JA, Ampofo K, Pavia AT, Blaschke AJ. 2019. Clinical and molecular epidemiology of invasive Haemophilus influenzae serotype a infections in Utah children. J Pediatric Infect Dis Soc 9:650-655. https://doi.org/10.1093/jpids/piz088.

83. Antony S, Kaushik A, Mauriello C, Chatterjee A. 2017. Non-type b Haemophilus influenzae invasive infections in North Dakota and South Dakota, 2013-2015. J Pediatric Infect Dis Soc 6:281-284. https://doi.org/10.1093/ jpids/piw053.

84. Soeters HM, Oliver SE, Plumb ID, Blain AE, Zulz T, Simons BC, Barnes $M$, Farley MM, Harrison LH, Lynfield R, Massay S, McLaughlin J, Muse AG, Petit S, Schaffner W, Thomas A, Torres S, Watt J, Pondo T, Whaley MJ, Hu F, Wang X, Briere EC, Bruce MG. 2020. Epidemiology of invasive Haemophilus influenzae serotype a disease-United States, 2008-2017. Clin Infect Dis 2020:ciaa875. https://doi.org/10.1093/cid/ciaa875.

85. Soeters HM, Bozio C, Blain A, Burzlaff K, Doman B, Harrison L, Barnes M, Petit S, Watt J, Schaffner W, Triden L, Whaley M, Hu F, Briere E, Wang X, Oliver S. 2019. Invasive Haemophilus influenzae serotype a diseaseUnited States, 2008-2017, abstr OC- (EMGM2019-13210), p 82. https:// emgm.eu/meetings/emgm2019/emgm2019_abstracts.pdf.

86. Bruce MG, Zulz T, DeByle C, Singleton R, Hurlburt D, Bruden D, Rudolph K, Hennessy T, Klejka J, Wenger JD. 2013. Haemophilus influenzae serotype a invasive disease, Alaska, USA, 1983-2011. Emerg Infect Dis 19:932-937. https://doi.org/10.3201/eid1906.121805.

87. Plumb ID, Lecy KD, Singleton R, Engel MC, Hirschfeld M, Keck JW, Klejka J, Rudolph KM, Hennessy TW, Bruce MG. 2018. Invasive Haemophilus influenzae serotype a infection in children: clinical description of an emerging pathogen-Alaska, 2002-2014. Pediatr Infect Dis J 37:298-303. https://doi.org/10.1097/INF.0000000000001764.

88. Bozio $\mathrm{CH}$, Blain A, Edge K, Farley MM, Harrison LH, Poissant T, Schaffner W, Scheuer T, Torres S, Triden L, Briere E, Oliver SE. 2020. Clinical characteristics and adverse clinical outcomes of invasive Haemophilus influenzae serotype a cases-United States, 2011-2015. Clin Infect Dis 2020: ciaa990. https://doi.org/10.1093/cid/ciaa990.

89. Tsang RSW, Proulx JF, Hayden K, Shuel M, Lefebvre B, Boisvert AA, Moore D. 2017. Characteristics of invasive Haemophilus influenzae serotype a (Hia) from Nunavik, Canada and comparison with Hia strains in other North American Arctic regions. Int J Infect Dis 57:104-107. https://doi .org/10.1016/j.ijid.2017.02.003.

90. Tsang RS, Mubareka S, Sill ML, Wylie J, Skinner S, Law DK. 2006. Invasive Haemophilus influenzae in Manitoba, Canada, in the postvaccination era. J Clin Microbiol 44:1530-1535. https://doi.org/10.1128/JCM.44.4.1530 $-1535.2006$.

91. Cox AD, Barreto L, Ulanova M, Bruce MG, Tsang R, Conference Contributors. 2017. Developing a vaccine for Haemophilus influenzae serotype a: proceedings of a workshop. Can Commun Dis Rep 43:89-95. https://doi .org/10.14745/ccdr.v43i05a02.

92. Peltola H. 1997. Haemophilus influenzae type b disease and vaccination in Latin America and the Caribbean. Pediatr Infect Dis J 16:780-787. https://doi.org/10.1097/00006454-199708000-00010.

93. Garcia S, Lagos R, Muñoz A, Picón T, Rosa R, Alfonso A, Abriata G, Gentile A, Romanin V, Regueira M, Chiavetta L, Agudelo Cl, Castaneda E, De la Hoz F, Higuera AB, Arce P, Cohen AL, Verani J, Zuber P, Gabastou JM, Pastor D, Flannery B, Andrus J. 2012. Impact of vaccination against Haemophilus influenzae type $b$ with and without a booster dose on meningitis in four South American countries. Vaccine 30:486-492. https://doi .org/10.1016/j.vaccine.2011.10.101.

94. Danovaro-Holliday MC, Garcia S, de Quadros C, Tambini G, Andrus JK. 2008. Progress in vaccination against Haemophilus influenzae type $b$ in the Americas. PLoS Med 5:e87. https://doi.org/10.1371/journal.pmed .0050087 .

95. Tohme RA, Francois J, Cavallaro KF, Paluku G, Yalcouye I, Jackson E, Wright T, Adrien P, Katz MA, Hyde TB, Faye P, Kimanuka F, Dietz V, Vertefeuille J, Lowrance D, Dahl B, Patel R. 2017. Expansion of vaccination services and strengthening vaccine-preventable diseases surveillance in Haiti, 2010-2016. Am J Trop Med Hyg 97:28-36. https://doi.org/ 10.4269/ajtmh.16-0802.

96. Tuyama M, Corrêa-Antônio J, Schlackman J, Marsh JW, Rebelo MC, Cerqueira EO, Nehab M, Kegele F, Carmo GF, Thielmann DC, Barroso PF, Harrison LH, Barroso DE. 2017. Invasive Haemophilus influenzae disease in the vaccine era in Rio de Janeiro, Brazil. Mem Inst Oswaldo Cruz 112:196-202. https://doi.org/10.1590/0074-02760160391.

97. Rodriguez RS, Mascarenas C, Conde-Glez CJ, Inostroza J, Villanueva S, Velázquez ME, Sánchez-Alemán MA, Echániz G. 2010. Serological protection induced by Haemophilus influenzae Type $b$ conjugate vaccine in Mexican children: is a booster dose of the vaccine needed? Clin Vaccine Immunol 17:1639-1641. https://doi.org/10.1128/CVI.00249-10.

98. Ribeiro GS, Reis JN, Cordeiro SM, Lima JB, Gouveia EL, Petersen M, Salgado K, Silva HR, Zanella RC, Almeida SC, Brandileone MC, Reis MG, Ko Al. 2003. Prevention of Haemophilus influenzae type b (Hib) meningitis and emergence of serotype replacement with type a strains after introduction of Hib immunization in Brazil. J Infect Dis 187:109-116. https://doi.org/10.1086/345863.

99. Léon ME, Kawabata A, Nagai M, Rojas L, Chamorro G, Zárate N, Gómez G, Leguizamón M, Irala J, Ortellado J, Franco R, Segovia N. 2020. Epidemiologic study of Haemophilus influenzae causing invasive and non-invasive disease in Paraguay (1999-2017). Enferm Infecc Microbiol Clin 39:59-64. https://doi.org/10.1016/j.eimc.2020.02.020.

100. World Health Organization. 2019. Regional immunization profile: European Region. https://www.who.int/immunization/monitoring_surveillance/data/ EUR/en/.

101. Murphy TF. 2015. Haemophilus species, Including $H$. influenzae and $H$. ducreyi (Chancroid), p 2575-2583.e2. In Bennett JE, Dolin R, Blaser MJ (ed), Mandell, Douglas, and Bennett's principles and practice of infectious diseases, 8th ed. W. B. Saunders, Philadelphia, PA. https://doi.org/ 10.1016/B978-1-4557-4801-3.00227-7.

102. European Centre for Disease Prevention and Control. 2018. Haemophilus influenzae: annual epidemiological report for 2018. https://www.ecdc.europa.eu/ sites/default/files/documents/AER_for_2018_haemophilus_influenzae.pdf.

103. European Invasive Bacterial Infections Surveillance Network (EU-IBIS). 1999-2007. European Invasive Bacterial Infections Surveillance Network (EU-IBIS), on European Centre for Disease Prevention and Control. https://www.ecdc.europa.eu/en/about-us/networks/disease-and-laboratorynetworks/eu-ibd.

104. Heath PT, Booy R, Azzopardi HJ, Slack MP, Fogarty J, Moloney AC, Ramsay ME, Moxon ER. 2001. Non-type b Haemophilus influenzae disease: clinical and epidemiologic characteristics in the Haemophilus influenzae type b vaccine era. Pediatr Infect Dis J 20:300-305. https://doi .org/10.1097/00006454-200103000-00016.

105. Ladhani SN. 2012. Two decades of experience with the Haemophilus influenzae serotype b conjugate vaccine in the United Kingdom. Clin Ther 34:385-399. https://doi.org/10.1016/j.clinthera.2011.11.027.

106. Heath PT, McVernon J. 2002. The UK Hib vaccine experience. Arch Dis Child 86:396-399. https://doi.org/10.1136/adc.86.6.396.

107. Trotter CL, Ramsay ME, Slack MP. 2003. Rising incidence of Haemophilus influenzae type $b$ disease in England and Wales indicates a need for $a$ second catch-up vaccination campaign. Commun Dis Public Health 6:55-58. 
108. McVernon J, Andrews N, Slack MP, Ramsay ME. 2003. Risk of vaccine failure after Haemophilus influenzae type b (Hib) combination vaccines with acellular pertussis. Lancet 361:1521-1523. https://doi.org/10.1016/ S0140-6736(03)13171-6.

109. Eskola J, Ward J, Dagan R, Goldblatt D, Zepp F, Siegrist CA. 1999. Combined vaccination of Haemophilus influenzae type b conjugate and diphtheria-tetanus-pertussis containing acellular pertussis. Lancet 354:2063-2068. https://doi.org/10.1016/S0140-6736(99)04377-9.

110. Dagan R, Poolman JT, Zepp F. 2008. Combination vaccines containing DTPa-Hib: impact of IPV and coadministration of CRM197 conjugates. Expert Rev Vaccines 7:97-115. https://doi.org/10.1586/14760584.7.1.97.

111. Ladhani SN, Ramsay M, Slack MP. 2011. The impact of Haemophilus influenzae serotype $B$ resurgence on the epidemiology of childhood invasive Haemophilus influenzae disease in England and Wales. Pediatr Infect Dis J 30:893-895. https://doi.org/10.1097/INF.0b013e31822ef670.

112. Collins S, Litt D, Almond R, Findlow J, Linley E, Ramsay M, Borrow R, Ladhani S. 2018. Haemophilus influenzae type b (Hib) seroprevalence and current epidemiology in England and Wales. J Infect 76:335-341. https://doi.org/10.1016/j.jinf.2017.12.010.

113. Collins S, Groves N, Fry NK, Ladhani SN, Litt D. 2019. The rise (and fall) of invasive Haemophilus influenzae serotype a (Hia) disease in England), abstr C-(EMGM2019-13311), p 81. https://emgm.eu/meetings/ emgm2019/emgm2019_abstracts.pdf.

114. Litt D, Collins S, Fry NK, Ladhani SN. 2019. Epidemiology of invasive Haemophilus influenzae disease in England: national surveillance, 2017-2018, abstr PO-019-(EMGM2019-13268), p 28. https://emgm .eu/meetings/emgm2019/emgm2019_abstracts.pdf.

115. Takla A, Schönfeld V, Claus H, Krone M, An der Heiden M, Koch J, Vogel U, Wichmann O, Lâm TT. 2020. Invasive Haemophilus influenzae infections in Germany after the introduction of routine childhood immunization, 2001-2016. Open Forum Infect Dis 7:ofaa444. https://doi.org/10 .1093/ofid/ofaa444.

116. Lâm T-T, Claus H, Krone M. 2019. Invasive Haemophilus influenzae isolates in Germany 2017 and 2018: laboratory surveillance report, abstr PO-017-(EMGM2019-13294), p 26. https://emgm.eu/meetings/ emgm2019/emgm2019_abstracts.pdf.

117. Toropainen M. 2019. Epidemiology of invasive Haemophilus influenzae disease in Finland, 2016-2018, abstr PO-016-(EMGM2019-13238), p 25. https://emgm.eu/meetings/emgm2019/emgm2019_abstracts.pdf.

118. Neri $A$, Giufrè $M$, Fazio $C$, Vacca $P$, Ambrosio $L$, Palmieri $A$, Cardines $R$, Riccardo F, Fabiano M, Caporali MG, Leone P, Cerquetti M, Stefanelli P. 2019. Invasive diseases due to Neisseria meningitidis and Haemophilus influenzae, abstr PO-014-(EMGM2019), p 23. https://emgm.eu/meetings/ emgm2019/emgm2019_abstracts.pdf.

119. Johansson Kostenniemi U, Norman D, Sellin M, Silfverdal SA. 2019. Sustained reductions of invasive infectious disease following general infant Haemophilus influenzae type $\mathrm{b}$ and pneumococcal vaccination in a Swedish Arctic region. Acta Paediatr 108:1871-1878. https://doi.org/10 .1111/apa.14824.

120. Heliodoro CIM, Bettencourt C, Bajanca-Lavado MP, Portuguese Group for the Study of Haemophilus influenzae Invasive Infection. 2020. Molecular epidemiology of invasive Haemophilus influenzae disease in Portugal: an update of the post-vaccine period, 2011-2018. Eur J Clin Microbiol Infect Dis 39:1471-1480. https://doi.org/10.1007/s10096 -020-03865-0.

121. Bajanca-Lavado MP, Bettencourt C, Cunha F, Marques JG. 2019. Haemophilus influenzae serotype b vaccine failure in Portugal: a new threat?, abstr OC-(EMGM2019-13331), p 80. https://emgm.eu/meetings/emgm2019/ emgm2019_abstracts.pdf.

122. World Health Organization. 2016. Hib 3rd dose (Hib3) immunization coverage among 1-year olds, 1991-2018 (\%): 2018. https://www.who.int/ gho/immunization/Hib/en/.

123. Hong ET, Denizon M, Taha M-K, Deghmane A-E. 2019. Recent evolution of the epidemiology of Haemophilus influenzae type b and seroprevalence in France, abstr OC-(EMGM2019-13190), p 79. https://emgm.eu/ meetings/emgm2019/emgm2019_abstracts.pdf.

124. Setchanova LP, Kostyanev T, Markovska R, Miloshev G, Mitov IG. 2013. Serotypes, antimicrobial susceptibility, and beta-lactam resistance mechanisms of clinical Haemophilus influenzae isolates from Bulgaria in a pre-vaccination period. Scand J Infect Dis 45:81-87. https://doi.org/10 .3109/00365548.2012.710854.

125. Platonov AE, Griffiths UK, Voeykova MV, Platonova OV, Shakhanina IL, Chistyakova GG, Robertson SE, Moscow Hib Study Team. 2006. Economic evaluation of Haemophilus influenzae type $b$ vaccination in
Moscow, Russian Federation. Vaccine 24:2367-2376. https://doi.org/10 $.1016 /$ j.vaccine.2005.11.054

126. Griffiths UK, Clark A, Shimanovich V, Glinskaya I, Tursunova D, Kim L, Mosina L, Hajjeh R, Edmond K. 2011. Comparative economic evaluation of Haemophilus influenzae type b vaccination in Belarus and Uzbekistan. PLoS One 6:e21472. https://doi.org/10.1371/journal.pone.0021472.

127. Pilishvili T, Chernyshova L, Bondarenko A, Lapiy F, Sychova I, Cohen A, Flannery B, Hajjeh R. 2013. Evaluation of the effectiveness of Haemophilus influenzae type $\mathrm{b}$ conjugate vaccine introduction against radiologically-confirmed hospitalized pneumonia in young children in Ukraine. J Pediatr 163:S12-S18. https://doi.org/10.1016/j.jpeds.2013.03.025.

128. Szabo BG, Lenart KS, Tirczka T, Ostorhazi E. 2018. Clinical and microbiological characteristics of adult invasive Haemophilus influenzae infections: results of a 14-year single-center experience from Hungary. Infection 46:855-860. https://doi.org/10.1007/s15010-018-1213-6.

129. World Health Organization. 2019. Regional immunization profile: Eastern Mediterranean Region. https://www.who.int/immunization/ monitoring_surveillance/data/EMR/en/.

130. Hausdorff WP, Hajjeh R, Al-Mazrou A, Shibl A, Soriano-Gabarro M, Middle East \& North Africa Vaccine-Preventable Diseases Regional Advisory Group. 2007. The epidemiology of pneumococcal, meningococcal, and Haemophilus disease in the Middle East and North Africa (MENA) region-current status and needs. Vaccine 25:1935-1944. https://doi.org/ 10.1016/j.vaccine.2006.11.018.

131. Youssef FG, El-Sakka H, Azab A, Eloun S, Chapman GD, Ismail T, Mansour H, Hallaj Z, Mahoney F. 2004. Etiology, antimicrobial susceptibility profiles, and mortality associated with bacterial meningitis among children in Egypt. Ann Epidemiol 14:44-48. https://doi.org/10 .1016/S1047-2797(03)00075-9.

132. Daoud AS, Al-Sheyyab M, Batchoun RG, Rawashdeh MO, Nussair MM, Pugh RN. 1995. Bacterial meningitis: still a cause of high mortality and severe neurological morbidity in childhood. J Trop Pediatr 41:308-310. https://doi.org/10.1093/tropej/41.5.308.

133. Elsaid MF, Alsoub H, Bessisso MS, Janahi MA, Elshafie SS, Flamerzi AA, Abdulla MI. 2002. Clinical presentation of acute bacterial meningitis in Qatar. Neurosciences (Riyadh) 7:266-271.

134. Zaidi AK, Khan H, Sherali AR, Lasi R. 2010. Burden of Haemophilus influenzae type $\mathrm{b}$ disease in Pakistani children. East Mediterr Health J 16:590-594. https://doi.org/10.26719/2010.16.6.590.

135. Al-Mazrou YY, Al-Jeffri MH, Al-Haggar SH, Musa EK, Mohamed OM, Abdalla MN. 2004. Haemophilus type B meningitis in Saudi children under 5 years old. J Trop Pediatr 50:131-136. https://doi.org/10.1093/ tropej/50.3.131.

136. World Health Organization. 2019. Regional immunization profile: African region. https://www.who.int/immunization/monitoring_sur veillance/data/AFR/en/.

137. Bijlmer HA, van Alphen L, Greenwood BM, Brown J, Schneider G, Hughes A, Menon A, Zanen HC, Valkenburg HA. 1990. The epidemiology of Haemophilus influenzae meningitis in children under five years of age in the Gambia, West Africa. J Infect Dis 161:1210-1215. https://doi.org/10 .1093/infdis/161.6.1210.

138. von Gottberg A, Cohen C, Whitelaw A, Chhagan M, Flannery B, Cohen AL, de Gouveia L, Plessis M, Madhi SA, Klugman KP. 2012. Group for Enteric, Respiratory, Meningeal Disease Surveillance in South Africa (GERMS-SA). 2012. Invasive disease due to Haemophilus influenzae serotype b ten years after routine vaccination, South Africa, 2003-2009. Vac cine 30:565-571. https://doi.org/10.1016/j.vaccine.2011.11.066.

139. National Institute for Communicable Diseases. 2018. GERMS South Africa: annual surveillance review 2018. https://www.nicd.ac.za/wp -content/uploads/2019/11/GERMS-SA-AR-2018-Final.pdf.

140. Cowgill KD, Ndiritu M, Nyiro J, Slack MP, Chiphatsi S, Ismail A, Kamau T, Mwangi I, English M, Newton CR, Feikin DR, Scott JA. 2006. Effectiveness of Haemophilus influenzae type $b$ conjugate vaccine introduction into routine childhood immunization in Kenya. JAMA 296:671-678. https:// doi.org/10.1001/jama.296.6.671.

141. Hammitt LL, Crane RJ, Karani A, Mutuku A, Morpeth SC, Burbidge $P$, Goldblatt D, Kamau T, Sharif S, Mturi N, Scott JA. 2016. Effect of Haemophilus influenzae type $\mathrm{b}$ vaccination without a booster dose on invasive $H$ influenzae type $b$ disease, nasopharyngeal carriage, and population immunity in Kilifi, Kenya: a 15-year regional surveillance study. Lancet Glob Health 4:e185-e194. https://doi.org/10.1016/ S2214-109X(15)00316-2.

142. Howie SR, Oluwalana C, Secka O, Scott S, Ideh RC, Ebruke BE, Balloch A, Sambou S, Erskine J, Lowe Y, Corrah T, Adegbola RA. 2013. The 
effectiveness of conjugate Haemophilus influenzae type B vaccine in the Gambia 14 years after introduction. Clin Infect Dis 57:1527-1534. https://doi.org/10.1093/cid/cit598.

143. Mackenzie GA, Ikumapayi UN, Scott S, Idoko O, Odutola A, Ndiaye M, Sahito SM, Osuorah CD, Manjang A, Jarju S, Bojang A, Roca A, Secka O, Zaman A, Ceesay L, Lowe-Jallow Y, Sambou S, Jasseh M, Antonio M, Greenwood B, Kampmann B, Mulholland K, Corrah T, Howie SR. 2015. Increased disease due to Haemophilus influenzae type b: populationbased surveillance in eastern Gambia, 2008-2013. Pediatr Infect Dis J 34: e107-e112. https://doi.org/10.1097/INF.0000000000000645.

144. Jackson C, Mann A, Mangtani P, Fine P. 2013. Effectiveness of Haemophilus influenzae type $b$ vaccines administered according to various schedules: systematic review and meta-analysis of observational data. Pediatr Infect Dis J 32:1261-1269. https://doi.org/10.1097/INF .0b013e3182a14e57.

145. Howie SR, Morris GA, Tokarz R, Ebruke BE, Machuka EM, Ideh RC, Chimah O, Secka O, Townend J, Dione M, Oluwalana C, Njie M, Jallow M, Hill PC, Antonio M, Greenwood B, Briese T, Mulholland K, Corrah T, Lipkin WI, Adegbola RA. 2014. Etiology of severe childhood pneumonia in the Gambia, West Africa, determined by conventional and molecular microbiological analyses of lung and pleural aspirate samples. Clin Infect Dis 59:682-685. https://doi.org/10.1093/cid/ciu384.

146. Mwenda JM, Soda E, Weldegebriel G, Katsande R, Biey JN, Traore T, de Gouveia L, Du Plessis M, von Gottberg A, Antonio M, Kwambana-Adams B, Worwui A, Gierke R, Schwartz S, van Beneden C, Cohen A, Serhan F, Lessa FC. 2019. Pediatric bacterial meningitis surveillance in the World Health Organization African region using the Invasive Bacterial VaccinePreventable Disease Surveillance Network, 2011-2016. Clin Infect Dis 69: S49-S57. https://doi.org/10.1093/cid/ciz472.

147. Kourna HM, Khan D, Laouali B, Okoi C, Yam A, Haladou M, Worwui A, Ndow PS, Nse Obama R, Mwenda JM, Biey J, Ntsama B, KwambanaAdams BA, Antonio M. 2019. Pediatric bacterial meningitis surveillance in Niger: increased importance of Neisseria meningitidis serogroup C, and a decrease in Streptococcus pneumoniae following 13-valent pneumococcal conjugate vaccine introduction. Clin Infect Dis 69:S133-S139. https://doi.org/10.1093/cid/ciz598.

148. Sonko MA, Dube FS, Okoi CB, Diop A, Thiongane A, Senghore M, Ndow P, Worwui A, Faye PM, Dieye B, Ba ID, Diallo A, Boly D, Ndiaye O, Cisse MF, Mwenda JM, Kwambana-Adams BA, Antonio M. 2019. Changes in the molecular epidemiology of pediatric bacterial meningitis in Senegal after pneumococcal conjugate vaccine introduction. Clin Infect Dis 69: S156-S163. https://doi.org/10.1093/cid/ciz517.

149. Sanneh B, Okoi C, Grey-Johnson M, Bah-Camara $H$, Kunta Fofana B, Baldeh I, Papa Sey A, Labbo Bah M, Cham M, Samateh A, Usuf E, Ndow PS, Senghore M, Worwui A, Mwenda JM, Kwambana-Adams B, Antonio M. 2019. Declining trends of pneumococcal meningitis in Gambian children after the introduction of pneumococcal conjugate vaccines. Clin Infect Dis 69:S126-S132. https://doi.org/10.1093/cid/ciz505.

150. Tagbo BN, Bancroft RE, Fajolu I, Abdulkadir MB, Bashir MF, Okunola OP, Isiaka AH, Lawal NM, Edelu BO, Onyejiaka N, Ihuoma CJ, Ndu F, Ozumba UC, Udeinya F, Ogunsola F, Saka AO, Fadeyi A, Aderibigbe SA, Abdulraheem J, Yusuf AG, Sylvanus Ndow P, Ogbogu P, Kanu C, Emina V, Makinwa OJ, Gehre F, Yusuf K, Braka F, Mwenda JM, Ticha JM, Nwodo D, Worwui A, Biey JN, Kwambana-Adams BA, Antonio M. 2019. Pediatric bacterial meningitis surveillance in Nigeria from 2010 to 2016, prior to and during the phased introduction of the 10-valent pneumococcal conjugate vaccine. Clin Infect Dis 69:S81-S88. https://doi.org/10.1093/ cid/ciz474.

151. Tsolenyanu E, Bancroft RE, Sesay AK, Senghore M, Fiawoo M, Akolly D, Godonou MA, Tsogbale N, Tigossou SD, Tientcheu L, Dagnra A, Atakouma Y, Sylvanus Ndow P, Worwui A, Landoh DE, Mwenda JM, Biey JN, Ntsama B, Kwambana-Adams BA, Antonio M. 2019. Etiology of pediatric bacterial meningitis pre- and post-PCV13 introduction among children under 5 years old in Lome, Togo. Clin Infect Dis 69:S97-S104. https://doi.org/10.1093/cid/ciz473.

152. Renner LA, Usuf E, Mohammed NI, Ansong D, Dankwah T, Kusah JT, Owusu SK, Awunyo M, Arhin B, Addo Y, Asamoah J, Biey JN, Ndow PS, Worwui A, Senghore M, Ntsama B, Mwenda JM, Diamenu SK, Adams BK, Antonio M. 2019. Hospital-based surveillance for pediatric bacterial meningitis in the era of the 13-valent pneumococcal conjugate vaccine in Ghana. Clin Infect Dis 69:S89-S96. https://doi.org/10.1093/cid/ciz464.

153. Agossou J, Ebruke C, Noudamadjo A, Adedemy JD, Denon EY, Bankole HS, Dogo MA, Assogba R, Alassane M, Conde A, Mohamed FA, Kpanidja G, Gomina M, Hounsou F, Aouanou BG, Okoi C, Oluwalana C, Worwui A,
Ndow PS, Nounagnon J, Mwenda JM, Sossou RA, Kwambana-Adams BA Antonio M. 2019. Declines in pediatric bacterial meningitis in the Republic of Benin following introduction of pneumococcal conjugate vaccine: epidemiological and etiological findings, 2011-2016. Clin Infect Dis 69: S140-S147. https://doi.org/10.1093/cid/ciz478.

154. Boni-Cisse C, Jarju S, Bancroft RE, Lepri NA, Kone H, Kofi N, Britoh-Mlan A, Zaba FS, Usuf E, Ndow PS, Worwui A, Mwenda JM, Biey JN, Ntsama B, Kwambana-Adams BA, Antonio M. 2019. Etiology of bacterial meningitis among children $<5$ years old in Cote d'lvoire: findings of hospital-based surveillance before and after pneumococcal conjugate vaccine introduction. Clin Infect Dis 69:S114-S120. https://doi.org/10.1093/cid/ciz475.

155. Allali S, Chalumeau M, Launay O, Ballas SK, de Montalembert M. 2018. Conjugate Haemophilus influenzae type b vaccines for sickle cell disease. Cochrane Database Syst Rev 8:CD011199. https://doi.org/10.1002/ 14651858.CD011199.pub3.

156. World Health Organization. 2019. Regional immunization profile: South-East Asian region. https://www.who.int/immunization/monitoring_surveillance/ data/SEAR/en/.

157. Miller MA. 1998. An assessment of the value of Haemophilus influenzae type b conjugate vaccine in Asia. Pediatr Infect Dis J 17:S152-S159. https://doi.org/10.1097/00006454-199809001-00012.

158. Invasive Bacterial Infections Surveillance (IBIS) Study Group of the International Clinical Epidemiology Network. 2002. Are Haemophilus influenzae infections a significant problem in India? A prospective study and review. Clin Infect Dis 34:949-957. https://doi.org/10.1086/339327.

159. Gupta M, Prinja S, Kumar R, Kaur M. 2013. Cost-effectiveness of Haemophilus influenzae type $\mathrm{b}(\mathrm{Hib})$ vaccine introduction in the universal immunization schedule in Haryana State, India. Health Policy Plan 28:51-61. https://doi.org/10.1093/heapol/czs025.

160. Rerks-Ngarm S, Treleaven SC, Chunsuttiwat $S$, Muangchana $C$, Jolley D, Brooks A, Dejsirilert S, Warintrawat S, Guiver M, Kunasol P, Maynard JE, Biggs BA, Steinhoff M. 2004. Prospective populationbased incidence of Haemophilus influenzae type b meningitis in Thailand. Vaccine 22:975-983. https://doi.org/10.1016/j.vaccine.2003.09 013.

161. John TJ, Cherian T, Raghupathy P. 1998. Haemophilus influenzae disease in children in India: a hospital perspective. Pediatr Infect Dis J 17: S169-S171. https://doi.org/10.1097/00006454-199809001-00015.

162. Mäkelä HP, Nohynek H, Elja H. 2005. Prospective population-based incidence of Haemophilus influenzae type b meningitis in Thailand. Vaccine 23:2687-2688. https://doi.org/10.1016/j.vaccine.2004.11.054.

163. Wahl B, Sharan A, Deloria Knoll M, Kumar R, Liu L, Chu Y, McAllister DA, Nair H, Campbell H, Rudan I, Ram U, Sauer M, Shet A, Black R, Santosham M, O'Brien KL, Arora NK. 2019. National, regional, and state-level burden of Streptococcus pneumoniae and Haemophilus influenzae type b disease in children in India: modelled estimates for 2000-15. Lancet Glob Health 7:e735-e747. https://doi.org/10.1016/S2214-109X(19)30081-6.

164. You D, Hug L, Ejdemyr S, Idele P, Hogan D, Mathers C, Gerland P, New JR, Alkema L. 2015. Global, regional, and national levels and trends in under-5 mortality between 1990 and 2015, with scenario-based projections to 2030: a systematic analysis by the UN Inter-agency Group for Child Mortality Estimation. Lancet 386:2275-2286. https://doi.org/10 .1016/S0140-6736(15)00120-8.

165. Rajkumar $P$, Bharathy $S$, Girish Kumar CP, Veeraraghavan B, Verghese $V$, Gupta N, Kangusamy B, Ravi M, Jayaraman Y, HBSSPIBD Network Team. 2020. Hospital-based sentinel surveillance for Streptococcus pneumoniae and other invasive bacterial diseases in India (HBSSPIBD): design and methodology. BMJ Open 10:e034663. https://doi.org/10.1136/bmjopen -2019-034663.

166. Baqui AH, El Arifeen S, Saha SK, Persson L, Zaman K, Gessner BD, Moulton LH, Black RE, Santosham M. 2007. Effectiveness of Haemophilus influenzae type b conjugate vaccine on prevention of pneumonia and meningitis in Bangladeshi children: a case-control study. Pediatr Infect Dis J 26:565-571. https://doi.org/10.1097/INF.0b013e31806166a0.

167. Yang Y, Yang Y, Scherpbier RW, Zhu X, Chen Y, Zhou Y, Jiang Q. 2019. Coverage of Haemophilus influenzae type $b$ conjugate vaccine for children in mainland China: systematic review and meta-analysis. Pediatr Infect Dis J 38:248-252. https://doi.org/10.1097/INF.0000000000002132.

168. World Health Organization. 2019. Immunization profile: Western Pacific Region. https://www.who.int/immunization/monitoring_surveillance/data/ WPR/en/.

169. Yang Y, Pan X, Cheng W, Yang Y, Scherpbier RW, Zhu X, Chen Y, Zhou Y, Jiang Q. 2017. Haemophilus influenzae type $b$ carriage and burden of its 
related diseases in Chinese children: systematic review and meta-analysis. Vaccine 35:6275-6282. https://doi.org/10.1016/j.vaccine.2017.09.057.

170. Yang Y, Shen X, Jiang Z, Liu X, Leng Z, Lu D, Rao J, Liu J, Chang L. 1998. Study on Haemophilus influenzae type $b$ diseases in China: the past, present and future. Pediatr Infect Dis J 17(9 Suppl):S159-S165. https:// doi.org/10.1097/00006454-199809001-00013.

171. Lau YL, Low LC, Yung R, Ng KW, Leung CW, Lee WH, Ho A, Oppenheimer SJ. 1995. Invasive Haemophilus influenzae type b infections in children hospitalized in Hong Kong, 1986-1990. Hong Kong Hib Study Group. Acta Paediatr 84:173-176. https://doi.org/10.1111/j.1651-2227.1995.tb13604.x.

172. Milton A, Stirzaker S, Trungove M, Knuckey D, Martin N, Hastie C, Pennington K, Sloan-Gardner T, Fitzsimmons G, Knope K, Martinek S, Mills L, Barry C, Wright P, Power M, NNDSS Annual Report Writing Group. 2012. Australia's notifiable disease status, 2010 annual report of the National Notifiable Diseases Surveillance System. Commun Dis Intell Q Rep 36:1-69.

173. Menzies RI, Markey P, Boyd R, Koehler AP, Mclntyre PB. 2013. No evidence of increasing Haemophilus influenzae non-b infection in Australian Aboriginal children. Int J Circumpolar Health 72:20992. https://doi .org/10.3402/ijch.v72i0.20992.

174. Wan Sai Cheong J, Smith H, Heney C, Robson J, Schlebusch S, Fu J, Nourse C. 2015. Trends in the epidemiology of invasive Haemophilus influenzae disease in Queensland, Australia from 2000 to 2013: what is the impact of an increase in invasive non-typable $H$. influenzae (NTHi)? Epidemiol Infect 143:2993-3000. https://doi.org/10.1017/S0950268815000345.

175. Walls T, Cho V, Martin N, Williman J, Brunton C. 2018. Vaccine impact on long term trends in invasive bacterial disease in New Zealand children. Pediatr Infect Dis J 37:1041-1047. https://doi.org/10.1097/INF.0000000000002071.

176. Suga S, Ishiwada N, Sasaki Y, Akeda H, Nishi J, Okada K, Fujieda M, Oda M, Asada K, Nakano T, Saitoh A, Hosoya M, Togashi T, Matsuoka M, Kimura K, Shibayama K. 2018. A nationwide population-based surveillance of invasive Haemophilus influenzae diseases in children after the introduction of the Haemophilus influenzae type b vaccine in Japan. Vaccine 36:5678-5684. https://doi.org/10.1016/j.vaccine.2018.08.029.

177. Naito S, Takeuchi N, Ohkusu M, Takahashi-Nakaguchi A, Takahashi $H_{\text {, }}$ Imuta N, Nishi J, Shibayama K, Matsuoka M, Sasaki Y, Ishiwada N. 2018. Clinical and bacteriologic analysis of nontypeable Haemophilus influenzae strains isolated from children with invasive diseases in Japan from 2008 to 2015. J Clin Microbiol 56:e00141-18. https://doi.org/10.1128/ JCM.00141-18.

178. Collins S, Ramsay M, Campbell H, Slack MP, Ladhani SN. 2013. Invasive Haemophilus influenzae type b disease in England and Wales: who is at risk after 2 decades of routine childhood vaccination? Clin Infect Dis 57:1715-1721. https://doi.org/10.1093/cid/cit579.

179. Pollard AJ, Perrett KP, Beverley PC. 2009. Maintaining protection against invasive bacteria with protein-polysaccharide conjugate vaccines. Nat Rev Immunol 9:213-220. https://doi.org/10.1038/nri2494.

180. Briere EC, Rubin L, Moro PL, Cohn A, Clark T, Messonnier N. 2014. Prevention and control of Haemophilus influenzae type $b$ disease: recommendations of the Advisory Committee on Immunization Practices (ACIP). MMBR Morb Mortal Wkly Rep 63(RR01):1-14. https://www.cdc.gov/mmwr/preview/mmwrhtml/ rr6301a1.htm.

181. The World Bank. 2021. World Bank country and lending groups. https:// datahelpdesk.worldbank.org/knowledgebase/articles/906519-world-bankcountry-and-lending-groups.

182. World Health Organization. 2020. WHO recommendations for routine immunization-summary tables. https://www.who.int/immunization/policy/ Immunization_routine_table2.pdf?ua=1.

183. GAVI The Vaccine Alliance. 2019. GAVI annual progress report 2019. https://www.gavi.org/sites/default/files/programmes-impact/our-impact/ apr/Gavi-Progress-Report-2019_1.pdf.

184. Low N, Redmond SM, Rutjes AW, Martínez-González NA, Egger M, di Nisio M, Scott P. 2013. Comparing Haemophilus influenzae type b conjugate vaccine schedules: a systematic review and meta-analysis of vaccine trials. Pediatr Infect Dis J 32:1245-1256. https://doi.org/10.1097/INF .0b013e31829f0a7e.

185. Thumburu KK, Singh M, Das RR, Jaiswal N, Agarwal A, Kumar A, Kaur H. 2015. Two or three primary dose regime for Haemophilus influenzae type b conjugate vaccine: meta-analysis of randomized controlled trials. Ther Adv Vaccines 3:31-40. https://doi.org/10.1177/2051013615575871.

186. Charania NA, Moghadas SM. 2017. Modelling the effects of booster dose vaccination schedules and recommendations for public health immunization programs: the case of Haemophilus influenzae serotype b. BMC Public Health 17:705. https://doi.org/10.1186/s12889-017-4714-9.
187. Poolman J, Kaufhold A, De Grave D, Goldblatt D. 2001. Clinical relevance of lower Hib response in DTPa-based combination vaccines. Vaccine 19:2280-2285. https://doi.org/10.1016/S0264-410X(00)00517-X.

188. Kalies H, Verstraeten T, Grote V, Meyer N, Siedler A, Schmitt HJ, Breuer T, Moulton LH, von Kries R, Erhebungseinheit für seltene pädiatrische Erkrankungen in Deutschland Study Group. 2004. Four and one-half-year follow-up of the effectiveness of diphtheria-tetanus toxoids-acellular pertussis/Haemophilus influenzae type $b$ and diphtheria-tetanus toxoids-acellular pertussis-inactivated poliovirus/ $H$. influenzae type b combination vaccines in Germany. Pediatr Infect Dis J 23:944-950. https:// doi.org/10.1097/01.inf.0000141743.74443.73.

189. Cerquetti M, Giufrè M. 2016. Why we need a vaccine for non-typeable Haemophilus influenzae. Hum Vaccin Immunother 12:2357-2361. https:// doi.org/10.1080/21645515.2016.1174354.

190. Shuel M, Hoang L, Law DK, Tsang R. 2011. Invasive Haemophilus influenzae in British Columbia: non-Hib and non-typeable strains causing disease in children and adults. Int J Infect Dis 15:e167-e173. https://doi .org/10.1016/j.ijid.2010.10.005.

191. Jalalvand F, Riesbeck K. 2018. Update on non-typeable Haemophilus influenzae-mediated disease and vaccine development. Expert Rev Vaccines 17:503-512. https://doi.org/10.1080/14760584.2018.1484286.

192. European Centre for Disease Prevention and Control. 2021. Haemophilus influenzae, haemophilus influenzae disease. European Centre for Disease Prevention and Control. https://www.ecdc.europa.eu/en/ publications-data/haemophilus-influenzae-haemophilus-influenzae -disease.

193. Xirogianni APA, Kasanopoulos K, Georgakopoulou Tzanakaki G. 2019. Haemophilus influenzae in Greece-16 years of continuous surveillance (2003-2018), abstr PO-022-(EMGM2019-13325), p 31. https://emgm.eu/ meetings/emgm2019/emgm2019_abstracts.pdf.

194. Lâm TT, Nürnberg S, Claus H, Vogel U. 2020. Molecular epidemiology of imipenem resistance in invasive Haemophilus influenzae infections in Germany in 2016. J Antimicrob Chemother 75:2076-2086. https://doi .org/10.1093/jac/dkaa159.

195. Kuch A, Waśkol I, Kiedrowska M, Ronkiewicz P, Gołębiewska A, Wróbel I, Hryniewicz W, Skoczyńska A. 2019. Invasive Haemophilus influenzae disease in Poland, 1997-2018, abstr PO-018-(EMGM2019-13203), p 27. https://emgm.eu/meetings/emgm2019/emgm2019_abstracts.pdf.

196. Oliver S, Blain A, Soeters H, Pinell-McNamara V, Barnes M, Doman B, Harrison L, Petit S, Schaffner W, Triden L, Watt J, Wester R, Schmink S, Chang $\mathrm{H}-\mathrm{Y}$, Potts $\mathrm{C}$, Wang $\mathrm{X}$, Susan $\mathrm{H}$. Nontypeable invasive H.influenzae disease- United States, 2008-2017, abstr OC-(EMGM2019-13192), p 54. https://emgm.eu/meetings/emgm2019/emgm2019_abstracts.pdf.

197. Collins S, Litt DJ, Flynn S, Ramsay ME, Slack MP, Ladhani SN. 2015. Neonatal invasive Haemophilus influenzae disease in England and Wales: epidemiology, clinical characteristics, and outcome. Clin Infect Dis 60:1786-1792. https://doi.org/10.1093/cid/civ194.

198. Cevik M, Moncayo-Nieto OL, Evans MJ. 2020. Non-typeable Haemophilus influenzae-associated early pregnancy loss: an emerging neonatal and maternal pathogen. Infection 48:285-288. https://doi.org/ 10.1007/s15010-019-01359-6.

199. Gkentzi D, Slack MP, Ladhani SN. 2012. The burden of nonencapsulated Haemophilus influenzae in children and potential for prevention. Curr Opin Infect Dis 25:266-272. https://doi.org/10.1097/QCO.0b013e32835310a4.

200. Rusin P, Adam RD, Peterson EA, Ryan KJ, Sinclair NA, Weinstein L. 1991. Haemophilus influenzae: an important cause of maternal and neonatal infections. Obstet Gynecol 77:92-96.

201. Webster PB, Maher CF, Farrell DJ. 1995. Neonatal infection due to Haemophilus influenzae biotype IV. Aust N Z J Obstet Gynaecol 35:102-103. https://doi.org/10.1111/j.1479-828x.1995.tb01845.x.

202. Falla TJ, Dobson SR, Crook DW, Kraak WA, Nichols WW, Anderson EC, Jordens JZ, Slack MP, Mayon-White D, Moxon ER. 1993. Populationbased study of non-typable Haemophilus influenzae invasive disease in children and neonates. Lancet 341:851-854. https://doi.org/10.1016/ 0140-6736(93)93059-a.

203. Kragsbjerg P, Nilsson K, Persson L, Törnqvist E, Vikerfors T. 1993. Deep obstetrical and gynecological infections caused by non-typeable Haemophilus influenzae. Scand J Infect Dis 25:341-346. https://doi.org/10 .3109/00365549309008508.

204. Rubach MP, Bender JM, Mottice S, Hanson K, Weng HY, Korgenski K, Daly JA, Pavia AT. 2011. Increasing incidence of invasive Haemophilus influenzae disease in adults, Utah, USA. Emerg Infect Dis 17:1645-1650. https://doi.org/10.3201/eid1709.101991. 
205. Cardines R, Giufrè M, Mastrantonio P, Ciofi Degli Atti ML, Cerquetti M. 2007. Nontypeable Haemophilus influenzae meningitis in children: phenotypic and genotypic characterization of isolates. Pediatr Infect Dis J 26:577-582. https://doi.org/10.1097/INF.0b013e3180616715.

206. Sarangi J, Cartwright K, Stuart J, Brookes S, Morris R, Slack M. 2000. Invasive Haemophilus influenzae disease in adults. Epidemiol Infect 124:441-447. https://doi.org/10.1017/S0950268899003611.

207. Resman F, Ristovski M, Ahl J, Forsgren A, Gilsdorf JR, Jasir A, Kaijser B, Kronvall G, Riesbeck K. 2011. Invasive disease caused by Haemophilus influenzae in Sweden 1997-2009; evidence of increasing incidence and clinical burden of non-type b strains. Clin Microbiol Infect 17:1638-1645. https://doi.org/10.1111/j.1469-0691.2010.03417.x.

208. Giufrè M, Cardines R, Caporali MG, Accogli M, D'Ancona F, Cerquetti M. 2011. Ten years of Hib vaccination in Italy: prevalence of non-encapsulated Haemophilus influenzae among invasive isolates and the possible impact on antibiotic resistance. Vaccine 29:3857-3862. https://doi.org/ 10.1016/j.vaccine.2011.03.059.

209. Talbot B, Alexander E, Lewis S, Newport MJ, Slack MP, Litt DJ, Verma S, Webster DP. 2011. Hepatobiliary infections due to non-capsulated Haemophilus influenzae. J Med Microbiol 60:1383-1386. https://doi.org/10 .1099/jmm.0.031815-0.

210. Stærk M, Tolouee SA, Christensen JJ. 2018. Nontypable Haemophilus influenzae septicemia and urinary tract infection associated with renal stone disease. Open Microbiol J 12:243-247. https://doi.org/10.2174/ 1874285801812010243.

211. Dworkin MS, Park L, Borchardt SM. 2007. The changing epidemiology of invasive Haemophilus influenzae disease, especially in persons $\geq 65$ years old. Clin Infect Dis 44:810-816. https://doi.org/10.1086/511861.

212. Ladhani S, Ramsay ME, Chandra M, Slack MP, EU-IBIS. 2008. No evidence for Haemophilus influenzae serotype replacement in Europe after introduction of the Hib conjugate vaccine. Lancet Infect Dis 8:275-276. https://doi.org/10.1016/S1473-3099(08)70078-1.

213. Janson $H$, Ruan M, Forsgren A. 1993. Limited diversity of the protein $D$ gene (hpd) among encapsulated and nonencapsulated Haemophilus influenzae strains. Infect Immun 61:4546-4552. https://doi.org/10.1128/ IAI.61.11.4546-4552.1993.

214. Prymula R, Peeters P, Chrobok V, Kriz P, Novakova E, Kaliskova E, Kohl I, Lommel P, Poolman J, Prieels JP, Schuerman L. 2006. Pneumococcal capsular polysaccharides conjugated to protein $D$ for prevention of acute otitis media caused by both Streptococcus pneumoniae and non-typable Haemophilus influenzae: a randomised double-blind efficacy study. Lancet 367:740-748. https://doi.org/10.1016/S0140-6736(06)68304-9.

215. van den Bergh MR, Spijkerman J, Swinnen KM, François NA, Pascal TG, Borys D, Schuerman L, ljzerman EP, Bruin JP, van der Ende A, Veenhoven $\mathrm{RH}$, Sanders EA. 2013. Effects of the 10-valent pneumococcal nontypeable Haemophilus influenzae protein D-conjugate vaccine on nasopharyngeal bacterial colonization in young children: a randomized controlled trial. Clin Infect Dis 56:e30-e39. https://doi.org/10.1093/cid/ cis922.

216. Leroux-Roels G, Van Damme P, Haazen W, Shakib S, Caubet M, Aris E, Devaster JM, Peeters M. 2016. Phase I, randomized, observer-blind, placebo-controlled studies to evaluate the safety, reactogenicity and immunogenicity of an investigational non-typeable Haemophilus influenzae (NTHi) protein vaccine in adults. Vaccine 34:3156-3163. https://doi .org/10.1016/j.vaccine.2016.04.051.

217. Teo E, Lockhart K, Purchuri SN, Pushparajah J, Cripps AW, van Driel ML. 2017. Haemophilus influenzae oral vaccination for preventing acute exacerbations of chronic bronchitis and chronic obstructive pulmonary disease. Cochrane Database Syst Rev 6:CD010010. https://doi.org/10 .1002/14651858.CD010010.pub3.

218. Clancy RL, Cripps AW. 2019. An oral whole-cell killed nontypeable Haemophilus influenzae immunotherapeutic for the prevention of acute exacerbations of chronic airway disease. Int J Chron Obstruct Pulmon Dis 14:2423-2431. https://doi.org/10.2147/COPD.S217317.

219. Albritton WL, Brunton JL, Meier M, Bowman MN, Slaney LA. 1982. Haemophilus influenzae: comparison of respiratory tract isolates with genitourinary tract isolates. J Clin Microbiol 16:826-831. https://doi.org/ 10.1128/JCM.16.5.826-831.1982.

220. Quentin R, Martin C, Musser JM, Pasquier-Picard N, Goudeau A. 1993. Genetic characterization of a cryptic genospecies of Haemophilus causing urogenital and neonatal infections. J Clin Microbiol 31:1111-1116. https://doi.org/10.1128/JCM.31.5.1111-1116.1993.

221. Nørskov-Lauritsen N. 2009. Detection of cryptic genospecies misidentified as Haemophilus influenzae in routine clinical samples by assessment of marker genes fucK, hap, and sodC. J Clin Microbiol 47:2590-2592. https://doi.org/10.1128/JCM.00013-09.

222. Giufrè M, Cardines R, Degl'Innocenti R, Cerquetti M. 2015. First report of neonatal bacteremia caused by "Haemophilus quentini" diagnosed by 16S rRNA gene sequencing, Italy. Diagn Microbiol Infect Dis 83:121-123. https://doi.org/10.1016/j.diagmicrobio.2015.05.019.

223. Cohen R, Finn T, Babushkin F, Karalnik S, Paikin S, Adler A, Geffen Y, Rokney A, Ron M. 2019. Disseminated "Haemophilus quentini" infection in a patient with multiple myeloma-a case report and review of the literature. Diagn Microbiol Infect Dis 94:293-296. https://doi.org/10.1016/j .diagmicrobio.2019.02.004.

224. Glover WA, Suarez CJ, Clarridge JE. 2011. Genotypic and phenotypic characterization and clinical significance of 'Haemophilus quentini' isolated from the urinary tract of adult men. J Med Microbiol 60:1689-1692. https://doi.org/10.1099/jmm.0.031591-0.

225. Kus JV, Shuel M, Soares D, Hoang W, Law D, Tsang RSW. 2019. Identification and characterization of "Haemophilus quentini" strains causing invasive disease in Ontario, Canada (2016 to 2018). J Clin Microbiol 57: e01254-19. https://doi.org/10.1128/JCM.01254-19.

226. Slack M, Esposito S, Haas $H$, Mihalyi A, Nissen M, Mukherjee $P$, Harrington L. 2020. Haemophilus influenzae type b disease in the era of conjugate vaccines: critical factors for successful eradication. Expert Rev Vaccines 19:903-917. https://doi.org/10.1080/14760584.2020.1825948.

227. National Institute for Communicable Diseases. 2006. GERMS South Africa annual report 2006. https://www.nicd.ac.za/assets/files/2006\%20 GERMS-SA\%20annual\%20report.pdf.

228. National Institute for Communicable Diseases. 2007. GERMS South Africa annual report 2007. https://www.nicd.ac.za/assets/files/2007_GERMSSA_Annual_Report.pdf.

229. National Institute for Communicable Diseases. 2008. GERMS South Africa annual report 2008. https://www.nicd.ac.za/assets/files/2008_GERMS-SA _Annual_Report(1).pdf.

230. National Institute for Communicable Diseases. 2009. GERMS South Africa annual report 2009. https://www.nicd.ac.za/assets/files/2009 GERMS-SA_Annual_Report.pdf.

231. National Institute for Communicable Diseases. 2010. GERMS South Africa annual report 2010. https://www.nicd.ac.za/assets/files/2010 _GERMS-SA_Annual_report_Final.pdf.

232. National Institute for Communicable Diseases. 2011. GERMS South Africa annual report 2011. https://www.nicd.ac.za/assets/files/2011\%20 GERMS-SA\%20Annual\%20report\%20pub\%20final(1).pdf.

233. National Institute for Communicable Diseases. 2012. GERMS South Africa annual report 2012. https://www.nicd.ac.za/assets/files/2012\%20 GERMS-SA\%20Annual\%20Report.pdf.

234. National Institute for Communicable Diseases. 2013. GERMS South Africa annual report 2013. https://www.nicd.ac.za/assets/files/GERMS -SA\%20AR\%202013(1).pdf.

235. National Institute for Communicable Diseases. 2014. GERMS South Africa annual report 2014. https://www.nicd.ac.za/assets/files/GERMS -SA\%20AR\%202014(1)(1).pdf.

236. National Institute for Communicable Diseases. 2015. GERMS South Africa annual report 2015. https://www.nicd.ac.za/assets/files/2015\%20 GERMS-SA\%20AR.pdf.

237. National Institute for Communicable Diseases. 2016. GERMS South Africa annual report 2016. https://www.nicd.ac.za/wp-content/uploads/ 2017/03/GERMS-SA-AR-2016-FINAL.pdf. 
Mary P. E. Slack is an independent Consultant Medical Microbiologist. She is currently a Professor in the School of Medicine and Dentistry at Griffith University, Gold Coast Campus, Queensland, Australia. She was formerly Head of the Haemophilus and Pneumococcal Reference Laboratories at Public Health England, London, United Kingdom, Head of the WHO Collaborating Centre for Haemophilus influenzae, and Head of the Global Reference Laboratory for Haemophilus

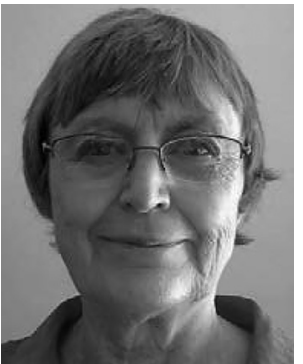
influenzae in the WHO Global Vaccine-Preventable Invasive Bacterial Disease (VP-IBD) Surveillance Network. She did her clinical training at Cambridge University, Kings College Hospital, London and Oxford, United Kingdom. Previous appointments include University Lecturer in Bacteriology at the University of Oxford, Consultant Medical Microbiologist at Public Health England, and Research Scientist at the Institute of Hygiene and Microbiology, University of Würzburg, Germany. Her research interests include Haemophilus influenzae and Streptococcus pneumoniae infections, the impact of Hib and pneumococcal conjugate vaccines, and the role of vaccines in combatting antimicrobial resistance and community-acquired pneumonia.

Allan W. Cripps is Emeritus Professor at the School of Medicine and Dentistry, Griffith University, and leads the Mucosal Immunology Research Group, Menzies Health Institute Queensland, at Griffith University. He has a Ph. D. in Immunology from the University of Sydney. He is a distinguished academic, clinical scientist, and health services leader. In 2015, he was awarded the Officer of the Order of Australia (AO) for his distinguished service to tertiary education and to public health as a

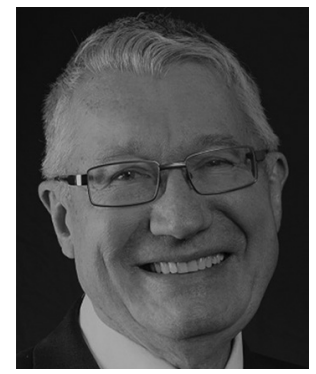
leading immunologist, academic, and researcher in the field of immunization. He has made a significant contribution to immunology through translational research and human clinical studies in the fields of diagnostic technology, vaccine antigen discovery for respiratory infections, particularly nontypeable Haemophilus influenzae and Pseudomonas aeruginosa, and mucosal immunization for bacterial infections related to chronic obstructive pulmonary disease, otitis media, and pneumonia. In 2012, he launched the first international peer-reviewed journal focused exclusively on pneumonia.
Keith Grimwood is Deputy Head of the School of Medicine and Dentistry (Research) and Professor of Infectious Diseases at Griffith University and a pediatric infectious diseases physician at Gold Coast University Hospital, Queensland, Australia. He did his clinical training in pediatrics in New Zealand and Australia, undertook an M.D. through the University of Melbourne on the systemic and mucosal antibody responses to rotavirus infections, and completed specialist infectious

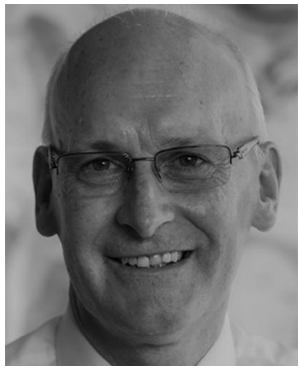
diseases training at the University of Calgary, Canada. Previous academic appointments include Senior Lecturer in Pediatrics at the University of Melbourne, Australia, Professor of Pediatrics at the University of OtagoWellington, New Zealand, Conjoint Professor of Pediatrics at the University of Queensland, and Inaugural Director of the Queensland Children's Medical Research Institute, Brisbane, Australia. His clinical research interests include respiratory infections, especially cystic fibrosis and bronchiectasis, Pseudomonas aeruginosa and Haemophilus influenzae infections, and vaccinepreventable diseases.

Grant Mackenzie is an epidemiologist/ pediatrician. His medical training was at the University of Melbourne. He trained in pediatrics at the Royal Children's Hospital in Melbourne and in Darwin in tropical Australia. He completed an M.P.H. and a Ph.D. at Flinders University and Menzies School of Health Research in Darwin. He has been a Clinical Epidemiologist with the MRC Unit, The Gambia, at the London School of Hygiene \& Tropical Medicine since 2008. He

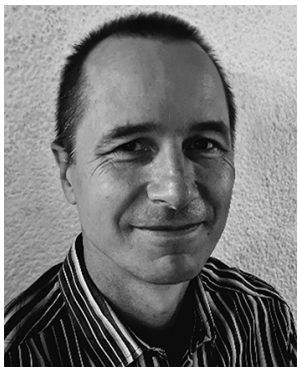
also holds appointments as Associate Professor at the University of Melbourne, Murdoch Children's Research Institute in Melbourne, and at London School of Hygiene \& Tropical Medicine. He coordinates surveillance for pneumococcal disease and carriage in The Gambia, evaluating the effectiveness of pneumococcal conjugate vaccine. He is currently conducting a cluster-randomized trial of different pneumococcal vaccine schedules. His research interests cover vulnerable children at increased risk of mortality with a motivation to reduce child mortality through vaccination interventions. 
Marina Ulanova is Professor of Immunology at the Northern Ontario School of Medicine (NOSM) and Adjunct Professor in the Departments of Biology, Chemistry, and Health Sciences of Lakehead University, Thunder Bay, Canada. Dr. Ulanova received her M.D. as well as an M.Sc. and Ph.D. in Immunology in Moscow (Russia) and a Ph.D. in Clinical Immunology from University of Gothenburg (Sweden). She moved to Canada in 2000, completed postdoctoral training at

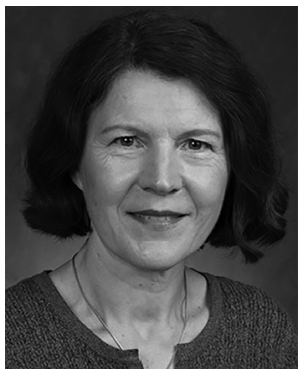
the University of Alberta, and became one of the founding faculty members at NOSM when the school was open in 2005. She runs a research program in immunoepidemiology of bacterial infections, vaccinology, and host-pathogen interactions. Her major research interests include the immune response to Streptococcus pneumoniae and Haemophilus influenzae in immunocompromised adults. For the last 10 years, she has been involved in the development of a new vaccine to prevent invasive $H$. influenzae type a disease in North American Indigenous people. 